\title{
DETERMINING OPERATION GROUNDSWELL'S FUTURE BUSINESS DIRECTIONS FOR SUSTAINABLE TOURISM
}

\author{
by
}

Halina (Hally) Charendoff

Bachelor of Arts (Honours), Queen's University, April 2015

\begin{abstract}
A thesis presented to Ryerson University
in partial fulfillment of the requirements for the degree of Master of Applied Science in the program of Environmental Applied Science and Management
\end{abstract}

\author{
Toronto, Ontario, Canada, 2019 \\ (C) Halina (Hally) Charendoff, 2019
}




\section{Author's Declaration}

I hereby declare that I am the sole author of this thesis. This is a true copy of the thesis, including any required final revisions, as accepted by my examiners.

I authorize Ryerson University to lend this thesis to other institutions or individuals for the purpose of scholarly research.

I further authorize Ryerson University to reproduce this thesis by photocopying or by other means, in total or in part, at the request of other institutions or individuals for the purpose of scholarly research.

I understand that my thesis may be made electronically available to the public. 
Determining Operation Groundswell's Future Business Directions for Sustainable Tourism

\author{
MASc 2019 \\ Halina (Hally) Charendoff \\ Environmental Applied Science and Management \\ Ryerson University
}

\begin{abstract}
Operation Groundswell (OG) is a non-governmental organization (NGO) and tour operator that offers volunteer backpacking trips. This study evaluates two ways in which OG aims to achieve sustainable tourism: their approach to voluntourism and their carbon offset initiative. A qualitative consumer analysis was conducted to evaluate how OG can move forward as a facilitator of sustainable tourism utilizing 1) their approach to voluntourism and 2) their carbon offset initiative. Findings from this study reveal that OG's carbon offset initiative should be made more prevalent and transparent on their website and in their marketing to attract green consumers, that they should continue to engage with voluntourism with a critical lens so as to emphasize how voluntourism can be accomplished in an ethically-just and sustainable manner, and that they should consider developing hybrid trip offerings that emphasize the interconnectedness of their four program themes of health, education, human rights and the environment.
\end{abstract}




\section{Acknowledgements}

This thesis is a result of the support I have received from my academic mentors, industry partners, family and friends. I would first like to thank my supervisor, Dr. Rachel Dodds for her guidance throughout this process. Rachel's insight was instrumental in my successful completion of this undertaking. Further gratitude is extended to Dr. Andrew Laursen, Dr. Cory Searcy and Dr. Sonya Graci who sat on my thesis committee, offering their expert knowledge and providing me with valuable feedback.

The opportunity to work collaboratively with Operation Groundswell was a privilege, enabling me to sink my teeth into a project I was excited about. I would like to express my gratitude to Executive Director Eyal Rosenblum for his patience, enthusiasm and commitment to this project as my primary point of contact. Additional thanks go to Operation Groundswell's marketing team for the time and effort put into this endeavour. A special shout-out is extended to Alan Levine for his faith in my abilities and willingness to pitch my idea for this study.

My parents Lisa and Jay, siblings Michael and Miriam, and sister-in-law Alana have offered steadfast encouragement throughout my graduate studies; I truly could not have done this without their support. My good friend and academic role model, Josh Goodfield, was always happy to lend an ear and never complained about my relentless questions.

Thank you. 


\section{Dedication}

This thesis is dedicated to my dog Rufus Benny Charendoff, who consistently brightens my days and gets me through difficult times. 


\section{Table of Contents}

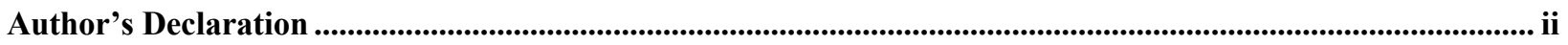

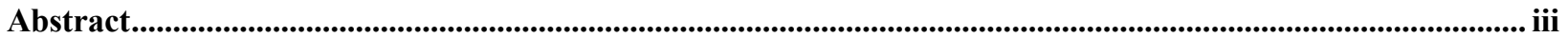

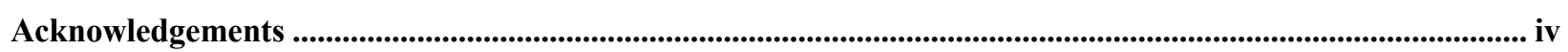

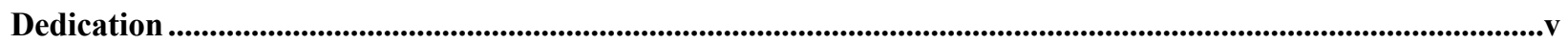

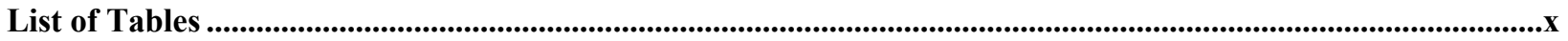

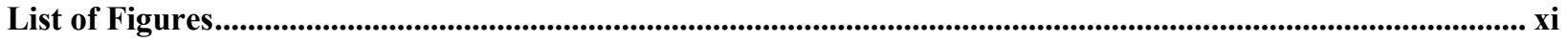

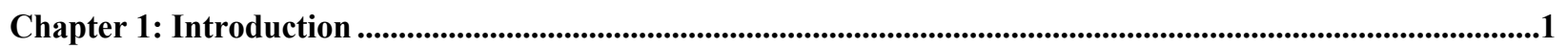

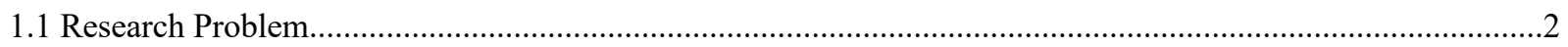

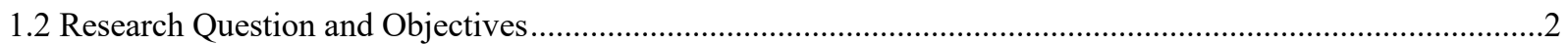

Chapter 2: Case Study Context - Operation Groundswell.................................................................................................5

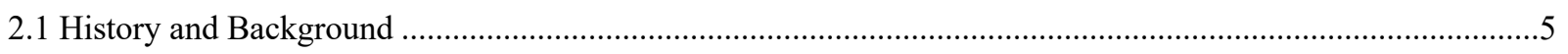

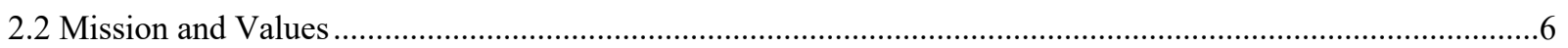

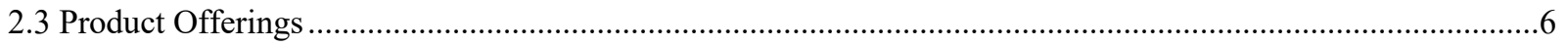

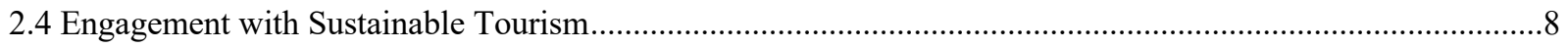

2.5 Collaboration with Local Partners and Capacity Building .......................................................................

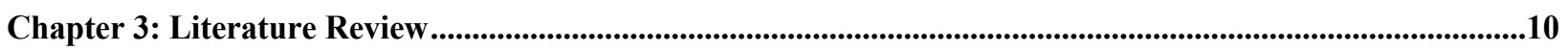

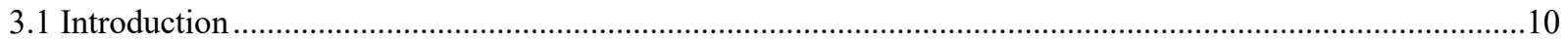

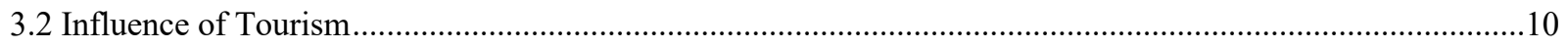

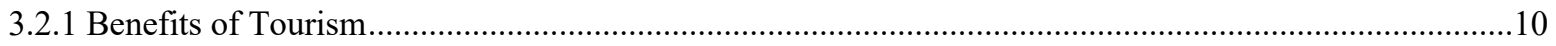

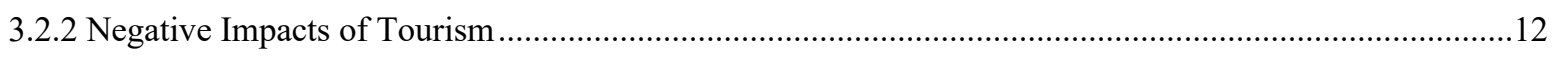

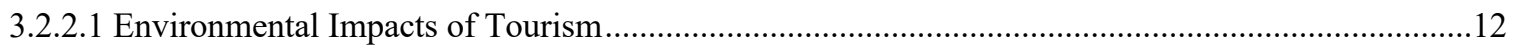

3.3 Sustainable Tourism as a Way of Alleviating the Negative Impacts of Tourism.............................................13

3.3.1 Consumer Perspectives of Sustainability in the Tourism Industry ........................................................17

3.3.1.1 Green Consumerism Within the Tourism Industry ................................................................... 17

3.4 Strategies Used to Address the Negative Impacts of the Tourism Industry ..................................................18

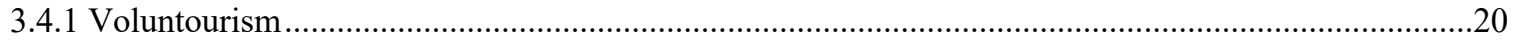

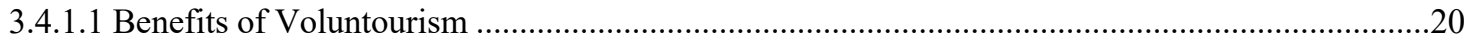

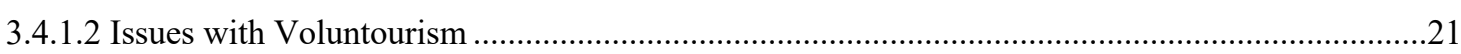

3.4.1.3 Travellers' Motivations to Participate in Voluntourism...............................................................22

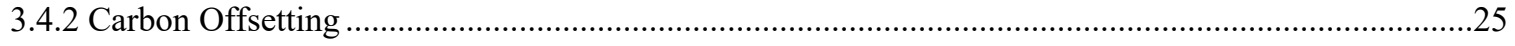

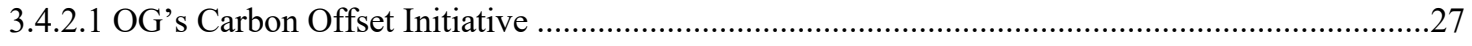

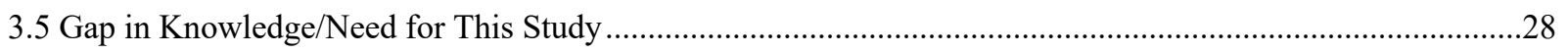

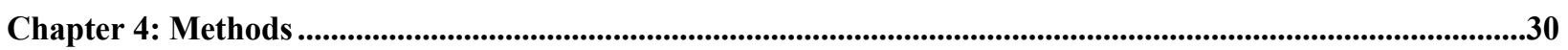

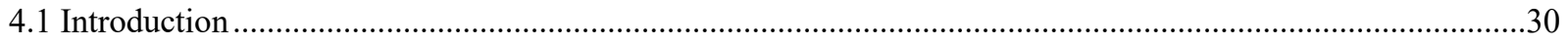

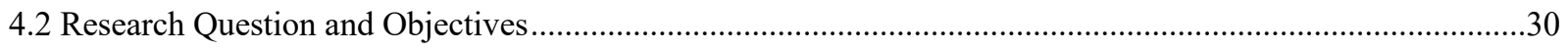

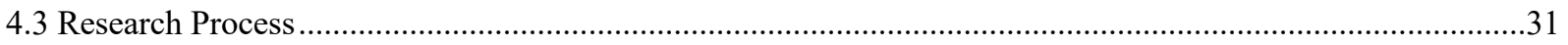




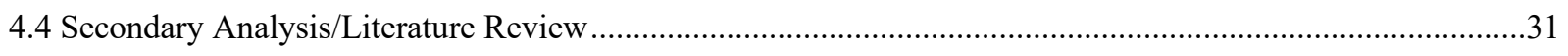

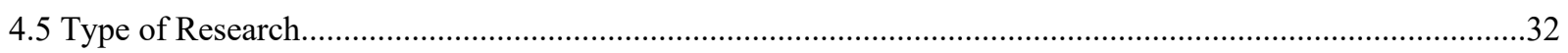

4.5.1 Qualitative Analysis Within an Interpretive Paradigm .........................................................................32

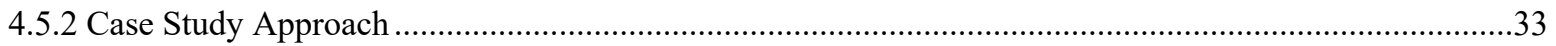

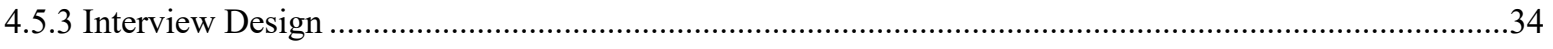

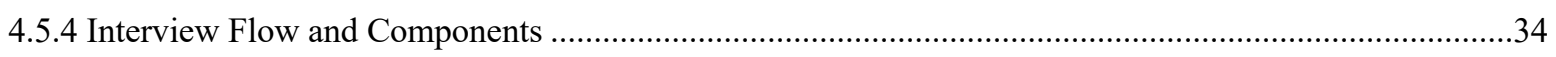

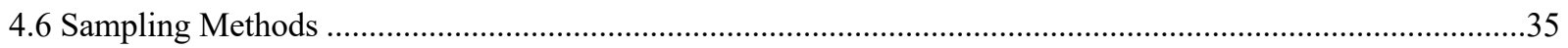

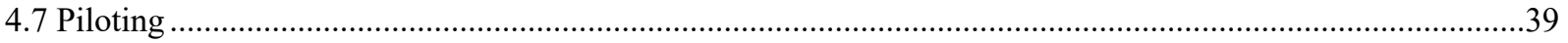

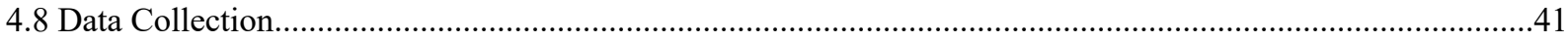

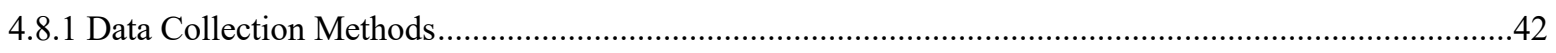

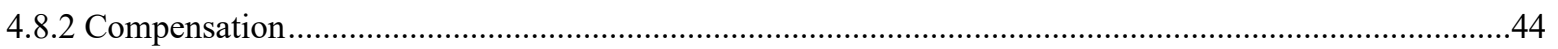

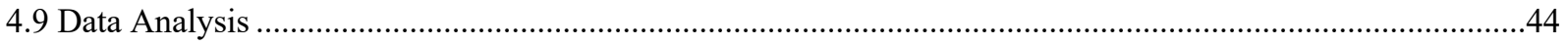

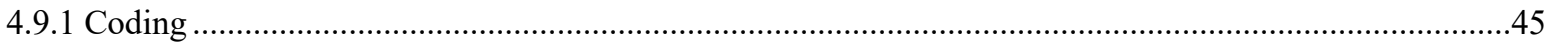

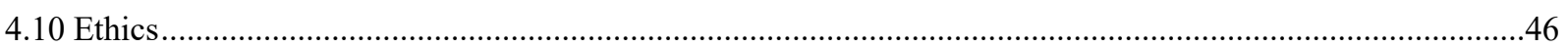

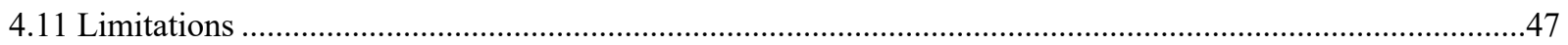

Chapter 5: Interview Results .....................................................................................................................................50

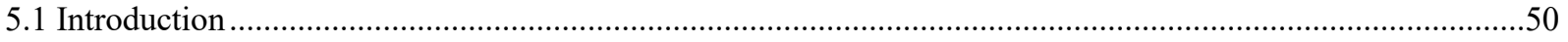

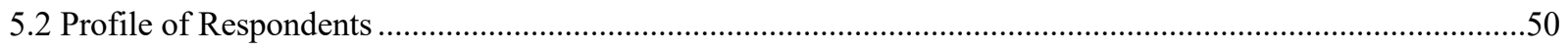

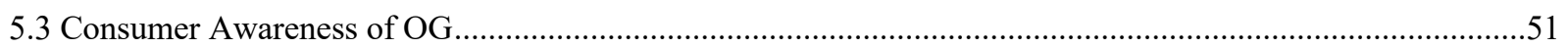

5.4 Consumer Motivations to Travel with OG/Perceived Benefits of Travelling with OG .................................52

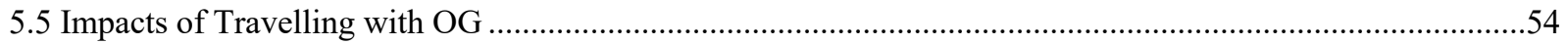

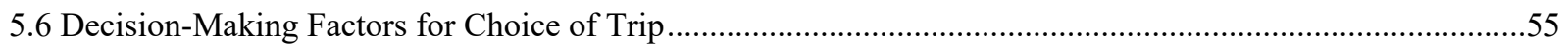

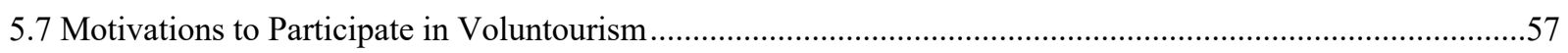

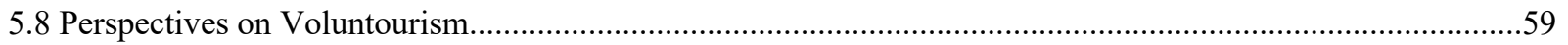

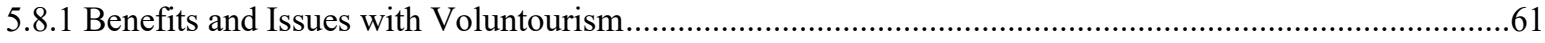

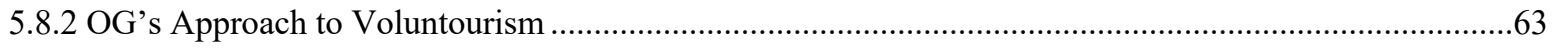

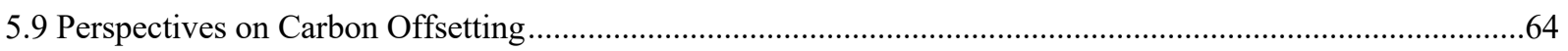

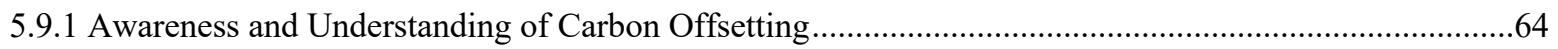

5.9.2 Awareness, Perception and Understanding of OG's Carbon Offset Initiative........................................66

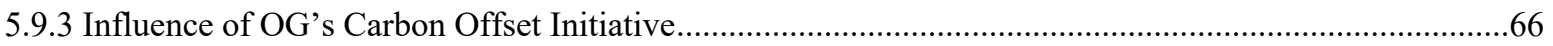

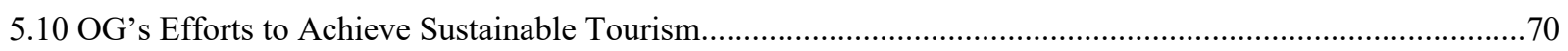

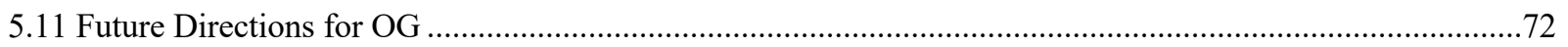

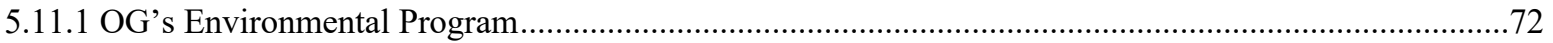

5.11.2 Suggestions for New Environmentally-Focused Trips .........................................................................73

5.11.3 Suggestions for How to Incorporate Important Elements of the Natural Environment into Future OG

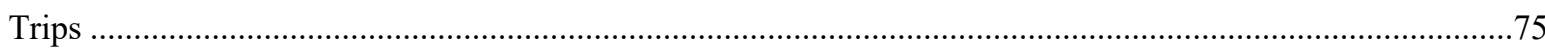

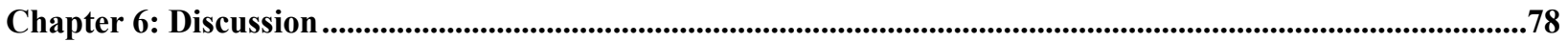




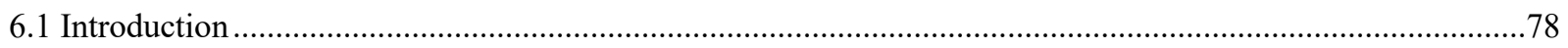

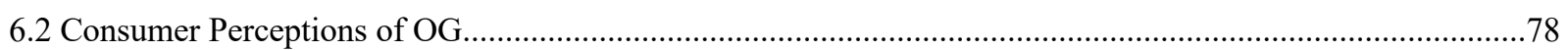

6.3 OG's Program Themes Are an Uninfluential Element of Consumers' Decision-Making.................................79

6.4 Perceived Benefits and Tangible Impacts of Travelling With OG ...............................................................8

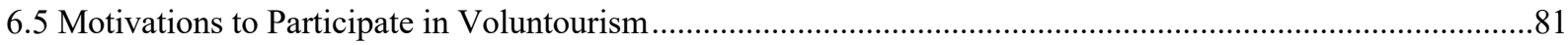

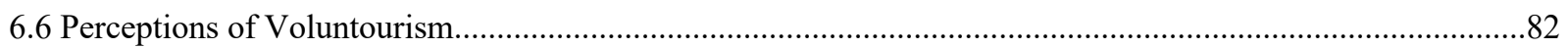

6.7 Low Awareness of OG's Carbon Offset Initiative/Influence of OG's Carbon Offset Initiative .......................85

6.7.1 OG's Carbon Offset Initiative Should Remain an Included Cost .............................................................86

6.7.2 Green Consumers Within OG's Consumer Market …..................................................................................

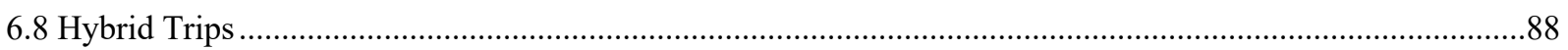

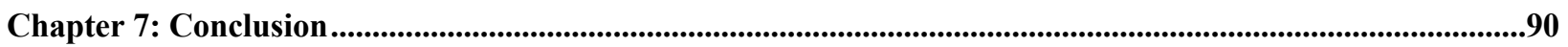

7.1 How OG Can Move Forward as a Facilitator of Sustainable Tourism Utilizing Their Approach to

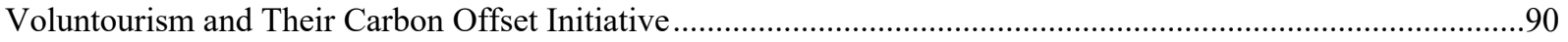

7.2 Summary of How the Research Objectives Were Addressed .......................................................................91

7.2.1 Consumer Motivations to Participate in OG's Voluntourism Trips .........................................................91

7.2.2 The Perceived Benefits and Tangible Impacts of Travelling with OG ......................................................91

7.2.3 The Importance and Influence of OG's Carbon Offset Initiative .............................................................92

7.2.4 Consumer Perceptions of OG's Approach to Voluntourism As an Effective Way of Engaging with

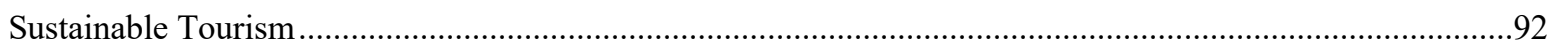

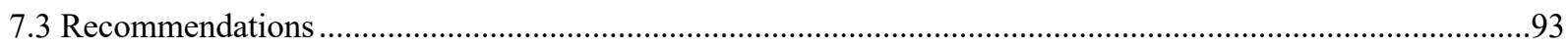

7.3.1 Increase Information, Transparency and Marketing of Carbon Offset Initiative......................................93

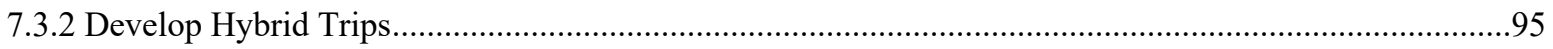

7.3.3 Market Their Approach to Voluntourism More Clearly to Prospective Consumers ................................96

7.3.4 Focus on Broadening Their Sustainability Efforts ....................................................................................99

7.3.5 Additional Market Research to Identify Environmental Topics for Future Trips......................................98

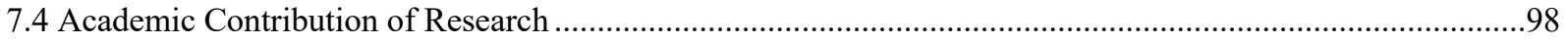

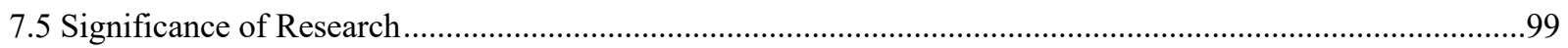

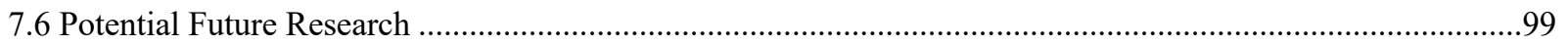

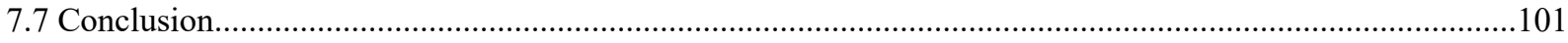

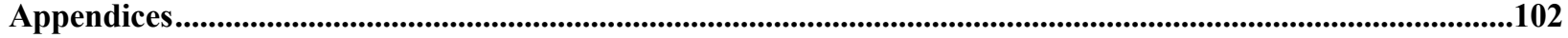

Appendix A1: Participant Recruitment Email - Category 1 (Alumni) ..............................................................102

Appendix A2: Participant Recruitment Email - Category 2 (Drop-Outs) ............................................................103

Appendix A3: Participant Recruitment Email - Category 3 (Prospects).................................................................104

Appendix B: Informed Consent Form.........................................................................................................105

Appendix C1: Interview Guide Before Pilot - Category 1 (Alumni) .....................................................................107

Appendix C2: Interview Guide Before Pilot - Category 2 (Drop-Outs) ………..................................................110

Appendix C3: Interview Guide Before Pilot - Category 3 (Prospects) ..............................................................112 
Appendix D1: Interview Guide After Pilot - Category 1 (Alumni) ..................................................................114

Appendix D2: Interview Guide After Pilot - Category 2 (Drop-Outs) ……........................................................117

Appendix D3: Interview Guide After Pilot - Category 3 (Prospects) ……..........................................................119

Appendix E: Example of NVivo Nodes and Theme Organization ...............................................................121

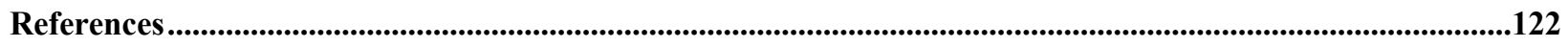




\section{List of Tables}

Table 1 UNWTO Sustainable Development Goals and Their Applications to Tourism ...........................................16

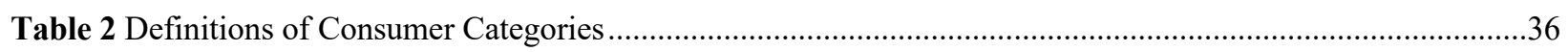

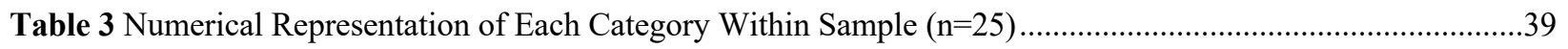

Table 4 Interview Methods, Length and Data Recording ...................................................................................

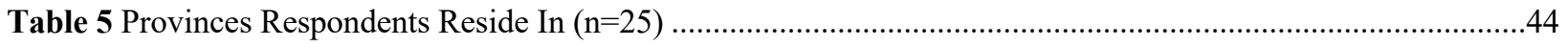

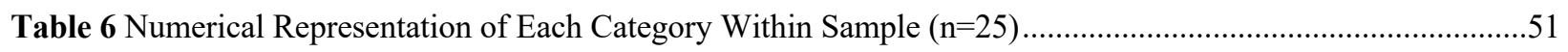

Table 7 Breakdown of How All Respondents Within the Total Sample First Heard About OG $(n=25)$..................51

Table 8 Breakdown of How Respondents Within Each Consumer Category First Heard About OG $(n=25) \ldots \ldots \ldots \ldots . . .52$

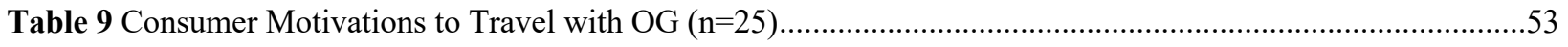

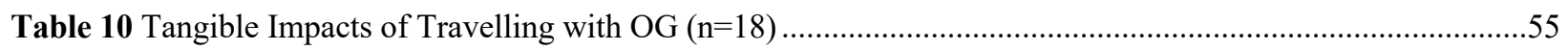

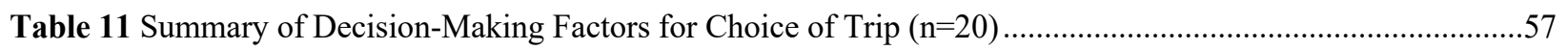

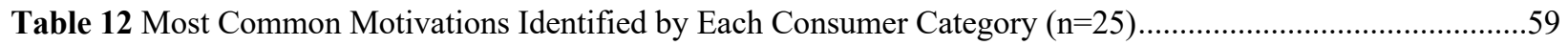

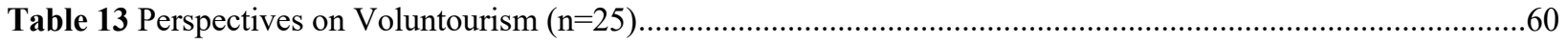

Table 14 How OG's Approach to Voluntourism Differs from Traditional Voluntourism/How OG Addresses the

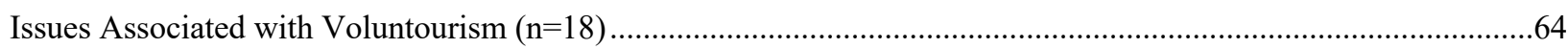

Table 15 Did You Come Across Information About OG's Carbon Offset Initiative on Their Website? (n=25)........66

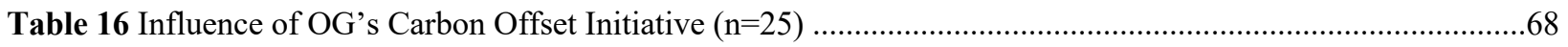

Table 17 Would You Voluntarily Contribute to OG's Carbon Offset Initiative If It Were Not Included? (n=25).....70

Table 18 Does OG Successfully Integrate Principles of Sustainable Tourism? $(\mathrm{n}=18)$............................................71

Table 19 How Does OG Successfully Integrate Principles of Sustainable Tourism? $(n=15)$...................................72

Table 20 Should OG Expand Their Environmental Program to Include More Trips with Different Environmental

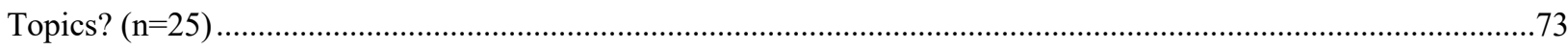

Table 21 What Elements of the Natural Environment Do You Consider the Most Important? $(n=25)$.....................74

Table 22 Suggestions for How to Incorporate Important Elements of the Natural Environment into Future OG Trips $(\mathrm{n}=13)$. . .76 


\section{List of Figures}

Figure 1 Communication of Carbon Offset Initiative on OG's Website ................................................................28

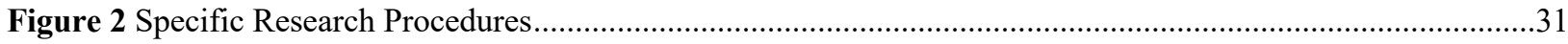

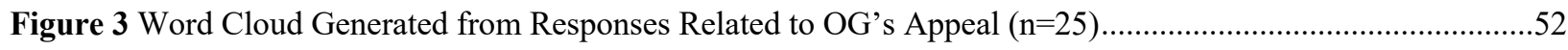

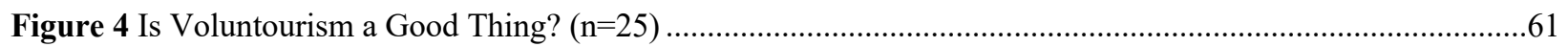

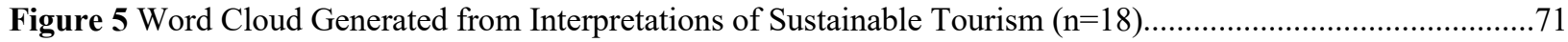




\section{Chapter 1: Introduction}

Within the tourism industry, consumer demand for environmentally friendly, sustainable products and services continues to increase in prominence (Han \& Yoon 2015; Sanchez-Medina et al. 2016). Engaging with sustainability has become a central component of business strategy (Kreiss et al. 2016; Popsa 2017; Walsh \& Dodds 2017), appealing to green consumers who "[express] a preference for products and services that reflect a company's commitment to the environment" (Sanchez-Medina et al. 2016: 389). This shift in consumer behaviour has permeated into the tourism industry, motivating products and services in the sector to integrate sustainable tourism (Neto 2003; Aragon-Correa et al. 2015; Popsa 2017). As the tourism industry is heavily dependent on both environmental and cultural resources (Kasim 2006), it can result in environmental degradation in addition to diverse social and cultural consequences if improperly managed (Gossling \& Peeters 2015; Hashemkhani Zolfani et al. 2015). As such, the tourism industry has adopted principles of sustainable tourism to varying extents to alleviate such impacts (Ayuso 2007; Dodds \& Kuehnel 2010; Aragon-Correa et al. 2015; Prud'homme \& Raymond 2016).

Operation Groundswell (OG) is one organization that is interested in sustainability and who have made efforts to engage with sustainable tourism. OG has identified an interest in obtaining insight on consumer perceptions about 1) their approach to voluntourism and 2) their carbon offset initiative. As such, this research will evaluate these two aforementioned practices in relation to OG's efforts to promote and facilitate sustainable tourism. OG is a small Toronto-based non-governmental organization (NGO) and tour operator that organizes and runs volunteer-based backpacking trips (Operation Groundswell 2019). Although OG has successfully developed backpacking programs committed to educating and engaging travellers with social and 
environmental topics, the NGO is seeking strategic market research to inform future business strategy pertaining to their sustainability efforts (E. Rosenblum, Executive Director Operation Groundswell, personal communication, June 21, 2018). This study evaluates how effective OG's sustainability efforts are, and if continued resource allocation is the strategic way forward for the continued growth of the organization.

\subsection{Research Problem}

OG has four program themes for which consumers can apply to participate in: 1) human rights, 2) education, 3) health and 4) environment. While OG has made concerted efforts to engage with principles of sustainable tourism by facilitating trips that focus on educational, human rights, health and environmental issues, the environmental issues program is less popular than other program options (E. Rosenblum, Executive Director Operation Groundswell, personal communication, June 21,2018). The information gathered from this study will help OG understand if and how their consumers are influenced by their sustainability efforts, and if their consumers perceive these sustainability efforts to be effective. More broadly, the results of this study may shed light on the green consumer market within the tourism industry and demonstrate if and how voluntourism can be accomplished in a sustainable manner.

\subsection{Research Question and Objectives}

The research question and objectives for this study were developed by working with OG to identify what they as an organization were keen to learn more about. The central research question and objectives were developed both to tackle the questions identified by OG and to address the gap in knowledge/research identified by the literature review. The research question that this thesis aims to answer is: How can OG move forward as a facilitator of sustainable tourism utilizing their approach to voluntourism and their carbon offset initiative? 
The following four objectives were developed to address this research question:

1. What motivates consumers to participate in OG's voluntourism trips?

2. What are the perceived benefits and tangible impacts of travelling with OG?

3. How influential and/or important for business success (i.e. attracting and retaining customers) is OG's carbon offset initiative?

4. Do OG's past and prospective consumers perceive OG's approach to voluntourism as an effective way of engaging with sustainable tourism?

\subsection{Thesis Structure}

This thesis uses OG as a case study to illustrate the influence of incorporating principles of sustainable tourism into voluntourism products, highlighting potential consumer buy-in for this form of sustainability within the tourism industry. OG was selected as a case study because they demonstrated enthusiasm to work collaboratively with the researcher, and also identified specific questions that were of interest to them that could address a current gap in research. In order to accomplish this case study analysis, the next chapter is dedicated to OG as a case study and outlines the organization's history and background, mission and values, product offerings and their engagement with sustainable tourism. Thereafter, a literature review is presented which outlines the current state of literature on a range of relevant topics including the benefits and impacts of tourism with particular emphasis on the environmental consequences of tourism, the notion of sustainable tourism, consumer perspectives of sustainability within the tourism industry including an overview of green consumerism within the tourism industry, and a discussion of voluntourism and carbon offsetting (the two strategies to achieve sustainable tourism that this study is evaluating) both in general and in the context of OG. Then, the gap in knowledge identified by the literature review will be presented and the need for this study will be outlined. Then, the research 
methodology is presented, including but not limited to a justification for conducting a qualitative analysis and selecting OG as a case study. Following this, the results collected from the semistructured interviews are presented and discussed. After the results have been outlined, the next chapter discusses the findings. Finally, a conclusion is provided that 1) proposes recommendations to OG based on the key findings, 2) acknowledges the implications and significance of this study in the field of sustainable tourism research and 3) outlines potential areas for future research on this topic. 


\section{Chapter 2: Case Study Context - Operation Groundswell}

This section provides information about the case study for which this study is evaluating OG - and provides insight into the history and development of the organization as well as their efforts to engage with voluntourism in a sustainable manner. The information presented in this chapter is derived both from OG's website and from personal communication with OG's Executive Director (E. Rosenblum, Executive Director Operation Groundswell, personal communication, 2019; Operation Groundswell 2019).

\subsection{History and Background}

OG was co-founded in 2006 by David Berkal and Jonah Brotman. Berkal and Brotman were interested in understanding if "volunteering abroad [was] really helping or harming the development world" and "[if] there [was] a way for [them] to contribute to development while also critiquing it" (Operation Groundswell 2019). OG's co-founders travelled to Accra, Ghana to evaluate if, and how the intended goals of international volunteering projects were being met. Through discussions with local communities, they discovered that the most effective way to affect positive change and address the aforementioned issues with traditional voluntourism was to work in solidarity with these communities on issues and projects deemed as priorities by the locals. As stated on their website, they determined that working in collaboration with local NGOs and charities, "not as a handout, not as charity - but in solidarity" (Operation Groundswell 2019), would be the most effective way to create the change they wanted to see in the voluntourism sector. OG's focus is on offering a voluntourism product that acknowledges and proactively educates travelers on the issues associated with voluntourism and simultaneously facilitates authentic and immersive travelling experiences. After this inaugural pilot program in West Africa OG has 
developed into a well-established, far-reaching voluntourism backpacking organization that has successfully run 162 programs to 18 countries worldwide since the organization's conception.

\subsection{Mission and Values}

OG has branded themselves as an organization that offers travel experiences that are "not your cookie-cutter vacation" (Operation Groundswell 2019). On their website, they convey to their consumers that they 1) offer immersive experiences by sharing meals with locals and practicing new languages, 2) facilitate ethical volunteering by avoiding the pitfalls of feel-good projects that don't have positive impacts by working in collaboration with local leaders, and 3) provide an opportunity to learn from experience by listening to personal stories of the local communities, and both participate in hands-on projects with local NGOs and engage in workshops to critically discuss what it means to make a difference. In these ways, OG identifies how their product is both more meaningful and engaging than travelling for leisure/personal pleasure, and how their product deviates from the traditional idea of feel-good voluntourism. OG's primary slogan is "backpacking with a purpose" (Operation Groundswell 2019). OG's website puts their mission in plain terms: "to create a more equitable, just and sustainable world through travel" (Operation Groundswell 2019). This is accomplished by actively and educationally engaging participants with a form of voluntourism that emphasizes the principles of sustainable tourism and simultaneously critically engages with the common critiques and pitfalls of traditional voluntourism so as to avoid the consequences associated with the practice.

\subsection{Product Offerings}

OG offers nine programs that fall into one of their four program themes of education, human rights, health and the environment. OG's current program offerings include but are not limited to trips entitled rights and resistance, farm to table, gender and religion and animal 
conservation. OG facilitates small group travel with a maximum of fourteen participants per trip, allowing groups to access places that large tours cannot and being more sustainable for the host countries/projects. All programs are crafted to provide participants with authentic, educational, voluntourism/community-service based backpacking experiences through collaboration with local NGOs and charities; each itinerary revolves around participant engagement in projects requested by local communities. For example, OG's trips within Thailand and Cambodia include visits to a grassroots NGO called Ockenden "whose aim is to improve rural communities' self-reliance by teaching small-town farmers about sustainable agricultural systems and techniques" (Operation Groundswell 2019). OG aims to "build a community of 'backpacktivists' - ethical travelers that are socially, environmentally and politically aware of their impact in the communities they travel to and live in" (Operation Groundswell 2019). Since OG was established in 2006, the trips offered have changed to reflect contemporary topics on both local and global scales, to ensure that participants are engaged with salient issues facing the world at the time, i.e. if something major happens in the world and they want to shed light on it, programs are developed to reflect these topics. However, the four main program themes have remained unchanged since the organization was established and future programs will fall into one of these categories. Currently, OG operates in three regions: Asia, Central America and South America. Within these regions, trips are offered in five countries: India, Thailand, Cambodia, Guatemala and Peru. Trips offered by OG range from eight to fourty days and integrate both tourism-based activities and excursions in addition to direct participation with local projects and educational workshops. With the exception of their animal conservation that visits both Thailand and Cambodia, all other trip offerings are focused on travelling within one country exclusively. Year to year the established programs within these destinations undergo improvements and are improved based on participant feedback. That being 
said, OG is more so focused on deepening the connections to the regions they already travel to and continuing to foster collaborative relationships with the local organizations in the region as opposed to continuously offering trips to new regions without established collaborative partnerships.

\subsection{Engagement with Sustainable Tourism}

OG has embraced the principles of sustainable tourism by educating travellers on salient social and environmental issues that have been identified as priorities by local charities and NGOs. OG's mission and core values demonstrate the company's departure from traditional understandings and critiques of voluntourism outlined in section 3.4.1.2 (e.g. neocolonialism and the exploitation of local communities). The website notes that in contrast to many "large, Western organizations that create and enforce development plans" (Operation Groundswell 2019), OG is committed to maintaining established relationships and forging new partnerships with these local organizations to avoid the commonly cited pitfalls of voluntourism. OG has developed an evolving document called the Backpacktivist Manifesto that outlines their core values. The document emphasizes awareness, immersion and respect for local cultures and traditions, the importance of education and learning while travelling, working in solidarity with local communities and encouraging travellers to become positive leaders and agents of change. Further, the core values outlined align with the multifaceted underlying principles of sustainable tourism. OG has five environmentally-focused trips that include animal conservation, environmental justice, sustainable agriculture and food security. As OG has specific trip offerings focused on environmental voluntourism, they have a well-established method of engaging with the ecological component of sustainable tourism. OG has placed a heavy focus on developing a business model that prioritizes and ensures that employees of OG and the local partners they work with are fairly compensated 
for their work. OG has also built regional offices that are closer to the frontline work, more equipped to work with local partners directly, and better able to evaluate established projects and programs.

\subsection{Collaboration with Local Partners and Capacity Building}

In choosing their local partners, OG has a set of criteria used to assess potential partnerships. The most impactful criteria are personal working reference from someone in the OG network (established local-partners or regional staff as examples). In other words, OG requires that potential partners have a connection to an individual(s) who have personal experience working with OG. OG begins by implementing short-term, one-day visits with local projects and if the experience is reciprocally positive and engaging, these one-day visits grow into multi-day visits. When establishing partnerships, OG drafts a memorandum of understanding (MOU) in collaboration with the organization in question before project proposals are vetted by regional committees comprised of local partners. OG places a heavy focus on building the capacity of their partner organizations, their participants and their program leaders. For OG's local partners, this entails close collaboration on project development, the provision of tools required to apply for external funding grants, workshops on how to host visiting groups (OG trips and otherwise), and workshops on how to get the word out about their organization/project. For OG's participants, this involves education on a theory of social change and substantial practical/experiential learning while travelling (i.e. how participants can become positive allies to communities locally/at home and not just while travelling with OG). For OG's program leaders, capacity building is accomplished by providing significant training on how to budget, manage projects, facilitate conversations, and lead groups through the learning process while travelling. 


\section{Chapter 3: Literature Review}

\subsection{Introduction}

The following literature review provides the framework to contextualize the central research question and objectives of the research study. First, the positive impacts of tourism are discussed, followed by an outline of the negative social, cultural and environmental impacts associated with tourism development and expansion. Next, the concept of sustainable tourism is introduced, offering an overview of the current state of literature on the topic. Following this, consumer perspectives of sustainability within the tourism industry is outlined, including a discussion of green consumerism within the tourism industry. Then, the two strategies to achieve sustainable tourism that this study is evaluating (voluntourism and carbon offsetting) are discussed both in general and in the context of OG. This section includes a discussion of the benefits and issues with voluntourism, the motivations of voluntourists, and OG's approach to voluntourism. Then, carbon offsetting within the tourism industry is discussed before outlining OG's carbon offset initiative. Lastly, the gap in knowledge identified by the literature review is presented.

\subsection{Influence of Tourism}

The following section highlights the benefits of tourism development before emphasizing the negative social, cultural and environmental impacts associated with the continued growth of the industry. This section demonstrates why sustainable tourism is an important study topic worthy of further investigation.

\subsubsection{Benefits of Tourism}

Within the last three decades the tourism industry has experienced tremendous local, regional and national growth on a global scale thus becoming increasingly influential in economic structures worldwide (Choi et al. 2013). The United Nations World Tourism Organization 
(UNWTO) noted that in 2017, the tourism industry generated USD $\$ 1,332$ billion globally (2018b). Tourism is also considered an integral tool to increase economic productivity, being a common industry for national governments to prioritize so as to achieve economic growth (Mbaiwa 2003). The UNWTO (2018b) reports that the international tourism industry is responsible for seven percent of the world's exports, represents ten percent of the world's gross domestic product (GDP) and accounts for one in every ten jobs globally. As an economic driver, tourism has also been commonly associated with increased investment opportunities for locals and increased tax revenues (Andereck et al. 2005; Andereck \& Nyaupane 2011).

Internationally, tourism is regarded as an important and influential economic tool that has proven and future potential to affect positive social change (Neto 2003; Aragon-Correa et al. 2015). Often, tourism attracts increased spending on infrastructure (Easterling 2004) and as a result, has the potential to improve the living standards of host communities (Easterling 2004; Andereck et al. 2005). Gurung and Seeland (2011) note that tourism development has been proven to improve living standards by increasing economic opportunities for locals such as the sale of local products and services and the demonstration of local cultural practices for tourist entertainment and/or education. Tourism can improve the quality of life of communities by increasing economic diversity, establishing and/or maintaining natural and cultural attractions and creating outdoor recreation activities (Andereck et al. 2005). Gjerald (2005) suggests that tourism can also provide opportunities to learn about and experience different cultures, obtain different skills and knowledge and reflect on personal cultural circumstances. The tourism industry also contributes to cultural preservation and cross-cultural engagement, environmental protection, peace and security, and global development (Cohen \& Kennedy 2000; UNWTO 2018a). 


\subsubsection{Negative Impacts of Tourism}

Alongside the positive impacts, tourism can also be associated with a range of negative economic, socio-cultural and environmental impacts (Buckley 2012; Aragon-Correa et al. 2015). As Budeanu (2005) outlines, the positive economic impacts of tourism "come at a high price paid by nature and societies" (91) and as with most industries, there are substantial trade-offs to be considered. The negative socio-cultural impacts that can result from tourism development and expansion include, but are not limited to, the deterioration or loss of native languages, the erosion of the social fabric of communities, the exacerbation of class divisions, increased congestion and crime, increased cost of living, friction between tourists and local communities and the degradation of cultural authenticity (Easterling 2004; Gursoy \& Rutherford 2004; Andereck et al. 2005). Displacement and "forced relocation" (Wilson 2008: 46) of local and indigenous communities is a common element of tourism development. Mbaiwa (2004) discusses how tourism can lack consideration for the wants and needs of surrounding communities, as is the case for enclave tourism, whereby tourism is developed in remote areas and is largely owned and controlled by outsiders. Mbaiwa (2004) further describes how tourism development can marginalize and/or increase the social stratification of local communities and result in internal colonialism whereby tourism products are not within the means of the local communities, and where the revenue generated from tourism activities does not benefit such communities.

\subsubsection{Environmental Impacts of Tourism}

As tourism grows, it has also significantly contributed to contemporary global climate change (Gossling \& Peeters 2015; Melissen et al. 2016; Borden et al. 2017). Recent research indicates that tourism is responsible for almost eight percent of global carbon dioxide $\left(\mathrm{CO}_{2}\right)$ emissions (Lenzen et al. 2018). While the tourism industry is a perpetrator of climate change, it is 
simultaneously a victim of climate change as the industry is being impacted by the alteration, unpredictability and vulnerability of tourist destinations (Becken 2004; Bows et al. 2009; Qiao \& Gao 2017). Bows et al. (2009) outline how the tourism industry is impacted by climate change, noting how winter sports are facing the threat of reduced and unpredictable snow cover, island destinations are encountering flooding, and water shortages are reducing the feasibility of developing and maintaining tourism. Tourism has inherent environmental impacts as an industry that is highly dependent on both overland transportation and air travel (Dodds \& Graci 2009; Tang et al. 2015) but can lead to other environmental consequences as well. The tourism industry contributes to land cover and land use change from the development of infrastructure such as accommodation establishments, airports, roads, ports, marinas, and golf courses (Gossling 2002; Ayuso 2007; Melissen et al. 2016), can disturb natural ecosystems and habitats (Zhong et al. 2008) and catalyzes the distribution of infectious pathogens and organisms (Gossling 2002). Uncontrolled or insufficiently managed tourism development can threaten the health of natural landscapes and ecosystems (Zhong et al. 2011) and result in habitat degradation and fragmentation (Zhong et al. 2008). Tourism can also result in illegal infrastructure development, noise pollution and stress on the natural resources of an area (Mbaiwa 2003). Anthropic tourism activities can also have significant negative impacts on marine environments such as "reducing species diversity, richness and abundance" (Machado et al. 2017: 8). Because tourism is "often developed in attractive but fragile environments" (Andereck et al. 2005: 1059), the environmental issues associated with the industry are particularly impactful.

\subsection{Sustainable Tourism as a Way of Alleviating the Negative Impacts of Tourism}

While the continued growth of the tourism industry is associated with inevitable environmental consequences, the engagement with principles of sustainable tourism can help 
alleviate such impacts. By practicing sustainable tourism, the tourism industry can continue to expand while sufficiently integrating the principles of sustainable development. The model of sustainable development was first introduced in the UN's Brundtland Report (World Commission on Environment and Development (WCED) 1987). Defined as "development that meets the needs of present generations without compromising the ability of future generations to meet their own needs" (WCED 1987:43), sustainable development is the organizing framework informing economic, social and environmental decision-making across a range of disciplines (Buckley 2012). Such development aims to balance the aforementioned competing interests of the economy, society and the natural environment. In parallel with sustainable development, sustainable tourism strives to equally prioritize environmental protection, preserve cultural integrity, integrate social justice, encourage economic growth and "[meet] the needs of the host population in terms of improved living standards both in the short and long term" (Hashemkhani Zolfani et al. 2015: 2). The United Nations Environment Programme (UNEP) and the UNWTO (2005) define sustainable tourism as "tourism that takes full account of its current and future economic, social and environmental impacts, addressing the needs of visitors, the industry, the environment and host communities" (12). However, despite these established definitions, there remains an element of ambiguity regarding what sustainable tourism entails. This indistinctness is centrally due to the fact that on a global scale, the tourism industry is "very fragmented and diverse" (Aall 2014: 2569). As there are multiple definitions of the term and so many contexts in which tourism takes place, there is room for interpretation regarding what sustainable tourism looks like in practice (Pforr 2001; Aall 2014). Yet, regardless of the various interpretations of sustainable tourism, considerable strides in integrating principles of sustainability into the tourism industry have been made (Budeanu 2005; Buckley 2012; Aragon-Correa et al. 2015). For tour operators, good practices for engaging with 
sustainable tourism include but are not limited to the development of environmental policies and plans, environmental training for staff, the integration of environmental education, supporting environmental and socio-cultural protection/conservation activities in destinations, bringing smaller volumes of tourists to destinations, utilizing locally-owned accommodation, local guides and local services, and conducting environmental audits and social impact studies before establishing tourism products in destinations (Curtin \& Busby 1999; Budeanu 2005; Dodds \& Kuehnel 2010; Goffi et al. 2018).

In the United Nations Agenda for Sustainable Development (2015), seventeen sustainable development goals and 169 targets to accomplish such goals are outlined. Included within these goals are policy developments that acknowledge the importance of sustainability within the tourism industry, such as policies that "promote sustainable tourism that creates jobs and promotes local culture and products" (United Nations General Assembly 2015: 20). Subsequently, the notion of sustainable tourism emerged and has been increasingly incorporated into both academic literature and applied research and action within the tourism industry (Buckley 2012; Prud'homme \& Raymond 2013; Mohd Suki \& Mohd Suki 2015). The UNWTO's (2015) Tourism and Sustainable Development Goals outlines how the seventeen Sustainable Development Goals (SDGs) apply to tourism development and expansion. Table 1 below lists the SDGs and summarizes how they can be applied in a tourism context, i.e. how the tourism industry can accomplish them. 
Table 1 UNWTO Sustainable Development Goals and Their Applications to Tourism

\begin{tabular}{|l|l|}
\hline \multicolumn{1}{|c|}{ UNWTO SDGs } & \multicolumn{1}{c|}{ How SDGs Apply to Tourism } \\
\hline 1. No Poverty & - Foster economic growth \\
\hline 2. Zero Hunger & $\begin{array}{l}\text { - Produce, use, and sell local products in tourist } \\
\text { destinations } \\
\text { - Integrate local products into tourism value chain }\end{array}$ \\
\hline 3. Good Health and Well-Being & $\begin{array}{l}\text { - Effects of tourism development and subsequent } \\
\text { economic growth on healthcare infrastructure and well- } \\
\text { being }\end{array}$ \\
\hline 4. Quality Education & - Vocational training in the tourism sector \\
\hline 5. Gender Equality & $\begin{array}{l}\text { - Job opportunities and income generation for women } \\
\text { in the tourism industry }\end{array}$ \\
\hline 6. Clean Water and Sanitation & - Improved water access/security and water sanitation \\
\hline 7. Affordable and Clean Energy & $\begin{array}{l}\text { - Can accelerate shift towards clean energy (as it is } \\
\text { such an energy-dependent industry) }\end{array}$ \\
\hline 8. Decent Work and Economic Growth & - Creates jobs by promoting local culture and products \\
\hline 9. Industry, Innovation and Infrastructure & $\begin{array}{l}\text { - Improved infrastructure to fuel the growth of the } \\
\text { tourism industry }\end{array}$ \\
\hline 10. Reduced Inequalities & $\begin{array}{l}\text { - Community development } \\
\text { - Involvement in the global economy }\end{array}$ \\
\hline 11. Sustainable Cities and Communities & $\begin{array}{l}\text { - Preserve cultural and natural heritage } \\
\text { - Promote regeneration of areas in decay }\end{array}$ \\
\hline 12. Responsible Consumption and Production & - Accelerate a global shift towards sustainability \\
\hline 13. Climate Action & $\begin{array}{l}\text { - Energy conservation and reduction in high } \\
\text { consumptive sectors (e.g. accommodation) } \\
\text { - Shift to renewable energy }\end{array}$ \\
\hline 14. Life Below Water & $\begin{array}{l}\text { - Conservation and sustainable use of oceans and other } \\
\text { bodies of water }\end{array}$ \\
\hline 15. Life on Land & $\begin{array}{l}\text { - Importance of natural landscapes and wilderness } \\
\text { areas to tourism } \\
- \text { Promote conservation and preservation } \\
\text { - Enhanced awareness and education of environmental } \\
\text { issues }\end{array}$ \\
\hline 17. Partnerships for the Goals & - Multi-cultural and inter-faith tolerance/understanding \\
\hline & $\begin{array}{l}\text { - Foster public/private partnerships and engage } \\
\text { multiple stakeholders }\end{array}$ \\
\hline
\end{tabular}

Note: Adapted from UNWTO Tourism and Sustainable Development Goals (2015)

While all of the SDGs outlined in Table 1 are applicable in the tourism context, a select few are of particular importance to the topics outlined in this literature review. Goal eleven includes an element of preserving both cultural and natural heritage. Goal fifteen emphasises the important role tourism has in protecting the natural environment including the role of tourism in improving conservation and preservation of natural/wilderness areas, and the potential for tourism to encourage environmental education. Goal sixteen highlights how tourism is dependent on sociocultural interaction and is a crucial element of establishing and/or improving understanding 
between, and within different cultures and global religions. Additionally, this SDG prioritizes tourism activities that can benefit and engage communities by creating financial opportunities, reinforcing cultural identities and promoting entrepreneurship.

\subsubsection{Consumer Perspectives of Sustainability in the Tourism Industry}

The increasing prominence of sustainability within the tourism industry can be attributed to multiple factors. These factors include but are not limited to an acknowledgement of the impacts of tourism development and the importance of sustainable tourism, a recognition of the growing prevalence of green consumers within the tourism industry (see section 3.3.1.1), and an understanding that engaging with principles of sustainability can result in a competitive advantage for tourist products (Popsa 2017). Small and medium enterprises (SMEs) within the tourism industry can be motivated to by a variety of factors, including reasons relating to management, reasons relating to altruism, and reasons relating to customers (i.e. economic or management interests, wanting to give back/do the right thing and corporate image/customer perception, respectively) (Garay et al. 2018). The academic literature on the business case for sustainability within the tourism industry is primarily focused on the sustainability efforts of large corporations within the accommodation sector (Garay et al. 2018). Therefore, there is a need to discuss the sustainability efforts of NGOs and smaller organizations within the tourism industry which have not been substantially analyzed in this regard in academic literature.

\subsubsection{Green Consumerism Within the Tourism Industry}

The notion of green consumerism has become a central facet of contemporary decisionmaking as purchasers are increasingly considering the ecological impacts of products and services (Ambec \& Lanoie 2008; Onel 2017). Green consumers are individuals that consider social and environmental factors when making purchasing decisions and that frequently make buying 
decisions based on environmental and/or social altruism (Onel 2017). When sufficient demand for environmentally-friendly products and services is present, businesses that integrate environmental initiatives into their business models can "differentiate their products and fill a green market niche" (Alberini \& Segerson 2002: 161). Proactively engaging with and marketing sustainability can aid in customer acquisition as well as retention (Hockerts 2015; Rahman et al. 2015). The recognition of the green consumer market is demonstrated by the increase in eco-labelling and the marketing of environmental management (Alberini \& Segerson 2002). Consequently, businesses within the tourism industry are now integrating "environmental awareness, sustainable initiatives and green marketing" (Dodds \& Holmes 2016: 1) into their management strategies. There are examples of accommodation establishments adopting environmental policy instruments (Ayuso 2006; Ayuso 2007; Aragon-Correa et al. 2015) and tour operators integrating eco-tourism, socio-economic sustainability and environmental education into their product offerings (Budeanu 2005; Tepelus 2005; Poon Tip 2009; Dodds \& Kuhenel 2010). Yet, despite increased marketing of proenvironmental behavior on the part of businesses, skepticism surrounding greenwashing (making misleading or unproven claims about the environmental benefits of a product or service) is prevalent (Smith \& Font 2014; Rahman et al. 2015).

\subsection{Strategies Used to Address the Negative Impacts of the Tourism Industry}

While tourism does have inherent impacts, there are efforts employed that aim to reduce or alleviate the impacts of the industry. While tourism has demonstrated potential to negatively impact the environment, "there are well-founded reasons to believe that it can also be a force for protection" (Hughes 2002: 458). The development of game reserves and wildlife sanctuaries (Sekhar 2003; Naidoo \& Adamowicz 2005; Ballantyne et al. 2009), the tightening of regulations in national parks (Andereck et al. 2005; Silva \& Khatiwada 2014; Sujarittanonta 2014) and the 
expansion of responsible nature-based tourism and ecotourism (Hashemkhani Zolfani et al. 2015) are examples that demonstrate such efforts. Stakeholders within the tourism industry have also employed strategies to reduce the negative impacts of their activities and have demonstrated how the tourism industry can accomplish the goals of sustainable tourism. The accommodation sector has made strides in promoting energy efficiency and water conservation (Ayuso 2006; Ayuso 2007; Melissen et al. 2016), airlines have integrated carbon offsetting into their ticket prices (Becken \& Mackey 2017), cruises have developed and adopted technological innovations to reduce the environmental impacts of their operations (Caric \& Mackelworth 2014; Polat 2015) and tourism policies are now being established that reflect the urgency to protect and restore natural environments (Sirilersuang \& Pongkijvorasin 2018). In addition to the aforementioned environmental efforts, the tourism industry has also worked to address the social impacts of tourism. Overtourism policies are being developed to reduce congestion and crowding (Cheer et al. 2019), heritage tourism continues to develop (Murtagh et al. 2017; Noonan \& Rizzo 2017) and in some cases, tourism has served as a tool for the preservation of local cultures and languages (Greathouse-Amador 2005). Tour operators, including voluntourism organizations are a large player in the tourism industry, yet there has been limited academic research on strategies used by tour operators to achieve sustainable tourism (with the exception of Dodds \& Kuehnel 2010; Goffi et al. 2018). This study, therefore, focuses on one tour operator which is an NGO and non-profit OG - and two of the strategies they have employed in order to achieve sustainable tourism. The two sustainable tourism efforts analyzed in this study are OG's approach to voluntourism and their carbon offset initiative. Both strategies are outlined in general below before being further analyzed within the context of OG. 


\subsubsection{Voluntourism}

Volunteer tourism - also referred to as voluntourism - is a form of travel whereby individuals incorporate volunteer work into their travel itineraries or center their travels around contributing to/participating in charity projects (McGloin \& Georgeou 2016). Voluntourism is considered to be one of many methods to accomplish the goals of sustainable tourism (Bailey \& Russell 2012; Wearing \& McGehee 2013; Boluk et al. 2016), yet there are a variety of concerns associated with this form of travel. The benefits of voluntourism are outlined below before the issues and common concerns associated with voluntourism are presented.

\subsubsection{Benefits of Voluntourism}

Voluntourism can be understood as tourism where tourists travel to participate in "aiding or alleviating the material poverty of some groups in society, [restoring] certain environments, or research[ing] into aspects of society or environment" (Hasanova 2017: 4). Voluntourism is commonly referred to as tourism centered upon "making a positive contribution to the social, natural and economic environment... where both the volunteer and the host community gain from the experience" (Ooi \& Laing 2010: 191), or tourism that promotes "intercultural learning exchanges" (Liston-Heyes \& Daley 2017: 286). Voluntourism can be defined as "a different kind of vacation experience, one which enriches the local community at the same time as offering the opportunity for a more profound travel experience" (Wilson 2015: 201). Voluntourists can be classified as individuals "seeking more sustainable and responsible tourism experiences that [provide] benefits to local communities and [foster] transformative learning for volunteers" (Wearing et al. 2017: 512). Studies that have examined the impacts of voluntourism experiences on participants have suggested that many individuals have referred to enhanced consciousness of contemporary global issues (McGehee \& Santos 2005) and some have "developed a new 
perspective on life at home [and] discovered an intrinsic need for meaning and purpose in their lives" (Lepp 2008: 98).

Voluntourism can engage travellers in a range of social and environmental topics, including but not limited to community development, environmental conservation and restoration, education, historic preservation and medicine (Brown 2005) and is framed as a way for tourists to become "engaged and active global citizens" (Foller-Carroll \& Charlebois 2016: 140). Voluntourism is considered a primary component of the alternative tourism paradigm, "foster[ing] a reciprocal and mutually beneficial relationship between the host and guest" (Wearing \& Neil 2000: 543) and creating opportunities to engage with tourism in a sustainable manner (Sin 2009). Compared to mass tourism which is commonly associated with consumption, exploitation and ecological damage (Sin 2009), voluntourism is traditionally considered to be "more benign or beneficial to the local community and the ecological environment" (Sin 2009: 482). However, voluntourism can also be a consumptive, exploitative and ecologically damaging activity if improperly organized and managed (Wearing et al. 2017).

\subsubsection{Issues with Voluntourism}

Although there are many benefits which can be gained from voluntourism, there are also issues. A plethora of potential difficulties with voluntourism are discussed in voluntourism literature (Wearing \& McGehee 2013). Such concerns are rooted in the perception of voluntourism as a modern form of colonialism that solidifies power dynamics between developed and developing nations or regions (Blackman \& Benson 2010; Luh Sin et al. 2015; Hasanova 2017). This narrative "perpetuate[s] an illusion that Western society represents the only solution to the global development issues of the South" (Hammersley 2014: 867) and promotes the idea that "voluntourists will bestow development on those in need, and that the needy will be dutifully 
grateful" (McGloin \& Georgeou 2016: 411). Voluntourism can reinforce perceived superiority, may threaten cultural values and beliefs of communities, is often critiqued as having limited influence on participants and being exploitative of locals, and may not contribute significantly either to local environments or communities (Bailey \& Russell 2012; Coren \& Gray 2012; FollerCarroll \& Charlebois 2016).

The common critiques and ethical concerns of voluntourism demonstrate why there is a need to improve the practice. In order to address the issues of voluntourism, voluntourism organizations need to ensure that programs are carefully developed and effectively managed (Raymond \& Hall 2008; Atkins 2012). Raymond and Hall (2008) suggest that voluntourism can effectively avoid the traditional concerns associated with the practice by adopting three strategies: 1) developing programs that address the concerns of locals and offer tangible value to the communities visited, 2) approaching voluntourism as a learning process by integrating experiential learning techniques, and 3) deliberately facilitating cultural interactions so as to avoid problematic encounters between participants and locals. Guttentag (2009) further suggests that consultation and collaboration with local communities is a necessary element of effective voluntourism program development. With careful planning and collaboration with local communities, voluntourism organizations can "play an important role in ensuring that [voluntourism] stereotypes are broken rather than reinforced" (Raymond \& Hall 2008: 541).

\subsubsection{Travellers' Motivations to Participate in Voluntourism}

The current state of literature on voluntourism highlights several factors that motivate travellers to participate in voluntourism. Commonly cited motivational theory related to tourism includes Maslow's hierarchy of needs; in a voluntourism context, this cognitive framework describes the necessity for individuals to have their physiological and safety needs met 
before being motivated to travel to make a positive difference in others' lives (Maslow 1954;1970). Broad (2003) adds to this by suggesting that belonging and self-actualization which are higher on the spectrum of needs have been considered potential motivations for voluntourists. Voluntourists fall into either one of two categories: volunteer-minded and vacation-minded, the former describing voluntourism whereby individuals spend the majority of their trip contributing to volunteer projects, the latter describing voluntourism where individuals have the opportunity to partake in optional volunteer projects for a small portion of the overall trip, but also partake in tourism activities (Brown 2005).

Other motivators often discussed are social/political/environmental altruism and social egoism, the latter describing experiences that simultaneously benefit the traveler and the community or environment they are interacting with (Grimm \& Needham 2012; Liston-Heyes \& Daley 2017). The aforementioned motivations describe the desire to act as an agent of change for social, political or environmental concerns and the desire to partake in voluntourism to benefit the traveller and potentially the local community, respectively (Grimm \& Needham 2012; Liston Heyes \& Daley 2017). Bailey and Russell (2012) discuss diverse motivational theories as a framework to understand why individuals are compelled to participate in voluntourism. The authors identify diverse "prosocial motives" (Bailey \& Russell 2012: 124) that are likely to contribute to engagement with voluntourism. Such motives include openness (i.e. the extent to which individuals are open-minded and willing to/have a desire to have new experiences outside of their comfort zone), wisdom (i.e. to what extent individuals seek a deeper understanding of the world around them), civic attitude (i.e. if, and to what extent individuals believe that they can make a difference) and social environment and social engagement (i.e. how environments shape participation in social initiatives and vice versa) (Bailey \& Russell 2012). Andereck et al. (2012) 
cite potential voluntourism motivations such as seeking an alternative experience to mass tourism, participating in community development and contributing to the avoidance of "irreversible environmental changes" (131).

Yet, academic literature has also mentioned enhancing one's resume or curriculum vitae (CV) (McGloin \& Georgeou 2016) and wanting to feeling good about oneself (Germann Molz 2017) as potential motivations for voluntourists, as is evidenced by traditional pat on the back voluntourism experiences (Coren and Gray 2012). Voluntourism organizations tend to market such experiences as opportunities to give back and make a difference (Smith \& Font 2014), which likely influences consumers' perceptions of the product and leads them to believe they are participating for altruistic reasons. Broad (2003) also emphasizes that while voluntourists are most often motivated by altruism to some extent, most are also at least partially motivated by a desire to travel and see the world (Broad 2003). Although altruism may be an element of travellers' motivations for participating in voluntourism, personal development, individualism and selfinterest are probable contributing factors (Coghlan 2008; Guttentag 2009; Wearing \& McGehee 2013). As Guttentag (2009) suggests, understanding and thus satisfying the motivations of voluntourists is important as it is a crucial component of attracting participants. This is because "understanding volunteers' motivations is vital to the design and operation of successful conservation programmes that rely on volunteers as their primary labour source" (Broad \& Jenkins 2008: 72). However, when focusing too intently on the motivations and desires of voluntourists there is the potential to neglect the needs of the host communities (Guttentag 2009).

A subset of voluntourism is known as environmental voluntourism which has an explicit environmental focus and can take the form of "ecological volunteering, [i.e.] working with wildlife or in fragile ecosystems" (Occhipinti 2016: 259). Environmental voluntourism emphasizes 
environmental topics and actively engages voluntourists with preservation and restoration of natural environments, allowing voluntourists to partake in environmental initiatives and projects and/or promoting environmental education (Broad 2003; Ballantyne et al. 2009; Brondo et al. 2016). Schneller and Coburn (2018) note that environmental voluntourism can improve community stakeholder perceived value of environmental projects, enhance concern and awareness of both environmental and social issues and have unexpected longer-term outcomes including continued pro-environmental behaviour and extended academic careers of participants (Schneller \& Coburn 2018), demonstrating the potential for environmental voluntourism to affect positive change both within the context of the volunteer projects and with the volunteers themselves. Broad (2003) notes that "learning new skills, meeting like-minded people, experiencing a new destination or culture, and [participating in] a worthwhile experience" (Broad 2003: 66) are commonly referenced motivations for participating in environmental voluntourism.

\subsubsection{Carbon Offsetting}

The practice of carbon offsetting is discussed below before outlining the specifics of OG's carbon offset initiative. As the tourism industry is associated with high carbon emissions, climate change mitigation is essential for the sustainability of the industry (Gossling et al. 2007; Dodds \& Graci 2009; Dodds et al. 2012; Qiao \& Gao 2017). As the impacts of climate change continue to increase in frequency and severity, strategies aimed at reducing and/or compensating for GHG emissions have become prevalent within the tourism industry (Wang et al. 2017). Carbon offsetting is a strategy used to mitigate climate change (Lovell et al. 2009) as it is the counteraction of $\mathrm{CO}_{2}$ emissions with the reduction of equivalent $\mathrm{CO}_{2}$ emissions in another form. That is, carbon offsets "allow carbon to be reduced by compensating for excess emissions in one location through carbon reductions in another" (Bumpus \& Liverman 2008: 131). Carbon offsetting is a process whereby 
individuals, organizations or otherwise can offset the $\mathrm{CO}_{2}$ emissions created from their activities by purchasing carbon credits "generated by such projects as forest planting, renewable energy, biofuels, methane capture, energy-efficient wood-stoves and lighting" (Bumpus \& Liverman 2008: 128). Lovell et al. (2009) note that compared to other sustainable products, carbon offsets are not tangible products, nor do they offer material benefits to the consumer. Yet, companies and organizations increasingly opt to purchase carbon offsets to gain a competitive advantage in the green consumer market (Lovell et al. 2009).

Although carbon offsetting can compensate for emissions from a variety of sources (Bumpus \& Liverman 2008), this research focuses on carbon offsetting for aviation emissions. As a central facet of tourism, emissions associated with the aviation sector are crucial when discussing sustainable tourism (Gossling et al. 2007). According to Gossling et al. (2007), voluntary carbon offsetting within the tourism industry caters to "those who are aware of the environmental consequences of aviation but do not want to, or are not able to, forego flying altogether" (225). Mair (2011) notes that "voluntary carbon offsetting has become increasingly publicized by airlines and popular amongst concerned travelers as a means to mitigate the impact of their air travel" (215), yet there is considerable skepticism and debate surrounding the effectiveness of carbon offsetting due to a lack of universal standards and verification, and limited transparency of where and how the money generated is spent (Taiyab 2006; Dodds et al. 2012). Tour operators are increasingly advertising the possibility of voluntary carbon offsetting to customers, with some integrating carbon offsetting into their program fees instead of relying on consumers to voluntarily contribute (Gossling et al. 2007) as there is evidence suggesting tourists are more likely to pay for carbon offsetting and other climate change mitigation programs when they are presented as optout options as opposed to opt-in options (Arana et al. 2013). 


\subsubsection{OG's Carbon Offset Initiative}

OG has a carbon offset initiative for all trips (i.e. not only those with an explicit environmental focus), whereby a portion of the community contribution fee (ten percent) is diverted to PlanetAir (Operation Groundswell 2019). The community contribution fee is an element of the program fees whereby participants are encouraged to fundraise (the majority of the community contribution is diverted to the in-country projects visited by participants). PlanetAir is a carbon offsetting agency that supports environmental initiatives aiming to mitigate climate change (Operation Groundswell 2019). OG's website notes that PlanetAir is regarded by the Suzuki Foundation as an industry leader (Operation Groundswell 2019). This carbon offset initiative is an included element of the program fees and is not a voluntary initiative for which consumers can opt-into or out of. Figure 1 on the following page depicts OG's communication of their carbon offset initiative on their website. This webpage breaks down the elements of the community contribution fee to communicate to consumers where these funds are allocated. 
WHERE DOES IT GO?

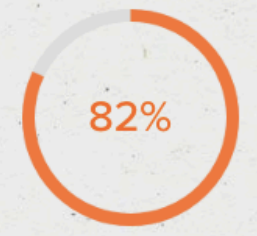

IN COUNTRY PROJECTS

$82 \%$ of team members' community contributions go directly to support projects implemented by the local non-profits, charities, and communities that we are partnered with. From constructing the first Ubuntu Blox styrofoam factory in Haiti to supporting literacy programis in Tanzania, our groups always strive to make a lasting impact. Each team contributes to one or two major local projects while abroad. Teams may also choose to allocate funds to the Alumni Project Fund, a communal pool to support alumni who have continued working on development projects with local partners.

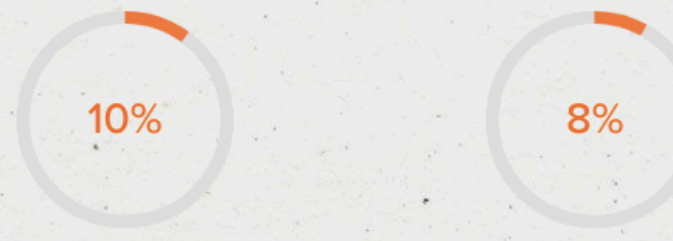

CARBON OFFSETTING

There is no question that round-trip flights leave a large carbon footprint. If we are going to fly, we want to encourage environmental responsibility.

For this reason, we carbon offset all of our programs. $10 \%$ of each community contribution is allocated to PlanetAir, a Canadian organization regarded by the Suzuki Foundation as one of the leaders in the industry.

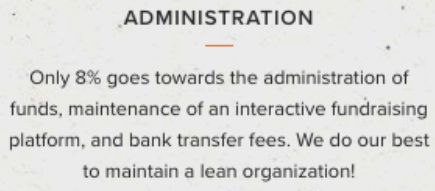

ADMINISTRATION

Only $8 \%$ goes towards the administration of funds, maintenance of an interactive fundraising platform, and bank transfer fees. We do our best to maintain a lean organization!

Figure 1 Communication of Carbon Offset Initiative on OG's Website

\subsection{Gap in Knowledge/Need for This Study}

The gap in knowledge identified by the literature review that this thesis aims to address is the efforts of tour operators, specifically NGOs, in achieving sustainable tourism. As academic literature on the business case for sustainability in the tourism context is primarily focused on large corporations within the accommodation sector (Garay et al. 2018), there is a need to evaluate the sustainability efforts of NGOs and smaller organizations within the tourism industry. Further, while voluntourism has been considered one way to achieve the goals of sustainable tourism (Bailey \& Russell 2012; Wearing \& McGehee 2013; Boluk et al. 2016), there is limited research that investigates whether this form of tourism is perceived by participants/consumers to be an effective way of attaining sustainable tourism. This thesis will add to the very limited body of academic literature that evaluates consumer perceptions of voluntourism as an effective way to 
accomplish the goals of sustainable tourism. Additionally, this thesis will be the first to include an analysis of the perspectives of both past and prospective consumers of OG. 


\section{Chapter 4: Methods}

\subsection{Introduction}

The following chapter outlines the methodological approach that was used to address the central research question and objectives. First, the research question and objectives, as identified by OG, are presented. Next, the type of research selected is outlined and justified, encompassing a discussion of qualitative research within an interpretive paradigm and the case study method. Following this, the sampling methods including the type of sampling employed, the study population and the sample size are outlined. Then, the piloting and data collection processes are presented. Following this, the approach and methods for data analysis are described. Next, the ethics process is outlined. Finally, the limitations of the selected methods are noted.

\subsection{Research Question and Objectives}

OG played a major role in the development of the research question and objectives of this study; the researcher had discussions with OG's Executive Director to identify what they as an organization were keen to learn more about. After identifying that consumer perceptions of their approach to voluntourism and their carbon offset initiative were topics of interest, the researcher developed the research questions to simultaneously tackle the questions identified by OG and to address the gap in knowledge/research identified by the literature review. Both the research question and objectives were subsequently approved by OG. The research question that this thesis aims to answer is: How can OG move forward as a facilitator of sustainable tourism utilizing their approach to voluntourism and their carbon offset initiative?

The following four objectives were developed to address this research question:

1. What motivates consumers to participate in OG's voluntourism trips?

2. What are the perceived benefits and tangible impacts of travelling with OG? 
3. How influential and/or important for business success (i.e. attracting and retaining customers) is OG's carbon offset initiative?

4. Do OG's past and prospective consumers perceive OG's approach to voluntourism as an effective way of engaging with sustainable tourism?

\subsection{Research Process}

A qualitative approach was used to answer the research question and objectives developed from the literature review. Figure 2 provides an illustration in the form of a flow chart of these specific research procedures. Each phase of the research process is described in further detail below.

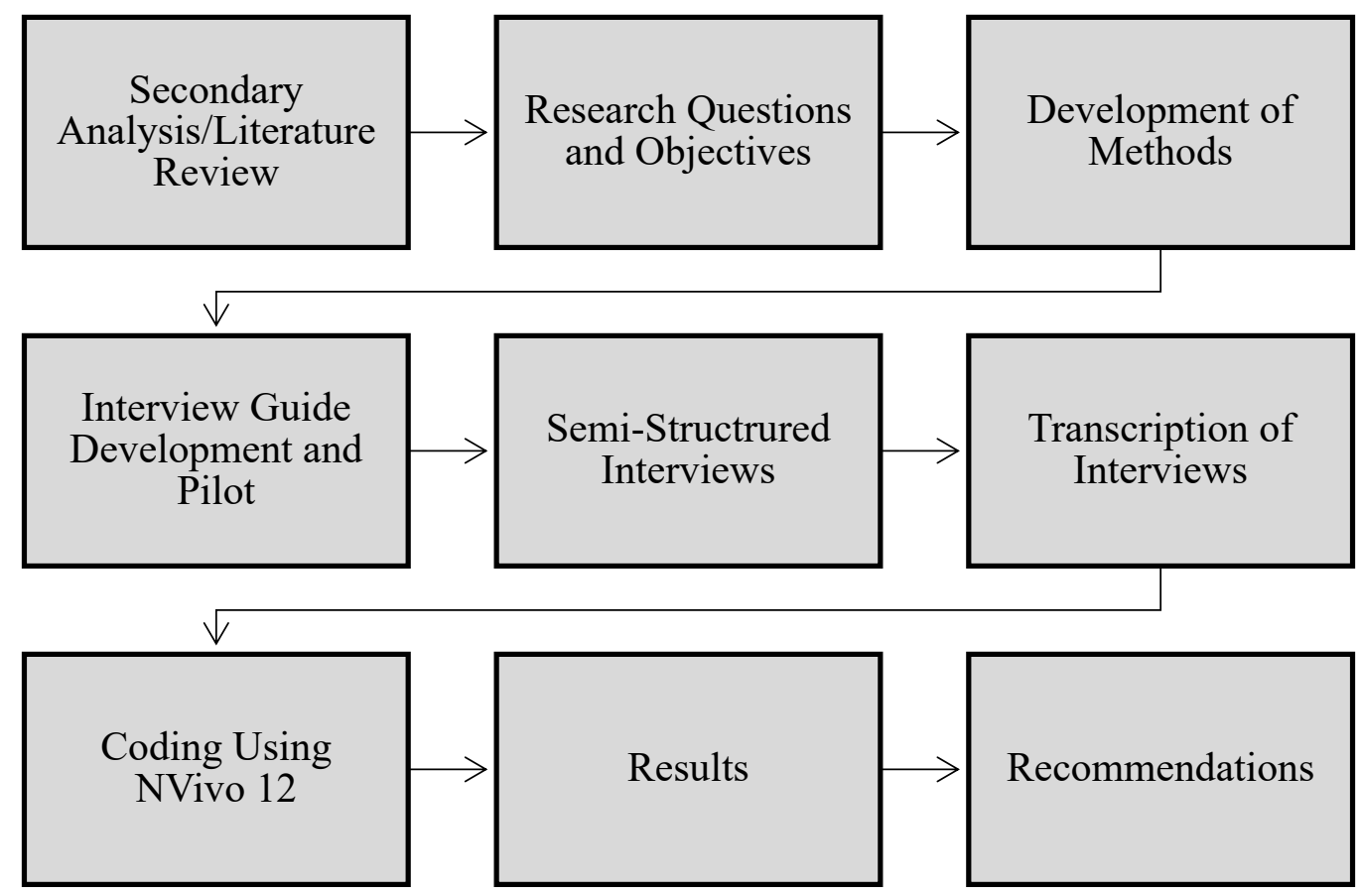

Figure 2 Specific Research Procedures

\subsection{Secondary Analysis/Literature Review}

The first phase of this research process was to conduct a secondary analysis, accomplished through the writing of a literature review. Peer-reviewed academic journals, books, publications from intergovernmental organizations (IGOs) and media sources (OGs website) were consulted 
and investigated to develop the literature review. Webster and Watson (2002) note that a comprehensive literature review encompasses the nuances of a topic and is not limited to one research approach or methodology, one type of journal or one geographic area. Instead, a literature review should attempt to provide a conceptual understanding of the themes and topics covered within the research (Webster \& Watson 2002). A complete literature review "serves to explain, justify and contextualize the research question and its methodology" (Steward 2004: 497). The researcher wrote a literature review to ensure the research is unique from previous research, is not being duplicated and adds noteworthy information to the body of literature on the topic (Boote \& Beile 2005).

\subsection{Type of Research}

The following subsections outline the type of research that was used to conduct the study. First, a discussion and justification for the use of qualitative analysis within an interpretive paradigm is outlined. Thereafter, the case study method is described, emphasizing how and why this approach is appropriate to address the research question and objectives.

\subsubsection{Qualitative Analysis Within an Interpretive Paradigm}

This research study was conducted through a qualitative lens within an interpretive paradigm, consistent with similar studies that have been conducted to evaluate both past and prospective voluntourists (Broad 2003; Simpson 2004; Brown 2005; McIntosh \& Zahra 2007; Lo \& Lee 2011; Liston-Heyes \& Daley 2017). Compared to a quantitative approach, qualitative research enables second order interpretations whereby participants' explanations are further explained by the researcher (Tracy 2013). Qualitative research is also "richly descriptive" (Merriam 2009: 16), providing a thorough understanding of how people make sense of experiences and the world around them. A qualitative approach emphasizes "understanding attitudes rather 
than measuring them" (Brown 2005: 486). An interpretive paradigm involves the understanding of phenomenon through the subjective experiences of individuals (Goulding 1999). Qualitative research was selected for this study to allow for self-reflexivity and to shed light on OG's questions of "why" instead of only "what". A quantitative approach that would offer measurement-based findings was inconsistent with the questions identified by $O G$ and as such, was not selected for this research study.

\subsubsection{Case Study Approach}

In order to evaluate if OG's approach to voluntourism and their carbon offset initiative are effective at achieving the goals of sustainable tourism, this research study used a qualitative interview method using their own consumers to inform the case study. This approach was selected as it enables investigation into a "contemporary phenomenon within some real-life context" (Yin 2003: 1). The case study method is particularly valuable when applied to organizational and management research (Yin 2003). The case of this research is the consumer analysis conducted for OG about their approach to voluntourism and their carbon offset initiative, used to highlight how other similar tour operators and/or voluntourism organizations can adjust their business models to appeal to the growing green consumer market within the tourism industry. This study uses OG as an example by emulating the case studies conducted by Brown (2005) and ListonHeyes and Daley (2017) about the motivations, perceived benefits and perceptions of consumers of specific voluntourism organizations. Both studies employed the use of qualitative semistructured interviews, among other data collection methods (i.e. focus groups and questionnaires). The questions within the interview guide were derived from these two aforementioned studies and also drew inspiration from Lo and Lee (2011) who evaluated the motivations and perceived value 
of volunteer tourists from Hong Kong. See section 4.8 for a comprehensive overview of the selected data collection methods.

\subsubsection{Interview Design}

Data for this research study was collected through the conduction of participant interviews, referred to as in-depth interview studies (McIntosh \& Zahra 2007; Babbie \& Benaquisto 2010). Interviews were selected for this study as they "provide opportunities for mutual discovery, understanding, reflection and explanation via a path that is organic, adaptive and oftentimes energizing" (Tracy 2013: 132). Interviews also enable the researcher to "gain access to more inclusive sets of feelings and emotions that a structured instrument could not capture" (Brown 2005: 486). This research study aimed to gain insight into the perceptions and motivations of consumers in relation to OG's approach to voluntourism and their carbon offset initiative. As such, a qualitative approach utilizing interviews (as opposed to another form of qualitative data collection such as observation) was selected to identify what, how and why consumers feel and act a certain way as opposed to simply identifying what they feel or how they act.

\subsubsection{Interview Flow and Components}

Interviews for this research study were semi-structured. According to Blackman and Benson (2010), one-on-one, semi-structured interviews "[allow] flexibility during the actual interview process" (226). As structured interviews "lack flexibility and depth" (Tracy 2013: 139), and unstructured interviews can be too flexible and yield incomparable results, semi-structured interviews that have a "general set of questions and topics that the researcher wishes to cover in each interview" (Babbie \& Benaquisto 2010: 342), yet allow for elaboration and discussion have been deemed the most appropriate for this research study. All interested participants were made aware of the nature of the research study and how their participation would contribute to the 
overarching research goals before they committed to partake. Research participants were sent an electronic informed consent form prior to their scheduled interview, so they had time to review the information and ask the researcher any questions before signing. Informed consent forms were signed electronically using DocuSign and returned to the researcher electronically before scheduled interviews. See Appendix B for the informed consent form.

Interviews were comprised of fifteen to twenty-two questions (depending on the consumer category), with the use of prompts. Each consumer category (Alumni, Drop-Outs, Prospects) had a different level of personal experience with OG and certain questions were not applicable to other categories. For example, those within the Alumni category were asked multiple questions about how their trip with OG impacted them, including if there are any pro-environmental behaviours they have adopted since travelling with OG. As those within the Drop-Outs and Prospects categories lacked personal experience with OG, these questions were not applicable and thus not included in their respective interview guides. Drop-Outs (Category 2) had fifteen questions, Prospects (Category 3) had sixteen questions and Alumni (Category 1) had twenty-two questions. Alumni (Category 1) had the most questions given that research participants within this category had personal experience with OG, and certain questions asked were irrelevant for the other two categories. See appendices C1, C2 and C3 for the interview guides for each respective category, before the feedback from the pilot was accounted for.

\subsection{Sampling Methods}

The sampling plan for this research study was purposive, meaning that research participants were selected only if they aligned with the parameters of the study's research questions, goals and purposes (Tracy 2013). In the case of this research study, only Canadian OG past and prospective consumers were eligible to participate. While OG has international consumers, this eligibility 
requirement was established to limit the scope of analysis to the Canadian market, to enable ease of data collection (limiting the time zones for which interviews would take place) and to ensure that data from one market segment could be easily analyzed and compared. This research study employed convenience sampling from a study population of Canadian OG past and prospective consumers. The researcher chose to have representation from both past and prospective consumers to provide the most comprehensive evaluation of OG's consumer market. The sample from which data was collected included participants from all of the following categories that represent past and prospective Canadian OG consumers: 1) Canadian alumni who have participated in at least one OG program, 2) Canadian individuals who have successfully registered for a program but have ultimately not participated for diverse reasons, and 3) Canadian individuals who have completed an online inquiry form expressing interest in participating/requesting more information. Category 1 is labelled as Alumni, Category 2 is labelled as Drop-Outs, and Category 3 is labelled as Prospects. Table 2 below summarizes the three consumer categories and outlines the definitions of each category.

Table 2 Definitions of Consumer Categories

\begin{tabular}{|l|l|}
\hline Consumer Category & \multicolumn{1}{c|}{ Defined As } \\
\hline Category 1 - Alumni & $\begin{array}{l}\text { Canadian individuals who have travelled with OG at } \\
\text { least once since OG was established in 2006 }\end{array}$ \\
\hline Category 2 - Drop-Outs & $\begin{array}{l}\text { Canadian individuals who registered for a trip with OG } \\
\text { but ultimately did not travel }\end{array}$ \\
\hline Category 3 - Prospects & $\begin{array}{l}\text { Canadian individuals who expressed an interest in OG } \\
\text { by completing an online inquiry form }\end{array}$ \\
\hline
\end{tabular}

The researcher signed a non-disclosure agreement (NDA) developed by OG to enable the researcher access to OG's consumer details and to ensure confidentiality and the protection of this personal information. The NDA was effective as of June $27^{\text {th }}, 2018$. A master list of the contact information of each consumer category was provided by OG so that research participants could be recruited. Research participants were recruited via email by the researcher. The researcher 
distributed one initial email to every individual in the Alumni, Drop-Outs, and Prospects categories. Subsequent emails were only sent if and when potential participants had questions for the researcher. The researcher did not send follow-up emails to solicit additional participants. This is because OG asked that emails be sent sparingly and only those who expressed an interest in participating were contacted. In other words, the researcher was asked to only reach out to potential participants once, and to avoid emailing past and prospective consumers if they had not already contacted the researcher. This translated into the distribution of 550 emails to Alumni, 117 emails to Drop-Outs and 2,772 emails to Prospects. The researcher distributed a total of 3,439 emails to solicit participation and had a response rate of 0.032 percent. The final sample was comprised of twenty-five participants: eighteen from the Alumni category (representing $72 \%$ of the total sample), two from the Drop-Outs category (representing $8 \%$ of the total sample), and five from the Prospects category (representing $20 \%$ of the total sample). While thirty-six interviews were scheduled, only twenty-five interviews took place due to cancellations and no-shows.

The researcher used mail merge to personalize each email to include potential participant's first names. The researcher obtained the highest volume of interest from the Alumni category, which is why the sample for this consumer category is the largest of the three consumer categories. Once twenty Alumni had been scheduled for interviews, the researcher concluded that the Alumni category was well-represented and advised other interested Alumni that they would not be selected to participate. However, two respondents from the Alumni category were no-shows, which is why the final sample for that consumer category consists of eighteen respondents. Only five individuals from the Drop-Outs category expressed an interest in participating and those five were scheduled for interviews. However, three participants either cancelled in advance of their scheduled interviews or were no-shows, which is why the final sample of the Drop-Outs category consists of 
only two participants. There were eleven individuals from the Prospects category who expressed an interest in participating, and those eleven were scheduled for interviews. However, six participants either cancelled in advance or were no-shows, which is why the final sample of the Prospects category consists of only five participants.

However, despite the lower-than-expected sample size, the final sample adheres to the recommendations of Creswell (2007) who indicates that for inductive qualitative research (see section 4.9.1 for more information), researchers should conduct between twenty to thirty interviews. Further, the twenty-five interviews that were conducted allowed the researcher to reach data saturation, the point where themes are repeated by multiple respondents and where subsequent interviews do not generate novel information (Fush \& Ness 2015). Since data saturation is dependent on the specific study in question (Fusch \& Ness 2015), the researcher had to evaluate if, once the twenty-five interviews were conducted, there was information uncovered that was not repeated by multiple respondents. The researcher continued to uncover consistent themes throughout the process of data collection and determined that data saturation had been reached with the established sample size. Had there been themes that were not repeated by multiple respondents, the researcher would have recruited a second round of participants and conducted more interviews until data saturation was reached. If that were to have been the case, the Alumni who were turned down as participants would have been contacted (to respect OG's request that subsequent participant recruitment emails were not sent to individuals who had not already expressed an interest in participating). Table 3 below depicts the representation of each category within the sample. 
Table 3 Numerical Representation of Each Category Within Sample $(n=25)$

\begin{tabular}{|c|c|c|}
\hline Consumer Category & n & Percentage of Sample (\%) \\
\hline Category 1-Alumni & 18 & $72 \%$ \\
\hline Category 2- Drop-Outs & 2 & $8 \%$ \\
\hline Category 3 - Prospects & 5 & $20 \%$ \\
\hline Total & $\mathbf{2 5}$ & $\mathbf{1 0 0 \%}$ \\
\hline
\end{tabular}

The researcher worked collaboratively with OG to craft the participant recruitment email, ensuring the content and language was consistent with OG's correspondence and would solicit interest in participating. See Appendices A1, A2 and A3 for the participant recruitment emails for each respective category.

\subsection{Piloting}

In November 2018 prior to data collection, piloting of the interview length, pace and questions was conducted. Before the pilot took place, the researcher collaborated with three OG employees to develop and edit the interview guides. OG provided the researcher with feedback on phrasing and clarity of questions. All three interview guides went through multiple iterations before being approved by OG. The researcher then conducted a pilot interview with one of the past consumers with whom she has a prior relationship, allowing the researcher to 1) gauge if the research questions yielded discussions and results that are consistent with the research goals and scope, 2) evaluate if the flow of the interview was logical and clear, 3) identify if the phrasing of the questions was easy to understand and 4) test out the video-conferencing software Zoom (a video-conferencing service similar to Skype that enables interviews to be audio-recorded) used for data collection, and ensure the audio-recording of the interview was reliable. The pilot took place on Thursday, November $29^{\text {th }}, 2018$ once all three interview guides had been approved by OG. The pilot enabled the researcher to identify any issues with clarity and specificity that had to be addressed before data collection took place. All three interview guides were thoroughly reviewed and edited by both the researcher and the three OG employees prior to the pilot taking place. The 
researcher only conducted a pilot of the interview guide for the Alumni category (Category 1), as it was the most comprehensive of the three and included questions that were not included in the interview guides for the Drop-Outs and Prospects categories (Category 2 and 3, respectively). That is, the interview guide for the Alumni category had the most questions, and all of the questions included in the Drop-Outs and Prospects interview guides also appeared in the interview guide for the Alumni (with the exception of questions that were not relevant and/or transferable to the other consumer categories). The only questions present in the interview guides for the Drop-Outs and Prospects categories that were not present in the interview guide for the Alumni category were also included in the pilot to evaluate phrasing and clarity. However, these questions were not answered by the past consumer who participated in the pilot as they could not speak to them. These questions aimed to obtain the same information (i.e. while posed differently for each consumer category, the questions aimed to understand what about OG was or is appealing), and thus while phrased differently for each consumer category, the questions themselves were in the same vein as the one tested in the pilot. Therefore, while the researcher did not pilot the individual interview guides for the Drop-Outs and Prospects categories, the pilot that was conducted also addressed the issues/concerns with phrasing, clarity and flow in the interview guides for the Drop-Outs and Prospects categories. The researcher opted to pilot the interview guide for the Alumni category because 1) they had access to a past consumer who was willing to participate and 2) because it allowed the researcher to address the issues/concerns of all three interview guides at once.

The first alteration of the interview guide based on the feedback from the pilot was the removal - from all three interview guides - of the question that presented OG's nine core values outlined in their backpacktivist manifesto and asked research participants 1) what their understanding of the core values were, and 2) what these core values meant to them. The pilot 
demonstrated that 1) this question was cumbersome, as the core values had to be repeated so the participant could recall them, and 2) that the responses the questions elicited did not support the research questions/objectives of this study.

The second alteration to the interview guide based on the feedback from the pilot was an adjustment to the phrasing and approach to the carbon offset initiative question. Before the pilot, the interview guide introduced the topic of carbon offsetting by asking participants to define carbon offsetting. The participant for the pilot identified the potential for participants to feel uncomfortable if they were unfamiliar with the term, or not familiar enough with it to provide an informed response. As such, the first question about carbon offsetting asks participants if they have heard of the term carbon offsetting. This question is followed by a question asking participants if they feel comfortable defining carbon offsetting. The follow-up questions about carbon offsetting remained unchanged from the pre-pilot interview guide.

An important piece of feedback from the pilot was to avoid elaborating/re-phrasing questions without being prompted. The pilot demonstrated that the questions asked - excluding those that were altered or removed - were presented clearly and phrased logically. As such, the researcher could read the questions as they were presented within the interview guide without concern that they were unclear or cumbersome to understand. If and when participants indicated that a question was unclear, the researcher could re-phrase or elaborate on the question. As such, a primary lesson learned from the pilot was to stick with the interview guide and only provide clarification on questions when prompted by research participants. See Appendices D1, D2 and D3 for the revised interview guides using the feedback from the pilot.

\subsection{Data Collection}

The following subsections discuss in detail how data was collected. 


\subsubsection{Data Collection Methods}

Interested participants were contacted by email to set up a date and time for their interview, all of which took place within an eleven-day period during December 2018 (December $\left.10^{\text {th }}-21^{\text {st }}\right)$. The researcher conducted up to six interviews per day between 11:00 AM EST and 9:00 PM EST. Interviews began with expectation setting including a synopsis of the research goals/scope, the expected length of the interview and the codes of conduct being adhered to by the researcher, e.g. confidentiality and the protection of personal information (Merriam 2009). Participants were then reminded of the process and timeline for compensation, including how winners would be contacted and when they could expect to be notified if they were to win (see section 4.8.3 for information on research participant compensation). Following this, the discussion questions were presented. Interviews lasted between nineteen minutes to an hour and ten minutes, with the average interview lasting approximately forty minutes. Table 4 below depicts the interview method, length and data recording for each interview. 
Table 4 Interview Methods, Length and Data Recording

\begin{tabular}{|c|c|c|c|c|}
\hline Interviewee & Consumer Category & Interview Method & $\begin{array}{c}\text { Interview Length } \\
\text { (Minutes) }\end{array}$ & $\begin{array}{c}\text { How Data Was } \\
\text { Recorded }\end{array}$ \\
\hline Respondent 1 & Drop-Out & Zoom & $20: 03$ & Zoom Audio \\
\hline Respondent 2 & Alumni & Zoom & $37: 21$ & Zoom Audio \\
\hline Respondent 3 & Prospect & Telephone & $23: 35$ & Audio-Recorder \\
\hline Respondent 4 & Alumni & Zoom & $28: 34$ & Zoom Audio \\
\hline Respondent 5 & Alumni & Zoom & $33: 45$ & Zoom Audio \\
\hline Respondent 6 & Alumni & Zoom & $53: 12$ & Zoom Audio \\
\hline Respondent 7 & Prospect & Zoom & $19: 42$ & Zoom Audio \\
\hline Respondent 8 & Prospect & Zoom & $38: 29$ & Zoom Audio \\
\hline Respondent 9 & Alumni & Zoom & $34: 23$ & Zoom Audio \\
\hline Respondent 10 & Prospect & Zoom & $45: 02$ & Zoom Audio \\
\hline Respondent 11 & Alumni & Zoom & $49: 37$ & Zoom Audio \\
\hline Respondent 12 & Alumni & Zoom & $43: 03$ & Zoom Audio \\
\hline Respondent 13 & Prospect & Zoom & $35: 25$ & Zoom Audio \\
\hline Respondent 14 & Alumni & Zoom & $47: 33$ & Zoom Audio \\
\hline Respondent 15 & Alumni & Zoom & $58: 04$ & Zoom Audio \\
\hline Respondent 16 & Drop-Out & Zoom & $36: 44$ & Zoom Audio \\
\hline Respondent 17 & Alumni & Zoom & $72: 13$ & Zoom Audio \\
\hline Respondent 18 & Alumni & Zoom & $56: 59$ & Zoom Audio \\
\hline Respondent 19 & Alumni & Zoom & $49: 10$ & Zoom Audio \\
\hline Respondent 20 & Alumni & Telephone & $41: 35$ & Audio-Recorder \\
\hline Respondent 21 & Alumni & Zoom & $38: 33$ & Zoom Audio \\
\hline Respondent 22 & Alumni & Zoom & $35: 28$ & Zoom Audio \\
\hline Respondent 23 & Alumni & Zoom & $37: 45$ & Zoom Audio \\
\hline Respondent 24 & Alumni & Zoom & $33: 59$ & Zoom Audio \\
\hline Respondent 25 & Alumni & Zoom & $55: 46$ & Zoom Audio \\
\hline
\end{tabular}

Note: Average interview duration was forty minutes

While OG has a dedicated office space that could have been used to conduct interviews, a neutral space distinct from the organization in question allowed the researcher to avoid potential participant bias of that nature (see section 4.11 for further details on avoiding bias). Although the researcher offered to conduct in-person interviews for those respondents who reside in Toronto and could meet in person, all interviews with the exception of two were conducted using Zoom given the geographic range of OG consumers. Respondents hailed from various provinces within Canada, and one respondent participated in the interview while living abroad in Japan. The majority of respondents $(76 \%)$ reside in Ontario, but there was also representation from British Columbia (8\%), Quebec (8\%), Alberta (4\%) and Manitoba (4\%). Table 5 below depicts the provinces respondents reside in. 
Table 5 Provinces Respondents Reside In ( $\mathrm{n}=25)$

\begin{tabular}{|c|c|c|c|c|c|}
\hline $\begin{array}{c}\text { Consumer } \\
\text { Category }\end{array}$ & Ontario & British Columbia & Quebec & Alberta & Manitoba \\
\hline Total Sample & 19 & 2 & 2 & 1 & 1 \\
\hline Total (\%) & $\mathbf{7 6 \%}$ & $\mathbf{8 \%}$ & $\mathbf{8 \%}$ & $\mathbf{4 \%}$ & $\mathbf{4 \%}$ \\
\hline
\end{tabular}

Two interviews were conducted over the telephone at the request of the interviewees. All interviews were audio-recorded to preserve data, both directly from Zoom (where applicable) and with the support of a backup audio-recording device. Interviews were then were manually transcribed so coding and data analysis could take place (Merriam 2009).

\subsubsection{Compensation}

To encourage participation in this research study, OG agreed to provide CAD $\$ 400.00$ towards purchasing gift cards at the outdoor outfitter, Mountain Equipment Co-Op (MEC). All twenty-five research participants were entered for a chance to win one of four CAD \$100.00 MEC gift cards, valid at any Canadian MEC location. MEC was selected given the relevance of products sold, and the nature of OG's programs. The four winners of the MEC gift cards were selected after all interviews had been completed on December $21^{\text {st }}, 2018$. The researcher randomly selected the four winners by using an online computer-generated name drawing program called Random Name Picker (www.randomlists.com/name-picker). Three of the winners belonged to the Alumni category and the other belonged to the Drop-Outs category. The researcher then sent the MEC gift cards by mail (post) to the four winners on December 31 2018 .

\subsection{Data Analysis}

The following section describes the methods that were used to analyze the data collected from the study, through the use of coding. 


\subsubsection{Coding}

As this research study employed qualitative data collection exclusively, the process of coding was necessary to identify and evaluate patterns within the data set (Broad 2003; Babbie \& Benaquisto 2010). The researcher used the qualitative data analysis software NVivo 12 to store, code and analyze the data collected from interviews (Blackman \& Benson 2010). NVivo was selected as it is a leading qualitative data analysis program, is one of the most commonly used computer-assisted qualitative data analysis software (CAQDAS) programs internationally and is considered more user-friendly than other software options (Leech \& Onwuegbuzie 2011). While the researcher had initially planned to ask participants for their preferred pseudonyms to be used in the reporting of data, participants were instead advised that they will be assigned a number (e.g. Respondent 1, Respondent 2, Respondent 3, and so on) assigned based on the order in which their interview took place. This choice was made to allow for consistency and ease of both reading and analysis.

In order to analyze the data collected from the participant interviews, the raw data had to be classified into categories of phenomena, so the researcher could compare and contrast the diverse information and come to meaningful conclusions (Babbie \& Benaquisto 2010). The first step in the data analysis process was the manual transcription of all twenty-five interviews. This process took approximately four weeks to complete. Once all interviews were transcribed, the process of coding could take place. First, open coding was performed, whereby the unorganized data was initially typified into smaller categories, referred to in NVivo as nodes (Leech \& Onwuegbuzie 2011). Open coding involved re-reading interview notes and transcripts of the interviews from audio-recordings and identifying and delineating noteworthy themes for analysis (McIntosh \& Zahra 2007). For example, during the open coding process the researcher organized 
data into one of two categories: 1) codes that relate to environmental topics and 2) codes that relate to consumer topics. Once the open coding process was completed, analytical coding was conducted. Analytical coding involves the analysis of data that has been identified as salient during the open coding process (i.e. comparing data from the themes and patterns that arise in several interviews) (McIntosh \& Zahra 2007; Merriam 2009). The researcher performed analytical coding by reviewing the nodes that had been created, extracting noteworthy and effectively phrased quotes and comparing coded data between the three consumer categories (see Appendix E for an example of NVivo nodes and theme organization).

Inductive, as opposed to deductive coding was used to analyze the raw data collected from the semi-structured interviews. Inductive coding "allow[s] research findings to emerge from the frequent, dominant or significant themes inherent in raw data" (Thomas 2006: 238). An inductive approach is distinct from a deductive approach that tests pre-conceived hypotheses or theories (Thomas 2006). As transcripts were reviewed and coded, nodes were created that allowed relevant and noteworthy data to be organized thematically. This process was repeated until all information important to data analysis was coded into a node or sub-node. NVivo was also used to run word frequency queries and generate word clouds representing the most common descriptive words within certain nodes. Complete transcripts of the interviews were omitted from this thesis to maintain confidentiality of respondents, yet notable excerpts from interviews are included within the results section.

\subsection{Ethics}

The researcher submitted an Ethics Review Application to the Ryerson Research Ethics Board (REB) on August $19^{\text {th }}, 2018$. On August $28^{\text {th }}, 2018$, the REB advised the researcher that the 
proposed research study did not require ethics approval. The following excerpt is derived from the email that was sent from the REB to the researcher on August $28^{\text {th }}, 2018$ :

"Based on the information provided it has been determined that the project does not require ethics review or approval. As you will be conducting interviews with individuals who are not themselves the focus of the research, but who are authorized in the course of their employment, to provide data about the organizations, policies, procedures and professional practices which your study explores, this study does not fall under the TCPS2 definition of research with human participants".

In further correspondence with the REB to ensure the study did not require ethics approval, the REB responded by stating the following:

"Standard phrasing cited by the TCPS was used to exempt this project. However, as this is a combination of evaluation and clients who will be providing feedback about the travel company, this project has been exempted".

The researcher went through the appropriate channels and did due diligence to ensure the data collection methods were legitimate and ethical before proceeding.

\subsection{Limitations}

While the selected methodological approaches were deemed the most appropriate for the scope of this research study, there are limitations to be noted. A primary limitation of this research study is the potential of social desirability bias (SDB), a form of response bias whereby conditions of the study cause research participants to respond untruthfully (Larson 2018). To avoid SDB, the researcher established herself to participants as an independent researcher without professional affiliation or personal experience with OG. The researcher has a personal relationship with at least two past consumers who have both participated in at least one trip with OG since the establishment of the organization in 2006. As such, interested participants who had a prior relationship with the researcher were not eligible to participate in the research study and were advised of this conflict of interest. Further, as was discussed in section 4.8.1, interviews did not take place in a space affiliated with OG, to encourage participants to be comfortable being candid and honest in their 
responses. The researcher also gave respondents the option not to answer questions. Discussions with all respondents that comprise the sample demonstrated their willingness to answer honestly and provide thorough responses to the questions asked.

Another limitation of this study was the geographic range of research participants. As research participants reside in multiple provinces and time zones within Canada, the researcher was unable to conduct in-person interviews. This limitation was overcome by conducting interviews with the use of Zoom. The researcher opted to conduct Zoom interviews as opposed to conducting phone interviews to allow for the interpretation of body-language and other physical cues. Two out of the twenty-five interviews were conducted over the phone at the request of the research participants as opposed to over Zoom, which was the preferred method. Although conducting these interviews over Zoom would have allowed the researcher to pick up on the aforementioned visual cues, the researcher was still able utilize the main benefits of qualitative interviews and obtain meaningful data from those interviews conducted over the phone.

A third limitation of this study is that this is a case study example that reflects the perspectives of one consumer group. OG does attract a particular consumer market based on their mission, values and philosophy. As such, the results from this study are not directly applicable to other voluntourism organizations. However, while the conclusions made about the consumer support and buy-in for sustainable tourism within OG may not translate to other similar products, this study does provide insight into the potential consumer support and buy-in for sustainability and represents an example of how organizations can aim for sustainability in the tour operating business. While the results of this case study do not speak for all voluntourism organizations or tour operators, the method utilized for this study could be employed to answer similar questions in a different research context. Therefore, despite this study producing results specifically for OG's 
consumer market, the approach could be replicated to generate consumer information for other voluntourism organizations or tour operators.

The final limitation of this study is the unequal representation of consumer categories. As a result of cancellations and no-shows, the final sample was comprised of a smaller number of respondents in the Drop-Outs and Prospects categories compared to the Alumni category. Having an equal number of respondents within each consumer category would have enabled the researcher to more easily compare statistical data. The researcher overcame this limitation by conducting semi-structured interviews which allowed for thorough and in-depth conversations to occur with all three consumer categories. The flexibility of the interviews allowed the researcher to deviate from the interview guide and have organic conversations with all respondents and supplemented the unexpectedly low number of respondents in the Drop-Outs and Prospects categories. 


\subsection{Introduction}

\section{Chapter 5: Interview Results}

This chapter outlines the findings of the primary research. To maintain confidentiality, research participants are labelled as R1 through R25. This chapter first provides a description of the sample and the three consumer categories before presenting the key findings of the research. Respondents' awareness of OG, their motivations to travel with OG and the perceived benefits of travelling with OG are outlined before the tangible impacts of travelling with OG are described. Then, respondents' motivations to participate in voluntourism are discussed before outlining the sample's perspectives on voluntourism and how OG's approach to voluntourism is perceived. Then, this chapter presents the findings relating to respondents' opinions about and understanding of carbon offsetting both as a general practice and specific to OG's carbon offset initiative. Following this, OG's efforts to achieve sustainable tourism are evaluated. Finally, OG's future directions are discussed by presenting respondents' opinions about OG's current environmentallyfocused trip offerings as well as suggestions for environmental topics that can be incorporated into future OG trips.

\subsection{Profile of Respondents}

The sample for this study was comprised of twenty-five Canadian past and prospective OG consumers. The sample was made up of three consumer categories: Alumni, Drop-Outs, and Prospects. The Alumni category was comprised of Canadian OG alumni who have participated in at least one OG trip since the NGO and tour operator was established in 2006. Only one of the eighteen respondents sampled had been on more than one trip with OG. The Drop-Outs category was comprised of Canadian individuals who had registered for an OG trip but ultimately did not participate for diverse reasons. The Prospects category was comprised of Canadian individuals who have completed an online inquiry form expressing interest in participating/requesting more 
information. These three consumer categories allowed the researcher to obtain a comprehensive understanding of OG's consumer market, enabling recommendations from this study to reflect the perspectives of potential returning customers as well as the perspectives of prospective customers. Within the sample, eighteen belonged to the Alumni category, two belonged to the Drop-Outs category, and five belonged to the Prospects category. Table 6 below depicts the numerical representation of each category within the sample.

Table 6 Numerical Representation of Each Category Within Sample $(\mathrm{n}=25)$

\begin{tabular}{|c|c|c|}
\hline Consumer Category & n & Percentage of Sample (\%) \\
\hline Category 1- Alumni & 18 & $72 \%$ \\
\hline Category 2- Drop-Outs & 2 & $8 \%$ \\
\hline Category 3 - Prospects & 5 & $20 \%$ \\
\hline Total & $\mathbf{2 5}$ & $\mathbf{1 0 0 \%}$ \\
\hline
\end{tabular}

\subsection{Consumer Awareness of OG}

The majority of respondents (72\%) first heard about OG through social media. Of this $72 \%$, most respondents mentioned Facebook specifically, while a small proportion referred to nonspecified social media platforms (which may include Facebook). Tables 7 and 8 below provide an overview of the ways in which all twenty-five respondents first heard about OG and a breakdown of how respondents within each consumer category first heard about OG, respectively.

Table 7 Breakdown of How All Respondents Within the Total Sample First Heard About OG $(\mathrm{n}=25)$

\begin{tabular}{|c|c|c|}
\hline Source & n & $\mathbf{\%}$ \\
\hline Facebook & 15 & $60 \%$ \\
\hline $\begin{array}{c}\text { Post-Secondary School's } \\
\text { Email System }\end{array}$ & 6 & $24 \%$ \\
\hline $\begin{array}{c}\text { Non-Specified Social Media } \\
\text { Platforms }\end{array}$ & 3 & $12 \%$ \\
\hline $\begin{array}{c}\text { Independent Online } \\
\text { Research }\end{array}$ & 1 & $\mathbf{1 0 0} \%$ \\
\hline Total & $\mathbf{2 5}$ & \\
\hline
\end{tabular}


Table 8 Breakdown of How Respondents Within Each Consumer Category First Heard About OG $(n=25)$

\begin{tabular}{|c|c|c|c|c|}
\hline $\begin{array}{c}\text { Consumer } \\
\text { Category }\end{array}$ & Facebook & $\begin{array}{c}\text { Post-Secondary } \\
\text { School's Email } \\
\text { System }\end{array}$ & $\begin{array}{c}\text { Non-Specified } \\
\text { Social Media } \\
\text { Platforms }\end{array}$ & $\begin{array}{c}\text { Independent } \\
\text { Online } \\
\text { Research }\end{array}$ \\
\hline Alumni (n) & 12 & 3 & 2 & 1 \\
\hline Drop-Outs (n) & 0 & 2 & 0 & 0 \\
\hline Prospects (n) & 3 & 1 & 1 & 0 \\
\hline Total (\%) & $\mathbf{6 0 \%}$ & $\mathbf{2 4 \%}$ & $\mathbf{1 2 \%}$ & $\mathbf{4 \%}$ \\
\hline
\end{tabular}

\subsection{Consumer Motivations to Travel with OG/Perceived Benefits of Travelling with OG}

Research participants were asked to describe what made them wanted to travel with OG. This question was asked to understand the perceived benefits of travelling with OG. Commonly mentioned consumer motivations to travel with OG were their sustainable approach to travel, travelling with a purpose, working directly with local communities, having educational experiences and having authentic and immersive cultural experiences. Figure 3 below represents the most common words used to describe why respondents wanted to travel with OG. The most commonly referenced words are those in larger text: interesting, sustainable, community, culture, purpose, educational and helpful. The smaller words were mentioned at least twice but were not as common as those in larger text.

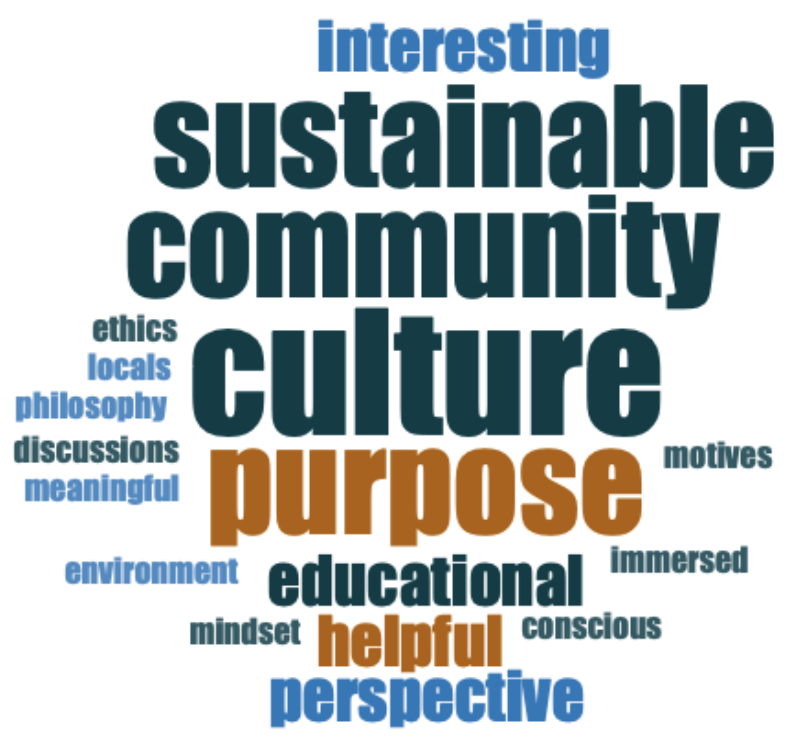

Figure 3 Word Cloud Generated from Responses Related to OG's Appeal ( $n=25)$ 
OG's mission, values and philosophy was the most pervasive motivation, while the second most commonly mentioned motivation was OG's focus on and integration of education and learning. R11 (Alumni) describes OG's mission and values compared to other similar voluntourism organizations offering a similar product, saying

"[OG] seemed to stand for a lot of the values that I am more so aligned with than a lot of the [other voluntourism organizations]... [the other voluntourism organizations] didn't seem as into the NGOs as [they were] into the travelling, so that was one thing I thought was really cool, because I had already done a lot of travelling and I was pretty comfortable with that but I wanted to learn a different side of it".

R23 (Alumni) also summed this up well by explaining

“...when I read about [OG], it was really interesting to see that they had a different take on tourism... it wasn't just like a trip, it was like a trip with a purpose, which I really liked and I really wanted to like volunteer and I wanted to make a difference in that way".

When analyzing the responses of each consumer category, there are differences to note.

Only one respondent outside of the Alumni category referred to OG's mission, values and philosophy as their main motivation to travel with OG, indicating that this is a less influential factor for prospective consumers. Both the Drop-Outs and Prospects categories had one respondent who provided more than one answer (mentioned more than one motivation), whereas no respondents within the Alumni category provided more than one answer. The Prospects category demonstrated the most diverse set of motivations, having representation in each of the six motivations outlined in Table 9 below (depicting the consumer motivations to travel with OG).

Table 9 Consumer Motivations to Travel with OG $(n=25)$

\begin{tabular}{|c|c|c|c|c|c|c|}
\hline $\begin{array}{c}\text { Consumer } \\
\text { Category }\end{array}$ & $\begin{array}{c}\text { OG's Values, } \\
\text { Mission and } \\
\text { Philosophy }\end{array}$ & $\begin{array}{c}\text { Education } \\
\text { and Learning }\end{array}$ & $\begin{array}{c}\text { Cultural } \\
\text { Immersion }\end{array}$ & $\begin{array}{c}\text { Travelling } \\
\text { with a } \\
\text { Purpose }\end{array}$ & $\begin{array}{c}\text { Specific } \\
\text { Trip } \\
\text { Offered }\end{array}$ & $\begin{array}{c}\text { Marketing } \\
\text { and } \\
\text { Visual } \\
\text { Aids }\end{array}$ \\
\hline Alumni (n) & 9 & 5 & 2 & 2 & 0 & 0 \\
\hline Drop-Outs (n) & 0 & 1 & 1 & 1 & 0 & 0 \\
\hline Prospects (n) & 1 & 1 & 1 & 1 & 1 & 1 \\
\hline Total (\%) & $\mathbf{4 0 \%}$ & $\mathbf{2 8 \%}$ & $\mathbf{1 6 \%}$ & $\mathbf{1 6 \%}$ & $\mathbf{4 \%}$ & $\mathbf{4 \%}$ \\
\hline
\end{tabular}

Note: Drop-Outs, Prospects and total (\%) exceed total of consumer categories and total sample, respectively as some respondents provided more than one answer 


\subsection{Impacts of Travelling with OG}

Respondents within the Alumni category were asked to describe how their trip with OG impacted them. This section is comprised only of the Alumni category as those in the Drop-Outs and Prospects categories could not speak to the impacts of travelling with OG. The most commonly mentioned impact of travelling with OG was education/instilling activism (78\%). Of the $78 \%$ who indicated that education/instilling activism was the primary tangible impact of travelling with OG, there were a variety of reasons as to why. R5 (Alumni) describes how travelling with OG educated them on the topic of voluntourism and demonstrated how they can approach voluntourism from a different perspective, noting

"I think more than anything it helped bring awareness to first the existence of problematic voluntourism companies and then kind of further from that or based on that, the idea that it doesn't mean we don't have to try and engage in development work while travelling but there are ways to do it ethically and there are ways to do it wrongly. I think it left me with a lot of optimism. I've had other experiences where I come away from it thinking, geez like what were we doing here this was probably a mistake and feeling quite guilty about it, and this was kind of one of the first trips I've had where I felt the opposite and felt like ok, this is maybe taking a step towards showing people that there is a way to engage with places in the developing world in a way that can help people learn without harming people that you're going out to learn from and help".

R18 describes the impact of their trip on their own pro-environmental habits and behaviours, saying

“... now I carry a metal straw in my purse all the time. Now I'm the person who's like I don't need a plastic bag with that, I'll carry my things outside... whenever I go to a restaurant, I say nobody at my table needs straws... I think that is how it has directly impacted my life".

There was also a large proportion of respondents who indicated that travelling with OG made them more inclined to integrate volunteering into their travel plans and that travelling with OG made them more inclined to volunteer locally/at home. Table 10 below depicts the distribution of responses from the Alumni category about the tangible impacts of travelling with OG. 
Table 10 Tangible Impacts of Travelling with OG ( $\mathrm{n}=18)$

\begin{tabular}{|c|c|c|c|c|c|}
\hline $\begin{array}{c}\text { Consumer } \\
\text { Category }\end{array}$ & $\begin{array}{c}\text { Education/Instilling } \\
\text { Activism }\end{array}$ & $\begin{array}{c}\text { Inclination to } \\
\text { Volunteer } \\
\text { While } \\
\text { Travelling }\end{array}$ & $\begin{array}{c}\text { Inclination to } \\
\text { Volunteer } \\
\text { Locally/At } \\
\text { Home }\end{array}$ & $\begin{array}{c}\text { Personal } \\
\text { Growth }\end{array}$ & $\begin{array}{c}\text { Learning } \\
\text { How to } \\
\text { Travel } \\
\text { Sustainably }\end{array}$ \\
\hline Alumni (n) & 14 & 10 & 9 & 6 & 2 \\
\hline Total (\%) & $\mathbf{7 8 \%}$ & $\mathbf{5 6 \%}$ & $\mathbf{5 0 \%}$ & $\mathbf{3 3 \%}$ & $\mathbf{1 1 \%}$ \\
\hline
\end{tabular}

Note: Total (\%) exceeds $100 \%$ as some respondents provided more than one answer

\subsection{Decision-Making Factors for Choice of Trip}

Respondents within the Alumni and Drop-Outs categories were asked to describe the most important factors in their decision-making when selecting which of OG's many trips to select. This section is comprised only of responses from those within the Alumni and Drop-Outs categories, as the Prospects category hadn't chosen one of OG's trips to participate in and as such, were not asked this question. More than half of the respondents indicated that the topic or focus of the trip was the most important factor in their decision-making. The second most commonly mentioned decision-making factor was the length/duration of the trip. When analyzing the responses of both consumer categories, there are minimal differences to note. Half of the respondents within the Alumni category mentioned the importance of the trip topic/focus in their decision-making, while both respondents within the Drop-Outs category mentioned the importance of the trip topic/focus in their decision-making. This may be attributed to the fact that the Drop-Outs category is considerably smaller than the Alumni category and as such, the probability of having a wide set of responses is lower. However, the trip topic/focus remains the most important decision-making factor for these consumer categories. Within the Drop-Outs category, one respondent could not recall the topic of the trip they had registered for but identified the topic as the main criteria they focused on when reviewing their options, while the other respondent (R16) was able to recall the topic of the trip and indicated that the topic was the most important factor in their decision-making because it aligned with their academic research interests on the impacts of climate change on 
vulnerable communities. R16 (Drop-Out) describes the aforementioned influence of the trip topic/focus by explaining

'I'm doing my master's in social work and I have an interest in sustainability and in the environment and social work... [I wanted to see] what [NGOs are] doing to help people and [learn about] the impact of climate change on certain communities... I was going in with an open lens to experience and observe that and see how, or if NGO's help and if there was even an NGO focused more on sustainability and to learn how they are operating".

R5 (Alumni) describes the importance of the trip topic in their selection, indicating that the topic of the trip is what influenced their selection between two trips visiting the same country/region, noting

"There were quite a few options within India, the programs that [OG] run[s]. I ended up going with the high-altitude education one because education I guess is something that I feel passionate about and just reading the program description about what local partners they were connecting with it was kind of an area of activism I didn't know a lot about but was really interested in engaging more with".

For the Alumni category, the length/duration of trip was the second-most important decision-making factor behind trip topic/focus. Most of the respondents who indicated length/duration of trip as an important decision-making factor indicated that they sought out OG's longer trips (two weeks minimum) because they wanted to participate in a trip that was long enough to be meaningful. R6 (Alumni) describes this by saying

"Both of [the programs they were deciding between] were forty-day periods and I was less keen on a shorter trip because I thought that by participating in a shorter one, I maybe wouldn't learn as much about the culture in the region I was travelling in... I thought that by staying there for a longer period of time I would be immersed into that region [and] that culture a little more".

By contrast, a smaller proportion of those who indicated length/duration of trip as an important decision-making factor indicated that they sought out OG's shorter trips (less than two weeks) to accommodate work and/or personal obligations. Table 11 below depicts all of the 
decision-making factors mentioned, providing a breakdown of the decision-making factors identified by both consumer categories.

Table 11 Summary of Decision-Making Factors for Choice of Trip $(n=20)$

\begin{tabular}{|c|c|c|c|c|}
\hline $\begin{array}{c}\text { Consumer } \\
\text { Category }\end{array}$ & $\begin{array}{c}\text { Topic/Focus of } \\
\text { Trip }\end{array}$ & $\begin{array}{c}\text { Length/Duration of } \\
\text { Trip }\end{array}$ & Destination & $\begin{array}{c}\text { Language of } \\
\text { Destination }\end{array}$ \\
\hline Alumni (n) & 9 & 7 & 5 & 3 \\
\hline Drop-Outs (n) & 2 & 0 & 0 & 0 \\
\hline Total (\%) & $\mathbf{5 5 \%}$ & $\mathbf{3 5 \%}$ & $\mathbf{2 5 \%}$ & $\mathbf{1 5 \%}$ \\
\hline
\end{tabular}

Note: Alumni and total (\%) exceed total of consumer category and total of the two consumer categories combined, respectively as some respondents provided more than one answer

\subsection{Motivations to Participate in Voluntourism}

Respondents were then asked to identify and describe some of their main motivations for wanting to participate in this form of travel, i.e. being involved in volunteer projects and community development initiatives as opposed to travelling solely for leisure or with another organization that does not include any element of volunteering into their itineraries. This question differs from the question about motivations to travel with OG as the question about OG's appeal sought to understand elements of OG specifically that consumers took note of, while this question sought to understand motivations for participating in voluntourism in general terms. The four most common motivations were education and learning, wanting to give back, wanting authentic and immersive cultural experiences, and wanting to travel with like-minded individuals, with education and learning being the most frequently mentioned motivation. While each consumer category displayed a variety of motivations, it was the respondents within the Alumni category who very clearly indicated that education and learning was their main motivation. R4 (Alumni) used the term "learning internship" to describe their experience travelling with OG, and R24 (Alumni) said that their trip with OG was "an extension of [their] education" having studied the trip topics of gender and religion during their undergraduate degree. The Alumni were also the only category to mention wanting to travel with like-minded individuals as a motivation. The Alumni category had 
at least one respondent mention one of the four most common motivations, whereas certain motivations were not mentioned by both the Drop-Outs and Prospects categories. This may be attributed to the larger sample size of the Alumni category, and the fact that some respondents within the Alumni category provided more than one answer. R16 (Drop-Outs) describes how they were motivated by multiple factors, explaining

"[Learning about the issues facing the communities visited] was one of my motivations for going... but [also] travelling with a purpose... So, going to get an experience but also give back if you can in a certain way... I feel like when you are able to give back it just means more".

R18 (Alumni) outlines their motivations, saying

“... [my main motivation] was [to] get awesome experiences that I can't get [at home], live in an entirely new culture for like a month and a half and then take those things back home... but then also like being able to give back to people who might not have as much".

When comparing results between consumer categories, the main noteworthy difference is that the Alumni category had the highest proportion of respondents that indicated education and learning as their primary motivation. Another difference between the consumer categories is that no respondents within the Prospects category mentioned wanting to give back as a primary motivation, whereas this was mentioned at least once in both the Alumni and Drop-Outs categories. This may be attributed to this category's limited personal experience with OG and their perception of the product based on their exposure to OG's online presence. Table 12 below outlines the most frequently mentioned motivations identified by each consumer category. 
Table 12 Most Common Motivations Identified by Each Consumer Category $(\mathrm{n}=25)$

\begin{tabular}{|c|c|c|c|c|}
\hline $\begin{array}{c}\text { Consumer } \\
\text { Category }\end{array}$ & $\begin{array}{c}\text { Education and } \\
\text { Learning }\end{array}$ & $\begin{array}{c}\text { Wanting to Give } \\
\text { Back }\end{array}$ & $\begin{array}{c}\text { Travel with } \\
\text { Like-Minded } \\
\text { Individuals }\end{array}$ & $\begin{array}{c}\text { Authentic and } \\
\text { Immersive } \\
\text { Cultural } \\
\text { Experiences }\end{array}$ \\
\hline Alumni (n) & 10 & 6 & 4 & 1 \\
\hline Drop-Outs (n) & 1 & 1 & 0 & 1 \\
\hline Prospects (n) & 2 & 0 & 0 & 1 \\
\hline Total (\%) & $\mathbf{5 2 \%}$ & $\mathbf{2 8 \%}$ & $\mathbf{1 6 \%}$ & $\mathbf{1 2 \%}$ \\
\hline
\end{tabular}

Note: Alumni and Drop-Outs exceed total of consumer categories as some respondents provided more than one answer, Prospects is less than total of consumer category as some respondents did not mention

any of the most common motivations and total (\%) exceeds the total sample as some respondents provided more than one answer

\subsection{Perspectives on Voluntourism}

Respondents were asked questions to understand their perspectives on voluntourism. First, respondents were asked to define the notion of voluntourism. There were a wide variety of definitions of voluntourism provided by respondents. More than half of the total sample $(60 \%)$ provided definitions of voluntourism that did not indicate skepticism towards the practice, while the remaining respondents' definitions indicated some skepticism. When comparing consumer categories, there are differences to note. Most of the respondents who indicated skepticism or lack of support for voluntourism belong to the Alumni category, with a few respondents within the Prospects category indicating skepticism as well. Of the respondents who indicated skepticism of voluntourism, most mentioned how traditional voluntourism organizations lack awareness/understanding of the needs of local communities and impose development plans on such communities. A smaller portion of those who indicated skepticism of voluntourism mentioned how traditional voluntourism organizations offer so-called pat on the back experiences that don't have tangible positive impacts on local communities and instead serve to make participants feel good about themselves. This is effectively described by R5 (Alumni) who explains

"I guess I would define [voluntourism] as first and foremost a type of tourism that is built on giving people who are there for the purpose of encountering new cultures the ability to 
maybe not have an impact but feel like their having an impact. I think it really does center more on the visitor versus the culture that is being interacted with"

R4 (Alumni) conveyed their skepticism of voluntourism by explaining how voluntourism

can be ethically problematic, outlining

"To me the word that you used, voluntourism... to me it has a negative meaning... like going to a place where you don't really understand the needs of the community or the impact that you're having on the community once you leave".

Neither of the respondents who belong to the Drop-Outs category provided a definition of voluntourism that indicated skepticism of the practice. R1 (Drop-Out) defined voluntourism as

“... you volunteer I guess and travel... I guess volunteer with the people but also travel around and do the main touristy things but help as you go".

While some respondents within the Prospects category provided definitions of voluntourism that indicated their skepticism of the practice, most provided definitions of voluntourism that did not indicate any skepticism. This is conveyed by R8 (Prospect) who describes voluntourism as

“...you travel and you might not [travel] necessarily for volunteering, but sometimes you do you volunteer specifically to volunteer, or you travel specifically to volunteer at an organization or in a country or in a specific field, but sometimes you just want to travel to a certain country, you travel there and like me for example me, while I'm there, I'll find opportunities to volunteer.

Table 13 below depicts the distribution of voluntourism definitions that indicated skepticism and those that did not, being separated by each consumer category.

Table 13 Perspectives on Voluntourism $(n=25)$

\begin{tabular}{|c|c|c|}
\hline Consumer Category & No Skepticism & Skepticism \\
\hline Alumni (n) & 10 & 8 \\
\hline Drop-Outs (n) & 2 & 0 \\
\hline Prospects (n) & 3 & 2 \\
\hline Total (\%) & $\mathbf{6 0 \%}$ & $\mathbf{4 0 \%}$ \\
\hline
\end{tabular}




\subsubsection{Benefits and Issues with Voluntourism}

After providing a definition, respondents were asked if they believed voluntourism to be a good thing or not. The majority of respondents indicated that they believed voluntourism has the potential to be a good thing if done properly. Figure 4 below depicts the distribution of responses from the total twenty-five-person sample.

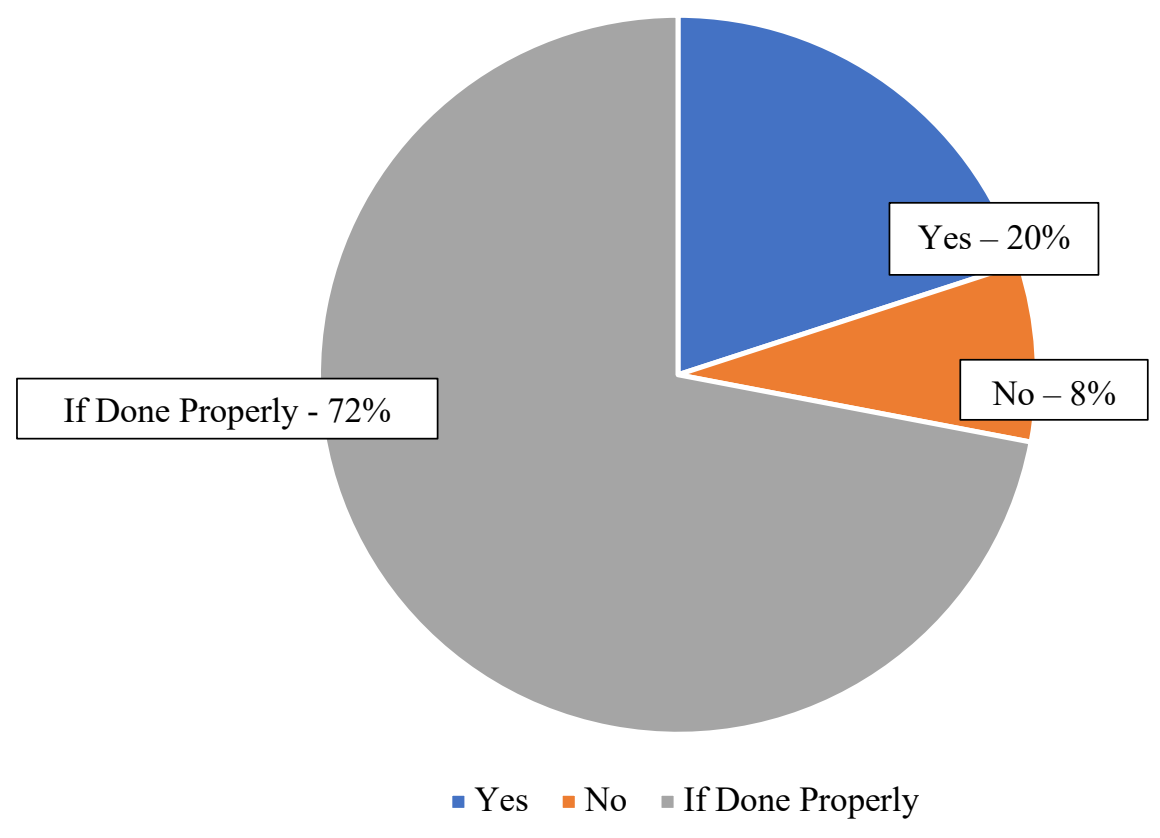

Figure 4 Is Voluntourism a Good Thing? $(\mathrm{n}=25)$

Almost all respondents, regardless of consumer category think that voluntourism is positive. The majority ( $72 \%)$, however, added a caveat that voluntourism is only positive if and when done properly. Most respondents within the Alumni category said they think that voluntourism has the potential to be a good thing if done properly. R23 (Alumni) explains this by describing OG's approach to voluntourism, suggesting

"I think it has to be done properly, I think OG had a really good way of doing it... I find that I liked that it was almost educational... we didn't force them to do things that we... like the more efficient ways that we think it's efficient like in North America... I really liked that way of doing it, that it was like we're coming to assist you in whatever you need, and that we were also learning about things as well while we were there... it was 
educational which I, like it completely changed who I am as a person, so that was really helpful for me... the reason I [don't] want to say making a difference is because I feel like that's putting it into our realm... our lens of viewing it... like oh we're making a difference, like now they can do farming this way but... I think it made a difference in that we built relationships with these people and helped them in a way that they needed help".

Both respondents within the Drop-Outs category said they think voluntourism is a good thing. R1 (Drop-Out) describes this by saying

“...you're helping people but then instead of just showing up and being like I'm going to help them with this, if you travel around and like tour and stuff you can kind of see what [communities] need and understand why they need it, so you kind of have more background and knowledge of why you are actually are helping them and what it'll do when you help".

Most respondents within the Prospects category said they think voluntourism has the potential to be a good thing if done properly. R3 (Prospect) discusses that in order for voluntourism to be done properly it must foster education and avoid negatively impacting the communities visited, noting

"I think it can have its benefits as long as the travellers are able to understand both sides of their actions. I know I just did a trip with habitat and we were able to see that the work we were doing wasn't actually taking away from the locals' jobs or anything like that so I think if you're able to get those learning pieces than it's a good thing but if it's just going for a pat on your shoulder kind of thing than I have a really bad view of it".

When comparing the results between the three consumer categories, considerable differences exist. Unsurprisingly most of the respondents within the Alumni category indicated that voluntourism has the potential to be a good thing if done properly, reflecting their exposure to the topic of problematic voluntourism and after having approached voluntourism in a critical manner while travelling with OG. Both respondents within the Drop-Outs category said that voluntourism is unequivocally a good thing, while most of the Prospects category said that voluntourism has the potential to be a good thing if done properly. Surprisingly, both respondents within the Drop-Outs category who had registered for a trip, and likely done research on OG did not identify the issues associated with voluntourism. Evidently, despite not having travelled with 
OG, there is a level of understanding about the issues associated with voluntourism from prospective consumers.

\subsubsection{OG's Approach to Voluntourism}

This section is comprised only of responses from the Alumni category, as the Drop-Outs and Prospects categories lacked the personal experience to speak to this topic and as a result were not asked this question. Respondents were asked to describe OG's approach to voluntourism compared to traditional voluntourism. In other words, respondents were prompted to discuss if and how OG deviates from the traditional practice of voluntourism and how OG's approach is preferable from an ethical and environmental perspective. All respondents acknowledged that OG has a unique approach compared to other voluntourism organizations, with some respondents mentioning more than one way in which OG differs. The most common response was that the focus on education is what differentiates OG. R14 (Alumni) outlines how OG's focus on education and their collaboration with local NGOs differentiates them from traditional voluntourism, explaining

"I think [voluntourism] definitely has its perks but it also has some negative connotations that go along with it... like it's a tricky thing to manage because you don't want to go into a place and assume that they need your help or they want your help and that what you're doing is actually going to benefit them in the long run... I think going in with that mindset is very like, colonial... as opposed to what OG does which I really enjoyed which was going and working with local groups that are already existing and already doing stuff regardless of whether we're there to help them... we worked with a local indigenous group that was reforesting a whole area and they were doing that regardless of if we were there or not... and the fact that we could go there and learn from what they're doing and why they're doing it and how it was helping them was really powerful".

R21 (Alumni) claimed

"what I really like about OG is that they communicate with their partners and then ask them what would you like us to do... because there are organizations that are really geared toward the volunteer to just be like feel good about yourself, you're doing something good but when in actuality you're not really helping people... they're only volunteering with the people and then the second they're out of there they're kind of put on a pedestal, a lot of 
organizations kind of gear it towards the person who is volunteering whereas what I really like about OG is that you're not put on a pedestal above anybody else... and I just really like that it was really hands-on with the volunteers as well, and it's not like just those oh go for a week, feel good about yourself and leave kind of thing".

The other ways in which respondents felt OG deviates from the traditional practice of voluntourism were OG's collaboration with local NGOs and communities to address the priorities identified by such communities, and OG's focus on participant growth and learning aiming to create more conscious global citizens and addressing the issues associated with voluntourism (as opposed to claiming that participants would make significant impacts to communities visited). Table 14 below depicts the distribution of responses from the Alumni category regarding how OG's approach to voluntourism differs from traditional voluntourism, and how OG addresses the issues associated with voluntourism.

Table 14 How OG's Approach to Voluntourism Differs from Traditional Voluntourism/How OG Addresses the Issues Associated with Voluntourism $(n=18)$

\begin{tabular}{|c|c|c|c|}
\hline Consumer Category & Education & $\begin{array}{c}\text { Collaboration with } \\
\text { NGO's }\end{array}$ & $\begin{array}{c}\text { Focus on Participant } \\
\text { Growth and Learning }\end{array}$ \\
\hline Alumni (n) & 14 & 7 & 5 \\
\hline Total (\%) & $\mathbf{7 8 \%}$ & $\mathbf{3 9 \%}$ & $\mathbf{2 8 \%}$ \\
\hline
\end{tabular}

Note: Alumni and total (\%) exceed total of consumer category as some respondents provided more than one answer

\subsection{Perspectives on Carbon Offsetting}

Respondents were asked a variety of questions about carbon offsetting: awareness of carbon offsetting as a general practice, if they can and how they would define carbon offsetting, if they are aware of OG's carbon offset initiative and if OG's carbon offset initiative is influential from a consumer standpoint.

\subsubsection{Awareness and Understanding of Carbon Offsetting}

Almost all (80\%) respondents said they have heard of the term carbon offsetting $(83 \%$ of Alumni, $100 \%$ of Drop-Outs and $60 \%$ of Prospects). More than half (56\%) were able to provide a definition carbon offsetting, with the most common descriptive words used to define the term being 
balance, equivalent, reduce, match, investment, reinvestment, emissions and responsibility. The Alumni category had the highest proportion of respondents who provided accurate definitions of carbon offsetting. R19 (Alumni) demonstrated a relatively strong understanding of carbon offsetting by defining it as

"the ability for organizations to offset their carbon by investing in environmental organizations or ways that we can reduce carbon by other means... [For example], taking that money for each plane ticket or large pollutant and reinvesting it to maybe balance out the impact".

While both respondents within the Drop-Outs category provided a definition of carbon offsetting, the definitions provided were inaccurate or incomplete. R16 (Drop-Out) demonstrated an understanding of the process of climate change, but did not adequately define the process of carbon offsetting, outlining

"I think it's the amount of carbon going into the atmosphere... and because the carbon actually is responsible for... it's creating that barrier and not allowing the gases that need to escape, so that's what is creating a warmer climate... essentially the carbon is not able to escape and... at least that's what I think it is... and then, it's basically the emissions from agriculture, from human activity, transportation that is contributing to climate change".

The respondents from the Prospects category that provided definitions of carbon offsetting all had a general understanding of what carbon offsetting entails, but the definitions provided were less specific and lacked detailed compared to the definitions provided by respondents within the Alumni category. R3 (Prospect) offered a definition of carbon offsetting focused on the individual as opposed to standardized carbon offsetting using carbon credits, explaining

"Well planting trees is always an obvious one... I know people are always talking about like not eating as much meat and doing other daily things that will kind of offset the one big one". 


\subsubsection{Awareness, Perception and Understanding of OG's Carbon Offset Initiative}

More than half of the respondents $(60 \%)$ demonstrated low awareness of OG's carbon offset initiative (low awareness being defined as respondents who said either 1) they did not come across information about OG's carbon offset initiative on their website or 2) they do not remember if they came across information about OG's carbon offset initiative on their website). Table 15 below summarizes these responses from each consumer category.

Table 15 Did You Come Across Information About OG's Carbon Offset Initiative on Their Website? $(\mathrm{n}=25)$

\begin{tabular}{|c|c|c|c|c|}
\hline $\begin{array}{c}\text { Consumer } \\
\text { Category }\end{array}$ & No & $\begin{array}{c}\text { Don't } \\
\text { Remember }\end{array}$ & Yes & $\begin{array}{c}\text { Told About } \\
\text { Initiative on Trip }\end{array}$ \\
\hline Alumni (n) & 5 & 4 & 5 & 4 \\
\hline Drop-Outs (n) & 1 & 1 & 0 & 0 \\
\hline Prospects (n) & 2 & 2 & 1 & 0 \\
\hline Total (\%) & $\mathbf{3 2 \%}$ & $\mathbf{2 8 \%}$ & $\mathbf{2 4 \%}$ & $\mathbf{1 6 \%}$ \\
\hline
\end{tabular}

\subsubsection{Influence of OG's Carbon Offset Initiative}

Respondents were asked to describe if and how OG's carbon offset initiative influences their decision-making as consumers. Respondents were asked if knowing that OG has an established sustainability initiative focused on emissions makes them more inclined to choose/support/recommend OG compared to an organization offering a similar product but without an established sustainability initiative. This question aimed to evaluate the extent to which green consumers exist within OG's market. A large proportion of the sample (72\%) said that the fact that OG has this carbon offset initiative makes them more inclined to choose OG over another similar organization. R15 (Alumni) notes that OG's carbon offset initiative makes them more inclined to choose OG because they know that a portion of their costs are going towards a greater cause. R5 (Alumni) shared this perspective, explaining how OG's carbon offset initiative is a differentiating factor for OG's product, noting

"I would absolutely advertise that as a draw factor for other people when I recommend the trip to them. I have a lot of friends who are way more into environmentalism and way more 
educated than I am in the area, but I think that would be a really big draw factor for them and for the organization".

Another respondent, R17 (Alumni) further explains this by noting

"I do wish they advertised more about [their carbon offset initiative], because this is something that people would really take into consideration... it's $10 \%$ of the fundraising fees, it's a lot... that's way more than people realize, and I really wish they would talk about it more".

Both respondents within the Drop-Outs category said that the fact that OG has an established sustainability initiative makes them more inclined to choose OG over another similar organization. R1 (Drop-Out) describes how OG's carbon offset initiative would influence them as a consumer as it would allow them to contribute to an environmental cause, explaining

"Well like everything in the news, well not the news, everything you see is... all this bad stuff is happening, but no one really believes it... it's like you have to do your own little part, like help as much as you can”.

R8 (Prospect) describes their willingness to pay more for OG as a result of their carbon offset initiative, saying

"Yeah I would definitely be willing to pay more to OG for this than pay less and go with another organization".

R10 (Prospect) describes how sustainability would set OG apart from other similar organizations if all of the other components of the products could be equally compared, noting

"I think it's one of the factors of many that I would consider... I think that works for any company, like I do always want to shop in the most environmentally friendly way for the companies that do have a good policy... it would be something I consider largely, and I think if it really did come down to the fact that I could lay it down, a few companies and all of them were exactly... the same experience and values, place, program, price, then [sustainability] would definitely be one of the things that would make me pick it over the other".

A small proportion of respondents $(16 \%)$ said the fact that $\mathrm{OG}$ has an established sustainability initiative is an added bonus but would not be the main reason they choose/support/recommend OG. These respondents mentioned that it is an added bonus after first 
indicating that the carbon offset has little influence and does not make them more inclined to choose/support/recommend OG. In other words, while certain respondents indicated that OG's carbon offset initiative would not be the main reason they choose/support/recommend OG, it is an added bonus that serves to differentiate OG's product and may be one of many contributing factors. R14 (Alumni) describes this by explaining

"I didn't realize that they had a sustainability initiative in place but that's really awesome. It doesn't really surprise me but I should have known that... but yeah I would definitely recommend OG, not necessarily because of their carbon offsetting program but that's always a little bonus to add in there because people do bring up sometimes, like especially when you're travelling internationally, like just emissions from travel like to go do environmental work there... but I don't know if that would like compensate for the emissions you spent getting there".

Table 16 below summarizes the responses from each consumer category.

Table 16 Influence of OG's Carbon Offset Initiative (n=25)

\begin{tabular}{|c|c|c|c|}
\hline $\begin{array}{c}\text { Consumer } \\
\text { Category }\end{array}$ & $\begin{array}{c}\text { More Inclined to } \\
\text { Choose/Support/Recommend }\end{array}$ & $\begin{array}{c}\text { Not More Inclined to } \\
\text { Choose/Support/Recommend }\end{array}$ & Added Bonus \\
\hline Alumni (n) & 12 & 6 & 4 \\
\hline Drop-Outs (n) & 2 & 0 & 0 \\
\hline Prospects (n) & 4 & 1 & 0 \\
\hline Total (\%) & $\mathbf{7 2 \%}$ & $\mathbf{2 8 \%}$ & $\mathbf{1 6 \%}$ \\
\hline
\end{tabular}

Note: Alumni, Total (n) and total (\%) exceeds number of respondents as some respondents provided more than one answer

On more than one occasion did respondents demonstrate skepticism of OG's carbon offset initiative due to concerns of greenwashing, with $28 \%$ of respondents indicating that there was a lack of information and transparency regarding the initiative on OG's website. Of those who indicated skepticism of OG's carbon offset initiative, most (57\%) said they had come across OG's carbon offset initiative on their website. The most common reasons respondents were skeptical of OG's carbon offset initiative were the lack of information about 1) the impact of plane travel, 2) what the practice of carbon offsetting entails, 3) where money is being diverted and 4) how this money is making a positive impact. R2 (Alumni) noted their skepticism of OG's carbon offset 
initiative, mentioning that an accolade or rating for carbon offsetting would demonstrate the legitimacy of OG's initiative, explaining

"In terms of carbon offsetting, is there an accolade that you could win from a well-known organization to indicate that an organization is [legitimate]? Depending on the answer to that question, if yes, then I would be more inclined to OG if not, it's subjective so there is really no way to prove that you are a carbon offsetting company versus somebody who does not broadcast as an advertisement".

R3 (Prospect) noted their skepticism of OG's carbon offset initiative by emphasizing the lack of information and transparency present on the website, suggesting

"I think it just said the base price of the trip plus whatever, $100 \$$ towards offset but I don't think I actually read how that 100 dollars is actually impacting the offset".

\subsubsection{Voluntary Contribution to OG's Carbon Offset Initiative}

Respondents were then asked if they would opt to contribute to the carbon offset initiative if it were voluntary as opposed to an included element of the program fees. Most respondents (40\%) indicated that they might opt to contribute. Certain respondents indicated their response but also mentioned that they appreciate how OG's carbon offset initiative is an included cost. Of those who said they might opt to contribute, only one respondent also mentioned that they appreciate that it is included. Of those who said they would likely not opt to contribute, two respondents also mentioned that they appreciate that it is included. Of those who said they would opt to voluntarily contribute, two respondents also mentioned that they appreciate that it is included. When comparing results between consumer categories, the main noteworthy difference is that only respondents within the Alumni category indicated that they appreciated that OG's carbon offset initiative is included. The vast majority of respondents did not unequivocally indicate that they would voluntarily contribute to OG's carbon offset initiative, and as such there is evidence suggesting that making the carbon offset initiative voluntary would be unsuccessful. Table 17 below summarizes these responses from each consumer category. 
Table 17 Would You Voluntarily Contribute to OG's Carbon Offset Initiative If It Were Not Included? $(\mathrm{n}=25)$

\begin{tabular}{|c|c|c|c|c|c|}
\hline $\begin{array}{c}\text { Consumer } \\
\text { Category }\end{array}$ & Maybe & Likely Not & $\begin{array}{c}\text { Appreciate } \\
\text { That it is } \\
\text { Included }\end{array}$ & Yes & $\begin{array}{c}\text { Cost } \\
\text { Depending }\end{array}$ \\
\hline Alumni (n) & 7 & 8 & 5 & 2 & 1 \\
\hline Drop-Outs (n) & 1 & 0 & 0 & 0 & 1 \\
\hline Prospects (n) & 2 & 1 & 0 & 2 & 0 \\
\hline Total (\%) & $\mathbf{4 0 \%}$ & $\mathbf{3 6 \%}$ & $\mathbf{2 0 \%}$ & $\mathbf{1 6 \%}$ & $\mathbf{8 \%}$ \\
\hline
\end{tabular}

Note: Alumni and total (\%) exceed number of respondents as some respondents provided more than one answer

\subsection{OG's Efforts to Achieve Sustainable Tourism}

Respondents within the Alumni category were asked to identify if and how OG effectively integrates principles of sustainable tourism into their trips. This section is comprised only of responses from those within the Alumni category, as the Drop-Outs and Prospects categories hadn't travelled with OG and could not speak to the integration of sustainable tourism into OG's trips. Respondents were asked to use their own definition or interpretation of sustainable tourism to evaluate whether or not OG successfully integrates these principles into their trips. Figure 5 below depicts the most commonly used words when respondents described their understanding of sustainable tourism. 


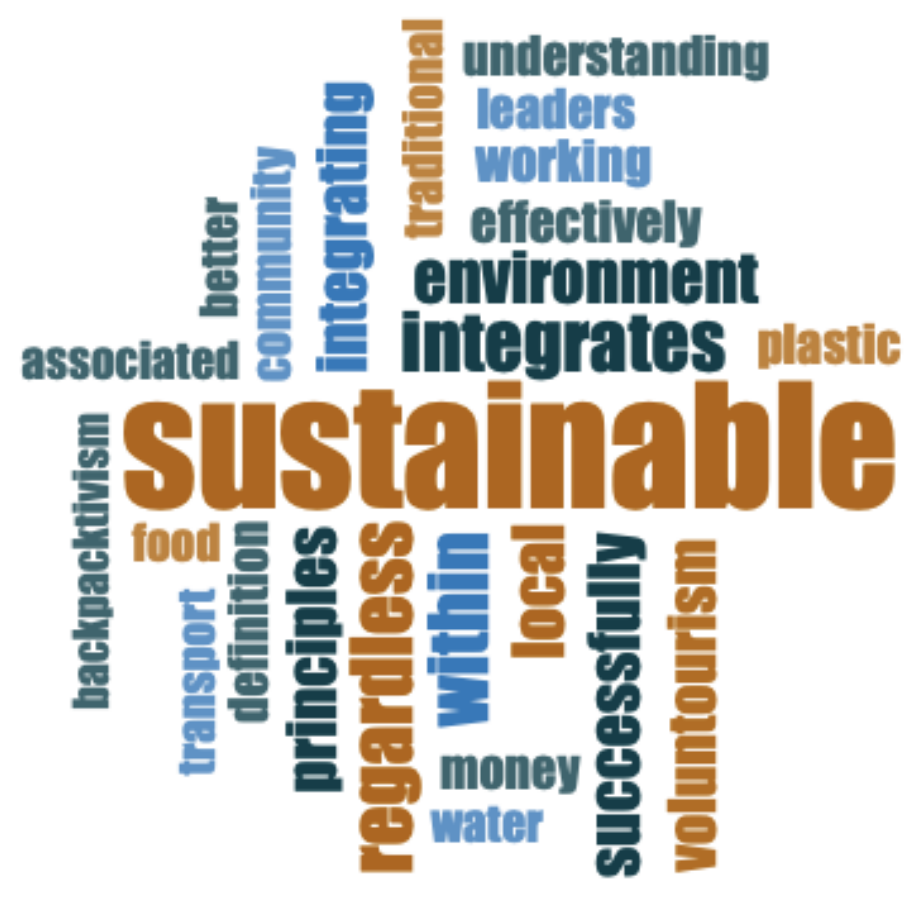

Figure 5 Word Cloud Generated from Interpretations of Sustainable Tourism $(n=18)$

Almost all respondents ( $83 \%)$ said that OG successfully integrates principles of sustainable tourism into their trips. Table 18 below depicts the distribution of responses from the Alumni category about if OG successfully integrates principles of sustainable tourism into their trips.

Table 18 Does OG Successfully Integrate Principles of Sustainable Tourism? (n=18)

\begin{tabular}{|c|c|c|}
\hline Consumer Category & Yes & They Do Their Best \\
\hline Alumni (n) & 15 & 3 \\
\hline Total (\%) & $\mathbf{8 3 \%}$ & $\mathbf{1 7 \%}$ \\
\hline
\end{tabular}

There were a range of reasons why respondents indicated that OG successfully integrates principles of sustainable tourism. The most common way in which respondents said OG does this is the use of local/public transportation where possible, mentioning how this is a more sustainable approach compared to other travel organizations that utilize private transportation. Several other respondents touched on OG's focus on supporting local businesses/products/services such as farmers markets, restaurants, accommodation and handicrafts to boost the local economy. Certain respondents mentioned that their OG leaders discouraged the use of single-use plastic and that they 
also emphasized the importance of generating less waste while travelling. A few respondents indicated that working in collaboration with local initiatives and projects aimed at enhancing environmental, social and cultural sustainability is a way in which OG successfully integrates principles of sustainable tourism. R9 (Alumni) describes some of the aforementioned ways in which they perceive OG to integrate principles of sustainable tourism, explaining

"[With OG it wasn't like] with [other tour operators] where they have this giant coach bus that is trying to get around and park and you see like all of these tourists running off... we [would] literally just go and walk around or we [would] take public transit and when we [went] shopping they [would] take us to the local market so you're supporting [local businesses]... not going to the huge shopping centers... even [when we would go out to eat] we [went] to the farmers markets and the local restaurants".

Table 19 below depicts the distribution of responses from the fifteen respondents within the Alumni category who indicated that OG successfully integrates principles of sustainable tourism.

Table 19 How Does OG Successfully Integrate Principles of Sustainable Tourism? (n=15)

\begin{tabular}{|c|c|c|c|c|}
\hline $\begin{array}{c}\text { Consumer } \\
\text { Category }\end{array}$ & $\begin{array}{c}\text { Use of } \\
\text { Local/Public } \\
\text { Transportation }\end{array}$ & $\begin{array}{c}\text { Supporting Local } \\
\text { Businesses/Products/Services }\end{array}$ & $\begin{array}{c}\text { Discouraging } \\
\text { Plastic Use/ Waste } \\
\text { Generation }\end{array}$ & $\begin{array}{c}\text { Working with } \\
\text { Local NGOs }\end{array}$ \\
\hline Alumni (n) & 9 & 8 & 5 & 4 \\
\hline Total (\%) & $\mathbf{6 0} \%$ & $\mathbf{5 3 \%}$ & $\mathbf{3 3 \%}$ & $\mathbf{2 7 \%}$ \\
\hline
\end{tabular}

Note: Alumni and total (\%) exceed number of respondents as some respondents provided more than one

\subsection{Future Directions for OG} answer

In order to determine future directions for OG, respondents were first asked about OG's current environmentally-focused trip offerings before they were asked what, if any new environmental topics they would suggest OG develop future trips around.

\subsubsection{OG's Environmental Program}

Respondents were asked if they think OG's environmental trips are sufficiently represented within their product offerings, and if they think OG should expand to include more trips with different environmental topics. There was almost an even split between respondents who believed 
OG should expand to include new environmental topics, and those who believed OG's environmentally-focused trip offerings are sufficient. Table 20 below depicts the distribution of these responses.

Table 20 Should OG Expand Their Environmental Program to Include More Trips with Different Environmental Topics? $(\mathrm{n}=25)$

\begin{tabular}{|c|c|c|c|c|}
\hline $\begin{array}{c}\text { Consumer } \\
\text { Category }\end{array}$ & $\begin{array}{c}\text { Should Expand to } \\
\text { Include New } \\
\text { Environmental } \\
\text { Topics }\end{array}$ & $\begin{array}{c}\text { Should Not } \\
\text { Expand as } \\
\text { Offerings Are } \\
\text { Sufficient }\end{array}$ & $\begin{array}{c}\text { Not Familiar } \\
\text { Enough with } \\
\text { Environmental } \\
\text { Offerings to Provide } \\
\text { Insight }\end{array}$ & $\begin{array}{c}\text { Program } \\
\text { Theme is an } \\
\text { Irrelevant } \\
\text { Decision- } \\
\text { Making Factor }\end{array}$ \\
\hline Alumni (n) & 6 & 8 & 3 & 1 \\
\hline Drop-Outs (n) & 2 & 0 & 0 & 0 \\
\hline Prospects (n) & 3 & 2 & 0 & 0 \\
\hline Total (\%) & $\mathbf{4 4 \%}$ & $\mathbf{4 0 \%}$ & $\mathbf{1 2 \%}$ & $\mathbf{4 \%}$ \\
\hline
\end{tabular}

\subsubsection{Suggestions for New Environmentally-Focused Trips}

Respondents were then asked to identify elements of the natural environment that they considered to be the most important. This question was posed so as to identify any potential environmental topics that OG's future environmental trips could be developed around. Water resources was the most commonly mentioned element of the natural environment. More than half of all respondents mentioned more than one element of the natural environment they consider to be the most important, and many also mentioned that identifying individual elements is difficult because they are all part of an interconnected and interdependent system. Table 21 below summarizes these responses. 
Table 21 What Elements of the Natural Environment Do You Consider the Most Important? $(n=25)$

\begin{tabular}{|c|c|c|c|c|c|c|c|}
\hline $\begin{array}{c}\text { Consumer } \\
\text { Category }\end{array}$ & $\begin{array}{c}\text { Water } \\
\text { Resources }\end{array}$ & $\begin{array}{c}\text { Arable } \\
\text { Land/Food } \\
\text { Security }\end{array}$ & Forests & Wildlife & $\begin{array}{c}\text { Urban } \\
\text { Sustainability }\end{array}$ & $\begin{array}{c}\text { Air } \\
\text { Quality }\end{array}$ & $\begin{array}{c}\text { Human } \\
\text { Impacts on } \\
\text { the } \\
\text { Environment }\end{array}$ \\
\hline $\begin{array}{c}\text { Alumni } \\
\text { (n) }\end{array}$ & 12 & 2 & 2 & 2 & 3 & 2 & 2 \\
\hline $\begin{array}{c}\text { Drop-Outs } \\
\text { (n) }\end{array}$ & 1 & 1 & 0 & 1 & 0 & 0 & 0 \\
\hline $\begin{array}{c}\text { Prospects } \\
\text { (n) }\end{array}$ & 3 & 1 & 2 & 0 & 0 & 0 & 0 \\
\hline Total (\%) & $\mathbf{6 4 \%}$ & $\mathbf{1 6 \%}$ & $\mathbf{1 6 \%}$ & $\mathbf{1 2 \%}$ & $\mathbf{1 2 \%}$ & $\mathbf{8 \%}$ & $\mathbf{8 \%}$ \\
\hline
\end{tabular}

Note: Alumni, Drop-Outs, Prospects and total (\%) exceed number of respondents as some respondents provided more than one answer

When comparing results between consumer categories, there are differences to note. The Alumni category provided the most diverse range of important environmental topics, having representation of each of the elements of the natural environment listed in Table 20. For the Alumni and Prospects categories, the highest proportion of respondents mentioned water resources. The Prospects category had the highest proportion of respondents that provided more than one answer, with $60 \%$ of respondents mentioning more than one element. The Alumni category also had a high proportion of respondents who provided more than one answer, with $56 \%$ of respondents mentioning more than one element.

While not an established question within the interview guide, conversations with several respondents led to the discussion of the interconnectedness of the four program themes that OG offers (human rights, health, education and environment). It was mentioned that while from a consumer standpoint it makes sense to clearly delineate between the four program themes, there is considerable overlap between all of these topics, and they cannot be viewed in mutually exclusive categories. During the conversations where this idea was organically brought up, the researcher asked respondents to speak to the potential of OG developing future "hybrid" trips that emphasize the overlap of health and the environment, or human rights and education, as examples. There was overwhelming support from respondents, with all respondents indicating that hybrid trips would 
allow for a more comprehensive and interdisciplinary educational experience while travelling. R21

(Alumni) describes this by noting

"Yeah I agree with [the idea to introduce hybrid trips] completely because even now that you brought it up and now that I'm thinking about it, I don't even know really if I could tell you what the category of the Amazon adventure was because we just did so much of each category and even the discussions that we had... even if it was a human rights issue, things were mentioned about the environment".

Several respondents within the Alumni and Drop-Outs categories were unable to recall which of OG's four program themes their trip belonged to, demonstrating OG's broad focus on sustainability. In other words, although OG has clearly distinct program themes, a range of human rights, health, education and environmental topics are emphasized and discussed on these trips regardless of which program theme the trip is classified as.

\subsubsection{Suggestions for How to Incorporate Important Elements of the Natural Environment into Future OG Trips}

After respondents identified elements of the natural environment, they were asked if and how they think these elements could be incorporated into an OG trip. Just over half (52\%) of respondents provided a response to this question. Those respondents who mentioned learning about the impacts of climate change suggested that visiting communities who are impacted by climate change and seeing how they have adapted is one way that OG can incorporate this topic into future itineraries. When comparing results between consumer categories, there are differences to note. All three consumer categories had one respondent mention that enhancing discussions about environmental topics is one way that OG can incorporate important elements of the natural environment into future trips. The Prospects category had the highest proportion of respondents who answered this question, with $80 \%$ of respondents providing an answer. The Alumni category was the only category who had respondents suggest the following three ideas: developing citybased itineraries to integrate the topic of urban sustainability/urban greenspace, having OG 
participants contribute to reforestation initiatives by planting at least one tree while on the trip, and incorporating shoreline cleanups into OG's itineraries. Table 22 below depicts the responses provided by each consumer category.

Table 22 Suggestions for How to Incorporate Important Elements of the Natural Environment into Future OG Trips ( $\mathrm{n}=13)$

\begin{tabular}{|c|c|c|c|c|c|c|}
\hline $\begin{array}{c}\text { Consumer } \\
\text { Category }\end{array}$ & $\begin{array}{c}\text { Learn } \\
\text { About the } \\
\text { Impacts of } \\
\text { Climate } \\
\text { Change }\end{array}$ & $\begin{array}{c}\text { Enhance } \\
\text { Discussions } \\
\text { About } \\
\text { Environmental } \\
\text { Topics }\end{array}$ & $\begin{array}{c}\text { Work with NGOs } \\
\text { Focused on } \\
\text { Environmental } \\
\text { Issues (Waste } \\
\text { Management, Plastic } \\
\text { Consumption, Air } \\
\text { Quality) }\end{array}$ & $\begin{array}{c}\text { Develop City-Based } \\
\text { Itineraries to } \\
\text { Integrate Urban } \\
\text { Sustainability/Urban } \\
\text { Greenspace }\end{array}$ & $\begin{array}{c}\text { Contribute to } \\
\text { Reforestation } \\
\text { Initiatives }\end{array}$ & $\begin{array}{c}\text { Participate } \\
\text { in } \\
\text { Shoreline } \\
\text { Cleanups }\end{array}$ \\
\hline Alumni (n) & 2 & 1 & 1 & 2 & 1 & 1 \\
\hline $\begin{array}{c}\text { Drop-Outs } \\
\text { (n) }\end{array}$ & 0 & 1 & 0 & 0 & 0 & 0 \\
\hline $\begin{array}{c}\text { Prospects } \\
\text { (n) }\end{array}$ & 2 & 1 & 1 & 0 & 0 & 0 \\
\hline Total (\%) & $\mathbf{3 1 \%}$ & $\mathbf{2 3 \%}$ & $\mathbf{1 5 \%}$ & $\mathbf{1 5 \%}$ & $\mathbf{7 \%}$ & $\mathbf{7 \%}$ \\
\hline
\end{tabular}

Note: Alumni, Drop-Outs, Prospects and total (\%) do not equal number of respondents for each category and do not equal $100 \%$, respectively as many respondents did not answer this question

\subsection{Summary of Key Findings/Conclusion}

This chapter first provided information on the profile of respondents that comprise the sample, outlining the three consumer categories represented. The motivations to travel with OG and the perceived benefits of travelling with OG were then determined. The tangible impacts of travelling with OG were then presented, with the most pervasive impact being education and instilling activism. The primary motivations and perceived benefits of travelling with OG were found to be the result of OG's philosophy, mission and values, as well as OG's focus on and integration of education. The motivations to participate in voluntourism were then outlined, the most common of which was determined to be education and learning while travelling. Then, respondents' perspectives on voluntourism were determined, including but not limited to perspectives on the benefits and issues associated with voluntourism as well as OG's approach to voluntourism. It was found that the majority of respondents think that voluntourism has the potential to be a good thing with an added caveat that voluntourism must be done properly with 
ethics and sustainability in mind. It was determined that most respondents perceive OG's approach to voluntourism unique compared to other similar organizations. Next, it was revealed that there is low consumer awareness of OG's carbon offset initiative, but that this sustainability initiative is influential from a consumer standpoint. This chapter then determined that OG's consumers perceive OG's efforts to achieve sustainable tourism to be successful, particularly when compared to other tour operators. Finally, this chapter presented respondents' perspectives on OG's future directions including but not limited to opinions about OG's environmentally-focused trip offerings and how environmental topics can be incorporated into future OG trips. The next chapter offers a discussion of the key themes that emerged from these findings. 


\section{Chapter 6: Discussion}

\subsection{Introduction}

This chapter provides a discussion of the seven key themes identified from this research study: 1) consumer perceptions of OG, 2) OG's program themes are an uninfluential element of consumers' decision-making, 3) the perceived benefits and tangible impacts of travelling with OG, 4) consumer motivations to participate in voluntourism, 5) consumer perceptions of voluntourism, 6) consumer perceptions towards carbon offsetting and the influence of OG's carbon offset initiative and 7) consumer support for the development of hybrid trips that emphasize the interconnections of OG's four program themes. Where applicable, sections within this chapter will offer comparisons between the consumer categories to identify any salient information specific to one or more consumer group.

\subsection{Consumer Perceptions of OG}

The first key theme that emerged from this research is that OG effectively communicates their mission and values as an organization and as a result, there were consistent elements of OG's appeal identified by respondents. Respondents provided answers that reflected OG's commitment to sustainability, travelling with purpose, learning and education, authentic and immersive cultural experiences and their travel approach that acknowledges the common concerns with voluntourism and actively works to avoid such issues. These results indicate that through OG's advertising, they are successful at 1) conveying their values through their product offerings and 2) attracting a consumer type that seeks out and/or values products reflecting the aforementioned elements of

their appeal. Despite which consumer category respondents belonged to, most had a good understanding of OG's mission, values and philosophy as an organization. Several respondents mentioned the effectiveness of OG's branding and communication of their product, indicating that 
OG's approach to voluntourism is made evident and differentiates OG from other organizations offering a similar product.

\subsection{OG's Program Themes Are an Uninfluential Element of Consumers' Decision-Making}

The second key theme identified was that respondents within the Alumni and Drop-Outs categories were unaware of the program theme that 1) they had participated in or 2) they had expressed an interested in. The two most pervasive decision-making factors identified were the topic/focus of the trip and the duration/length of the trip, whereas the program theme the trip belongs to (human rights, health, education, environment) was a seemingly uninfluential element of respondents' decision-making. Consumers can search for trips by program theme on OG's website, but when selecting a particular trip from the list of options, the program theme is not attached to the itinerary. Where applicable (i.e. when the title of the trip did not indicate which program theme it belonged to or when the trip in question was no longer offered by OG and the program theme could not be identified by looking on their website), the researcher asked respondents if they knew which of OG's four program themes the trip was classified as. None of the respondents were able to identify which program theme their trip would fit into. The results from this study indicate that the specific program theme appears to be an irrelevant factor for consumers, and that consumers are generally not motivated by the program theme. This key theme is relevant to the central research question of this study as it demonstrates how the program theme is not a significant factor in respondents' decision-making and therefore, OG may want to consider if and how classifying trip offerings within specific program themes is beneficial to them as an organization. Additionally, since OG' program themes are an established criterion for classifying their product, there is room to improve the centrality of program themes on their trips. In other words, considering respondents lacked awareness of which program theme they either participated 
in or expressed an interest in, it seems that OG is not entirely successful in thoroughly integrating or conveying these themes within their program offerings.

\subsection{Perceived Benefits and Tangible Impacts of Travelling With OG}

The third key theme is that most respondents felt that travelling with OG is more sustainable and ethically-conscious compared to other voluntourism organizations. The most common perceived benefits and tangible impacts of travelling with OG reflected respondents' understanding that voluntourism may not have significant impacts on the communities visited but instead is about learning, personal growth and the longer-term impacts of awareness and behavioural change. These results align with the information presented by Liston-Heyes \& Daley (2017) who suggest that OG's approach to voluntourism is focused on "intercultural learning exchanges" (286), and also support the information presented by Schneller and Coburn (2018) who note that voluntourism has the potential to enhance participants' concern and awareness of global issues and can encourage pro-environmental behaviour. Further, these results align with OG's communication of how their approach to voluntourism is unique and how their trips are not simply a "cookie-cutter vacation" (Operation Groundswell 2019). However, while respondents did claim to have increased awareness of global issues and a heightened inclination to participate in volunteer work in addition to suggesting that travelling with OG made them more aware of their environmental footprint, this study did not thoroughly evaluate the long-term impacts of travelling with OG. As such, respondents may have either embellished the positive impacts of travelling with OG or confused causation and correlation (suggesting that these behaviours are the result of travelling with OG instead of being one of many potential contributing factors) (Conn 2017). In other words, since OG does attract a certain breed of consumer (i.e. individuals who value sustainability or who are looking for a more meaningful experience than simply travelling for 
leisure), claiming that travelling with OG was the cause of these longer-term impacts may not be completely accurate.

\subsection{Motivations to Participate in Voluntourism}

The fourth key theme is the consistency of motivations to participate in voluntourism. One of the objectives of this study was to build on the results of the studies conducted by Brown (2005) and Liston-Heyes and Daley (2017), both of which sought to understand the motivations of voluntourists. The findings from this study support the findings of Brown (2005) who indicated that education and learning are primary motivational factors for those seeking voluntourism opportunities, and Liston-Heyes and Daley (2017) which indicated a mix of leisure and altruism as the primary motivational factors for those seeking voluntourism opportunities. The results from this study also reflect the information presented by Grimm and Needham (2012) who suggest that social egoism, whereby voluntourism experiences simultaneously benefit the traveler and the community or environment they are interacting with, is a central motivation for voluntourists. Yet, it is crucial to recognize that despite OG's efforts to avoid providing participants with pat on the back experiences, there is an aspect inherent to their program offerings that fosters these types of experiences (Coren and Gray 2012). So, while OG is comparatively more aware of the potential

for voluntourism to cultivate pat on the back experiences and consciously tries to avoid promoting such experiences, this form of travel intrinsically leaves participants feeling better about themselves than if they were to travel solely for personal pleasure or leisure. Additionally, while respondents did suggest that they were not motivated to participate in voluntourism solely for altruistic reasons, none mentioned some of the potential self-interested motivations cited in the literature such as enhancing one's CV (McGloin \& Georgeou 2016). Understanding the motivations of both past and prospective consumers is a crucial element for the success of 
voluntourism organizations and tour operators. This is because by understanding why consumers are motivated to partake in voluntourism, the organizations and/or businesses in question can appeal to the established consumer motivations, adjusting their products and marketing to reflect the perspectives of their consumer market.

\subsection{Perceptions of Voluntourism}

The fifth key theme identified is that most respondents indicated that voluntourism can be ethically problematic but believe that it has the potential to be a good thing if done properly. While there are well-founded reasons that voluntourism can be problematic, findings from this research demonstrate that respondents perceived voluntourism as mostly positive as long as it is done properly and addresses the ethical issues associated with the practice. Respondents mentioned many of the common pitfalls associated with voluntourism outlined by Blackman and Benson (2010), Wearing and McGehee (2013), Luh Sin et al. (2015) and Hasanova (2017). However, while respondents did acknowledge these potential issues, findings from this study demonstrate how OG's approach to voluntourism is perceived to effectively avoid the issues of the practice by integrating education and working collaboratively with local NGOs to address problems identified as priorities by communities. These results support the information presented by Raymond and Hall (2008) who postulate that voluntourism organizations can effectively avoid the issues associated with the practice by 1) developing programs that address concerns of locals and offer tangible value to the communities visited, 2) approaching voluntourism as a learning process by integrating experiential learning techniques and 3) deliberately facilitating cultural interactions so as to avoid problematic encounters between participants and locals. While OG does facilitate interactions between local partners and participants, whether or not OG's program leaders are monitoring/supervising cultural interactions external from these projects is unclear. Thus, whether 
or not $\mathrm{OG}$ does engage in this practice is uncertain but it is definitely not a marketed element of their approach. As such, OG does seemingly adhere to some of the recommendations for effective voluntourism, but not all three of the aforementioned strategies proposed by Raymond and Hall (2008). The results from this study also support the information presented by Guttentag (2009) who suggests that consultation and collaboration with local communities is a necessary element of effective voluntourism program development. Respondents mentioned how OG's partnerships with local NGOs, their integration of education and learning and their critical approach to voluntourism differentiates them from other voluntourism organizations and allows OG to ethically engage with the practice of voluntourism.

Another objective of this study was to evaluate if respondents perceived OG's approach to voluntourism as an effective way to achieve the goals of sustainable tourism. The most common ways in which respondents felt OG was successful at achieving the goals of sustainable tourism was through OG's use of public/local transportation and through the intentional support of local businesses, products and services. Respondents indicated that travelling as the locals do was not only more environmentally conscious than hiring a private vehicle but was also an element of the authentic cultural immersion experienced while travelling with OG. Respondents also mentioned how their OG leaders discouraged plastic use, encouraged participants to limit/reduce their waste generation and how they obtained a more culturally authentic and immersive travel experience than they would with a leisure-focused tour operator. These findings support the UNWTO Tourism and Sustainable Development Goals (2015), highlighting how tourism can foster economic growth through the sale of local products and services in tourist destinations, improve awareness and education of global environmental issues, preserve cultural and natural heritage by allowing 
travellers to live and work with locals on grassroots projects, and be a catalyst for multi-cultural and interfaith understanding.

A sub-element of voluntourism perceptions is the consumer perception of OG's approach to voluntourism, an approach that deviates from the traditional idea of voluntourism and aims to avoid the issues associated with the practice. Those who indicated that voluntourism has the potential to be a good thing if done properly highlighted why and how OG's product is different from traditional voluntourism. Several respondents referred to voluntourism organizations who lack a critical approach to the practice and offer pat on the back voluntourism experiences that contribute to the increase of global power dynamics and engage in ethically questionable activities. Several respondents who gave examples of the issues associated with voluntourism were also able to identify how OG departs from this narrative. Despite the overwhelming support and positive perceptions of OG's approach to voluntourism, acknowledging that respondents did - to some extent - demonstrate self-fulfillment from their participation with OG is important to this discussion. Even though OG does take a critical approach to the topic of voluntourism and proactively incorporates discussions and workshops on the ethics of voluntourism, respondents did still suggest that they felt good about their participation in OG's trips and they obtained more fulfillment than they would if travelling with a leisure-based tour operator. So, it is important to recognize that despite OG's efforts to transcend the traditional practice of voluntourism, there is an element of self-interest, personal development, and individualism that is present which reflects the information presented by Coghlan (2008), Guttentag (2009) and Wearing \& McGehee (2013) regarding the motivations of voluntourists.

On multiple occasions did respondents discuss their concerns with voluntourism organizations that impose development plans on local communities without collaborative 
discussion of the wants and needs of such communities, and how OG's approach to voluntourism supports local initiatives. These results reflect the information presented by Mbaiwa (2004) who discusses how tourism activities are often developed and managed by external stakeholders and disregard the wants and needs of local communities. The majority of respondents were actively aware of how OG's approach to voluntourism differs from other voluntourism organizations, demonstrating OG's success in differentiating their product and reaching consumers who are knowledgeable about the potential ethical concerns of voluntourism and who are seeking a product that deviates from traditional voluntourism. Respondents demonstrated positive perceptions of OG's efforts and recognized that OG is comparatively less problematic compared to other voluntourism organizations. However, recognizing the potential bias of the respondents sampled is important to this discussion, as there is always room for improvement. There was limited discussion from respondents about how OG could do better or what they currently do that may be problematic. This may be a result of respondents demonstrating SDB despite the efforts the researcher took to avoid this form of bias. Some confounding factors could be that respondents were 1) unaware of OG's limitations, 2) unable to identify what OG could improve, or 3) unable to outline how OG could improve.

\subsection{Low Awareness of OG's Carbon Offset Initiative/Influence of OG's Carbon Offset Initiative}

The sixth key theme that emerged is that there is low consumer awareness of OG's carbon offset initiative. Most respondents said they have heard of the term carbon offsetting, but despite this, only about half were able to provide a definition of the term. These results demonstrate general awareness of the practice of carbon offsetting but a lack of understanding of the practice. Only a small percentage confidently indicated that they remember reading information about OG's carbon offset initiative on their website. As only a small proportion of respondents had been made aware 
of OG's carbon offset initiative on their website, it is evident that the marketing of this sustainability initiative is lacking and could be used as a promotional tool for the organization, differentiating them from other similar voluntourism products and attracting the green consumer market. Another small proportion (exclusively those within the Alumni category) was aware of OG's carbon offset initiative because they were told about it while on a trip. These results indicate that this sustainability initiative is not prevalent enough on OG's website and in their marketing efforts. Once told about the carbon offset initiative, many of those respondents who were unaware of OG's carbon offset initiative indicated that making their carbon offset initiative more evident on the website and in their marketing would be a draw factor for consumers.

On multiple occasions did respondents mention skepticism of OG's carbon offset initiative because of the lack of information and transparency of the initiative on the website. These findings support the studies conducted by both Taiyab (2006) and Dodds et al. (2012) who suggest that limited transparency is a primary reason for skepticism of carbon offsetting and other green initiatives. The information provided about OG's carbon offset initiative on their website is limited to 1) the percentage of the community contribution fee that is diverted to their carbon offset initiative and 2) the carbon offsetting agency that funds are diverted to. While those who had come across information about OG's carbon offset initiative on their website indicated that the communication of the initiative was effective, numerous respondents mentioned that a dedicated webpage for the initiative, a link to PlanetAir's website and increased information about exactly how funds are being utilized would alleviate skepticism surrounding the initiative.

\subsubsection{OG's Carbon Offset Initiative Should Remain an Included Cost}

Another key theme was that OG's carbon offset initiative should remain an included cost as opposed to becoming a voluntary initiative for which consumers can opt to donate. OG has 
integrated their carbon offset initiative into their program fees as opposed to relying on consumers to voluntarily contribute. This reflects the information presented by Gossling et al. (2007) about tourism products proactively integrating sustainability initiatives into their products, and supports the evidence presented by Arana et al. (2013) that consumers are more likely to pay for carbon offsetting and other climate change mitigation programs when they are presented as opt-out options as opposed to opt-in options. Most respondents indicated that they would either 1) likely not or 2) might opt to voluntarily contribute to OG's carbon offset initiative. Although a portion did indicate they might opt to voluntarily contribute, these results should be taken with a grain of salt as there is considerable disconnect between what consumers claim they will pay for and their actual purchasing behaviours, referred to as the attitude/value-behaviour gap in willingness to pay studies (Dodds 2013; Huang et al. 2018; Hwang \& Lee 2018). Thus, these results indicate that OG's inclusion of their carbon offset initiative into their program fees is the appropriate approach. When comparing results between the three consumer categories, the primary noteworthy difference is that only those who belonged to the Alumni category mentioned that they appreciated that the initiative is included as opposed to an optional cost. This may be attributed to the fact that as Alumni, they have had experience travelling with OG and therefore have an idea of how the program fees are spent and likely are less skeptical of OG's sustainability efforts and/or operations.

\subsubsection{Green Consumers Within OG's Consumer Market}

As part of the discussion of OG's carbon offset initiative, the theme of green consumerism became evident. The majority of respondents indicated that the fact that $O G$ has this carbon offset initiative makes them more likely to choose, support or recommend OG compared to another similar organization without an established sustainability initiative in place, noting that OG's carbon offset initiative is a differentiating factor. Therefore, while actual behaviour was not tested 
in this research study, there is evidence suggesting that there are green consumers within OG's market and that their carbon offset initiative and future initiatives focused on sustainability may serve to attract these green consumers. That being said, as was outlined in section 6.7.1, respondents may have claimed that this initiative is a draw factor when in actuality it may not have much of an impact on their perceptions towards OG or their purchasing behaviours. Recognizing that respondents may have also overstated their commitment towards green products and services is important to note. However, based on the type of consumer that OG's product does attract, it is likely that respondents do at least have some awareness of the impacts of their purchasing decisions and would to some extent consider OG's carbon offset initiative as an influential element of their decision-making.

\subsection{Hybrid Trips}

The final key theme uncovered was the consumer support for developing hybrid trips that emphasize the interconnectedness of two or more of OG's program themes. Conversations with several respondents led to the discussion of the considerable overlap of the four program themes that $\mathrm{OG}$ offers (human rights, health, education and environment). It was mentioned that while from a consumer standpoint it makes sense to clearly delineate between the four program themes, they cannot be viewed in mutually exclusive categories. Although OG has clearly distinct program themes, a range of human rights, health, education and environmental topics are emphasized and discussed on these trips regardless of which program type the trip is classified as. Almost all respondents indicated support for trips that could highlight how OG's program themes cannot be discussed in mutually exclusive categories and instead, are significantly interrelated. Despite which consumer category respondents belonged to, there was overwhelming support for the idea of developing hybrid trips and an acknowledgement that trips emphasizing the interconnectedness 
of OG's program themes would encourage interdisciplinary learning and education, which was determined to be a central motivating factor for respondents. Hybridizing program themes to emphasize the interconnectedness of topics relating to human rights, health, education and the environment may be a strategic way for OG to bridge the gap between environmental topics and human-related topics. 


\section{Chapter 7: Conclusion}

The purpose of this thesis was to provide OG with an enhanced understanding of their consumer market and to provide them with the necessary information to make strategic business decisions moving forward as a facilitator of sustainable tourism. This chapter will begin by outlining how the research question was answered and how the objectives of the study were met. Following this, recommendations based on the key findings are presented. Then, the academic contribution of the research and the significance of the research are outlined. Finally, suggestions for potential future research on the topic are summarized.

\subsection{How OG Can Move Forward as a Facilitator of Sustainable Tourism Utilizing Their Approach to Voluntourism and Their Carbon Offet Initiative}

This research addressed a gap in the academic literature on 1) what the consumer support and buy-in is for voluntourism products that engage in sustainable tourism, and 2) the extent to which OG's approach to voluntourism is perceived as an effective approach to accomplishing the goals of sustainable tourism. The research question that this thesis aimed to answer is: how can OG move forward as a facilitator of sustainable tourism utilizing their approach to voluntourism and their carbon offset initiative? It was determined that in order for OG to move forward as a facilitator of sustainable tourism, 1) their carbon offset initiative should be made more prevalent and transparent on OG's website and in their marketing to attract green consumers, 2) that they should continue to engage with voluntourism with a critical lens by focusing on educating participants on the issues associated with the practice and 3) that OG should develop hybrid trip offerings that emphasize the interconnectedness of their four program themes (human rights, health, education and environment). The following section will summarize the objectives of this research, and how the results of this study meet each objective. 


\subsection{Summary of How the Research Objectives Were Addressed}

Four objectives were developed in order to comprehensively address the central research question. Each objective is listed below along with a summary of how each objective was met through the conduction of this research.

\subsubsection{Consumer Motivations to Participate in OG's Voluntourism Trips}

The primary research identified diverse motivations of Canadian past and prospective OG consumers. Findings from this study show that education and learning, wanting to give back, and wanting to have authentic, immersive cultural experiences are the most common motivations for wanting to participate in this form of travel, and with OG specifically. A large majority of respondents indicated that there was a balance between wanting to travel for their own personal reasons and wanting to do so in a way that gave back to the communities visited. This study also identified what about $\mathrm{OG}$ is appealing to consumers, demonstrating that $\mathrm{OG}^{\prime}$ communication of their values and philosophy is effective and that consumers appreciate OG's commitment to social and environmental sustainability in addition to OG's focus on education and learning, travelling with a purpose (not solely for personal pleasure or leisure) and OG's sustainable approach to tourism.

\subsubsection{The Perceived Benefits and Tangible Impacts of Travelling with OG}

Findings demonstrate that the perceived benefits and tangible impacts of travelling with OG are varied, but common themes are identified. The integration and prioritization of sustainability, the focus on education, the ability to obtain authentic and immersive travel experiences, and the ability to have meaningful cultural exchanges are the primary perceived benefits of travelling with OG. The most commonly mentioned impacts of travelling with OG were not about the perception of making a difference in the communities visited while travelling, but 
instead were the education and instilment of activism gained from travelling with $O G$ and the increased inclination to partake in volunteer work both while travelling and locally/at home.

\subsubsection{The Importance and Influence of OG's Carbon Offset Initiative}

Findings indicate low consumer awareness of OG's carbon offset initiative. For the most part, if consumers were aware of OG's carbon offset initiative it was because they had been told about it on their trip, not because they had heard about it or seen information about this initiative on OG's website. Enhanced marketing and transparency of OG's carbon offset initiative would provide OG with a competitive advantage and differentiate their product compared to similar organizations. While not every respondent indicated this initiative as a highly influential component of their decision-making, most recognized the importance for businesses to integrate and prioritize sustainability, indicating their support and appreciation of the initiative. On more than one occasion did respondents indicate skepticism regarding OG's carbon offset initiative due to awareness of greenwashing, mentioning that improved transparency and information about the initiative would alleviate apprehension surrounding this initiative. There is strong consumer support for OG's carbon offset initiative and a call for the enhanced marketing and transparency of this initiative.

\subsubsection{Consumer Perceptions of OG's Approach to Voluntourism As an Effective Way of Engaging with Sustainable Tourism}

OG's Canadian past and prospective consumers perceive OG's approach to voluntourism as a sustainable way of travelling compared to both other tour operators and other voluntourism organizations. While recognizing that tourism cannot be entirely sustainable, consumers are generally aware of the actions OG takes to engage with and promote sustainable tourism. All respondents have a baseline understanding of voluntourism, most understanding the common pitfalls associated with traditional voluntourism and indicating appreciation OG's novel approach. 
Some respondents feel that voluntourism is inherently a good thing, while most others mentioned that voluntourism has the potential to be a good thing if done properly, indicating how OG's approach to voluntourism adheres to the caveats of conducting adequate research, communicating and collaborating with local organizations, and prioritizing education and learning within their trip offerings.

\subsection{Recommendations}

Recommendations on how OG can strategically position themselves for growth as an organization as well as move forward as a facilitator of sustainable tourism were revealed. Each recommendation is explained in detail below.

\subsubsection{Increase Information, Transparency and Marketing of Carbon Offset Initiative}

The first recommendation is that OG should retain their carbon offset initiative, but also improve this effort by 1) increasing information and transparency of their carbon offset initiative to alleviate skepticism surrounding greenwashing, and 2) enhancing the prevalence and marketing of their carbon offset initiative on their website and in other promotional material to attract green consumers. As there is demonstrated low awareness of OG's carbon offset initiative, OG should increase information about the environmental impacts of air travel and what the practice of carbon offsetting entails, as well as improving transparency about where and how funds are diverted and the impact that these funds are having. Increasing transparency of the initiative could be accomplished by clearly outlining PlanetAir's process for carbon offsetting, presenting examples of the projects they are involved in, and conveying if and how these carbon offsets are actively mitigating climate change. By doing so, consumer skepticism surrounding greenwashing may be reduced. As most respondents said the fact that $\mathrm{OG}$ has a carbon offset initiative makes them more inclined to choose OG over another similar organization, OG's carbon offset initiative has the 
potential to differentiate OG's product and attract green consumers (as findings from this study demonstrate that green and ethically-minded consumers are prevalent within their market). Thus, utilizing the information presented by Alberini and Segerson (2002) who note that the integration of environmental initiatives can serve to distinguish products within the market, and Hockerts (2015) and Rahman et al. (2015) who suggest that engagement with and marketing of sustainability efforts can boost customer acquisition and retention, OG would likely obtain a competitive advantage by enhancing the predominance of their carbon offset initiative both on their website and in other promotional mediums. As OG's carbon offset initiative is only present on their website in a small section on the bottom of a webpage that is not dedicated specifically to this initiative, OG may consider advertising their carbon offset initiative on their main webpage, developing a distinct webpage for their carbon offset initiative and/or advertising their carbon offset initiative on their main webpage as well as including a quick-access link on the main webpage to bring consumers to the dedicated carbon offset initiative webpage. Additionally, OG's website only mentions that the Suzuki Foundation regards PlanetAir as an industry leader, not conveying that PlanetAir is Gold Standard certified (one of the most widely-used carbon offset standards and meeting the highest standards within the carbon offset market) (Green 2017). So, conveying that PlanetAir does in fact meet the Gold Standard for carbon offsetting would provide consumers with an enhanced understanding of the legitimacy of this initiative within the carbon offset market. As lack of awareness and limited transparency has been found to be a primary barrier to carbon offsetting in an aviation context (Babakhani et al. 2017), providing more comprehensive and transparent information about OG's carbon offset initiative is a good first step in garnering consumer support and attracting/retaining customers. As the majority of respondents first heard about OG through social media, OG should advertise their carbon offset initiative on predominant 
social media platforms as opposed to solely advertising this initiative on their website. In doing so, OG can simultaneously improve awareness of the initiative and differentiate their product.

Although it is recommended that OG retain their carbon offset initiative (whilst making improvements), discussing the importance of this initiative from a climate change mitigation standpoint is important. While engaging with carbon offsetting is certainly preferable to not having any established initiatives focused on emissions, there is debate regarding the effectiveness of carbon offsetting as a climate change mitigation strategy (Hyams \& Fawcett 2013). In addition to the lack of universal standards and verification for carbon offsetting, there is the perspective that carbon offsetting is only a partial and temporary solution (Scott et al. 2016). The lack of a legallybinding international cap on GHG emissions means that despite carbon offsetting strategies, global GHG emissions could remain fundamentally unchanged and as such, whether or not carbon offsetting actually serves to mitigate emissions from the aviation sector is unsubstantiated (Scott et al. 2016). Additionally, carbon offsetting in the form of reforestation/afforestation projects (which PlanetAir is involved in) is not considered to be highly effective, as it is impossible to guarantee that carbon will remain sequestered for long periods of time (Hyams \& Fawcett 2013; Scott et al. 2016). So, while maintaining their carbon offset initiative, OG should consider if this initiative is making a substantial positive impact and whether they can consider other sustainability initiatives to develop in the future, such as diverting funds to shoreline cleanup organizations or disaster relief organizations in the regions visited.

\subsubsection{Develop Hybrid Trips}

The second recommendation is that OG should consider developing hybrid trips that span multiple program themes, emphasizing the interconnectedness of such topics. For example, OG may consider developing trips focusing on the impacts of climate change on human health. As 
program themes were determined to have limited influence on respondents, developing hybrid trips would enhance the educational component of OG's trip offerings (determined to be the most common motivation to participate in voluntourism), and encourage interdisciplinary learning. By developing hybrid trips, OG could communicate the importance of analyzing their four program themes are part of a holistic system and could in turn demonstrate to participants the necessity to frame environmental issues within a human lens, and vice-versa.

\subsubsection{Market Their Approach to Voluntourism More Clearly to Prospective Consumers}

The third recommendation is that OG should increase and enhance communication of how their approach to voluntourism deviates from the traditional notion of voluntourism. As there were respondents within the Prospects category who indicated skepticism about voluntourism and demonstrated an awareness of the potential issues associated with the practice, there is room for OG to more clearly convey to prospective consumers that they are aware of and actively work to avoid engaging with voluntourism in a problematic way. While OG does have a dedicated space on their website describing why they are unique, this could be highlighted in their marketing efforts to make their novel approach more evident. There is ample information provided on OG's website about their approach and the strategies they have employed to practice voluntourism in a sustainable manner. However, consumers may not be inclined to read through all of this information and as such, OG should develop a way to quickly and effectively communicate this information to prospective consumers. This could be accomplished through the use of video and/or other multi-media sources to audio-visually compare traditional voluntourism to OG's approach, utilizing material and footage from past OG participants. Most of OG's social media advertisements convey the message of backpacking/travelling with purpose, which is a good start in differentiating their product. However, further integrating how their approach to voluntourism 
is unique compared to traditional voluntourism may serve to further differentiate their product and improve the overall image of voluntourism as a practice, demonstrating how voluntourism can be accomplished in an ethically-just and sustainable manner.

\subsubsection{Focus on Broadening Their Sustainability Efforts}

While recognizing that $\mathrm{OG}$ has made good strides in promoting and facilitating sustainable tourism, there is potential for them to expand and improve these efforts. Therefore, the fourth recommendation is that OG focus on broadening/expanding their current sustainability efforts. In order to become more sustainable, OG could attempt to more deeply integrate participants into local projects by increasing the duration for which participants visit such projects (considering certain projects are only visited by participants for one to two days) and also ensure that participants are able to contribute to projects in a hands-on manner (as some projects visited have an exclusively educational focus whereby local issues and the associated projects are explained to participants). OG could also commit to seeking out accommodation establishments that have implemented sustainability strategies such as energy and water conservation or adopted other voluntary policy instruments for sustainability. Another way OG could improve their sustainability efforts is by striving to partner with local NGOs and charities that also value and integrate sustainability (such as waste reduction or environmental restoration as examples) in addition to the focus of their respective organization. OG could communicate on their website if and how often they conduct environmental audits and social impact studies before they develop products in destinations to 1) bolster their sustainability efforts as an organization if these are not established practices and 2) increase transparency on what their sustainability efforts entail. In choosing their

local partners, OG could also consider going beyond the scope of the OG network to identify worthy local NGOs that could use support and could simultaneously offer benefits to OG's 
participants. Additionally, in the MOUs that are collaboratively developed between OG and their local partners, a preamble could be included that "acknowledges the broader forces that maintain the socio-economic status-quo" (Banki \& Schonell 2018: 1481). The development and inclusion of this preamble could further integrate the critical approach to voluntourism that OG values, recognizing the role that OG's trips and their participants have in solidifying power dynamics between different regions of the world.

\subsubsection{Additional Market Research to Identify Environmental Topics for Future Trips}

Although many respondents consider OG's environmental program offerings to be sufficient, there is a proportion of respondents who believe there is room for expansion to include additional environmental topics. As such, the fifth and final recommendation is that OG undertake further market research with a larger sample to 1) determine market interest on a larger scale and 2) probe consumers about how these topics could be integrated into future itineraries. This will allow OG to isolate topics of interest and provide them with the specific information required to develop itineraries.

\subsection{Academic Contribution of Research}

The state of literature on the business case for sustainability in the tourism industry is largely focused on large corporations within the accommodation sector (Garay et al. 2018) and as such, this study adds to the limited body of research evaluating the sustainability efforts of smaller organizations/NGOs within the tourism industry. Past research has examined examples of tourist products integrating principles of sustainable tourism (Budeanu 2005; Ayuso 2006; Buckley 2012; Aragon-Correa et al. 2015) as well as the potential impact of sustainability in creating a competitive advantage (Han \& Yoon 2015; Dodds \& Holmes 2016; Garay et al. 2018; Goffi et al. 2018). However, there is limited research regarding the influence of sustainability within 
voluntourism products, and the perception of voluntourism as a way to achieve the goals of sustainable tourism. The results of this study demonstrate the potential influence of sustainability initiatives from a consumer standpoint, building on previous research that has sought to understand the business case for sustainability within the tourism industry. The results of this study also display the positive perceptions of OG's approach to voluntourism as a way of achieving the goals of sustainable tourism.

\subsection{Significance of Research}

This research is significant as it adds to the existing body of literature on the motivations and perceived benefits of voluntourists, while presenting novel information specific to OG about their consumer market. The results of this study demonstrate that there are green consumers within OG's market who believe that their carbon offset initiative differentiates them from other similar voluntourism organizations, and that improved transparency, increased detail and enhanced marketing of this initiative would be beneficial for OG's growth. Further, this research presents unique information about consumer perceptions of voluntourism as an approach to achieve sustainable tourism, a topic that is not well-documented in academic literature. The results of this study demonstrate that consumers value sustainability initiatives such as OG's carbon offset initiative, and that such initiatives can and should be promoted to be used as a draw factor for green consumers within OG's market. This study can be used as a starting point for other voluntourism organizations to incorporate principles of sustainable tourism into their mission, values and philosophy in addition to their product offerings.

\subsection{Potential Future Research}

Future research on this topic would benefit from 1) an added quantitative analysis from a larger sample of OG consumers, 2) the analysis of OG's international consumers (i.e. not only 
Canadian consumers), 3) an element focusing on the long-term impacts that travelling with OG had on participants and 4) additional case studies of voluntourism organizations to evaluate if beyond the reach of OG's consumer market, there are green consumers seeking voluntourism products focused on sustainable tourism. An added quantitative component through the distribution of online surveys, for example, would supplement the qualitative data collected in this study and demonstrate if the results are representative of OG's market. This would allow OG to more comprehensively gauge interest in hybrid trips, identify elements of the natural environment that may be worthwhile to develop future trips around, and obtain further insight on the perceptions of OG's carbon offset initiative. As this study limited eligibility to Canadian consumers, duplicating this research with the rest of OG's market (i.e. international past and prospective consumers) would provide insight into the differences that exist when comparing different market segments and populations. By adding an element focusing on the long-term impacts of travelling with OG, OG would have a better understanding of if and how the information discussed, and lessons learned while participating with $\mathrm{OG}$ can translate into long-term behavioural change including but not limited to pro-environmental behaviour and activism. This could be accomplished by evaluating respondents' interests and other experiences that could have contributed to their behavioural change to try and identify the role that travelling with OG had on these behaviours. In doing so, OG could get a better idea of these impacts were caused by travelling with OG, or if they are simply correlated to the experience of travelling with OG. Conducting additional case studies of different voluntourism organizations (using the same methods used to conduct this case study) would evaluate if the key themes identified in this case study can be extrapolated into different consumer markets and therefore inform the business decisions of other similar voluntourism organizations. 


\subsection{Conclusion}

This chapter provided a synopsis on how this research addressed the research question and met the objectives of the study. Recommendations based on the key findings were then provided to communicate to OG how they can move forward as an organization that facilitates and promotes sustainable tourism. The academic contributions of this research and more broadly, the significance of this research study was then outlined. This chapter concluded by identifying areas for future research on the topic, emphasizing the ways in which more specific information about this particular case study can be obtained, as well as the ways in which additional case studies aiming to answer similar research questions within different contexts could be undertaken. The results from this research study demonstrate the potential for smaller organizations and NGOs within the tourism industry to incorporate and prioritize sustainable tourism, and the traction that can be obtained from effective marketing and communication of sustainability efforts and initiatives. 


\section{Appendices}

\section{Appendix A1: Participant Recruitment Email - Category 1 (Alumni)}

Hi there!

You are receiving this email today to see if you are interested in participating in a research study relating to Operation Groundswell.

As an organization, Operation Groundswell (OG) is looking to understand its participants better. OG is hoping to better understand how its alumni and new applicants feel about the range of trips within the environmental program, and the sustainability initiatives undertaken as a company. This study is being conducted by a graduate student at Ryerson University who does not have any prior experience with, nor a professional relationship with OG.

If you are receiving this email, you have participated in at least one OG trip in the past.

Participation in this study would require you to participate in a maximum one-hour long interview with a graduate student at Ryerson University who is conducting research on sustainable tourism. Depending on your location and preference, interviews can be held over Skype or in-person on the Ryerson University campus.

If you choose to participate, you will be entered for a chance to win one of four CAD $\$ 100.00$ gift cards to the outdoor outfitter, Mountain Equipment Co-Op (MEC), valid at any Canadian MEC location. MEC offers a range of gear that you may need for a future OG trip!

If you would like to learn more, please respond to this email and the researcher will be in touch to address any questions you may have. The first 40 individuals who would like to participate in this study will be contacted to set up a date and time for their interview. Interviews will take place during a two-week period in December, 2018.

Thank you for taking the time to read this. We hope you will help OG better understand their alumni so that OG can further prioritize and incorporate environmentally sustainable tourism moving forward. 


\section{Appendix A2: Participant Recruitment Email - Category 2 (Drop-Outs)}

Hi there!

You are receiving this email today to see if you are interested in participating in a research study relating to Operation Groundswell.

As an organization, Operation Groundswell (OG) is looking to understand its participants better. OG is hoping to better understand how its alumni and new applicants feel about the range of trips within the environmental program, and the sustainability initiatives undertaken as a company. This study is being conducted by a graduate student at Ryerson University who does not have any prior experience with, nor a professional relationship with OG.

If you are receiving this email, you have registered for but ultimately have not participated in an OG trip.

Participation in this study would require you to participate in a maximum one-hour long interview with a graduate student at Ryerson University who is conducting research on sustainable tourism. Depending on your location and preference, interviews can be held over Skype or in-person on the Ryerson University campus.

If you choose to participate, you will be entered for a chance to win one of four CAD $\$ 100.00$ gift cards to the outdoor outfitter, Mountain Equipment Co-Op (MEC), valid at any Canadian MEC location. MEC offers a range of gear that you may need for a future OG trip or another adventure!

If you would like to learn more, please respond to this email and the researcher will be in touch to address any questions you may have. The first 40 individuals who would like to participate in this study will be contacted to set up a date and time for their interview. Interviews will take place during a two-week period in December, 2018.

Thank you for taking the time to read this. We hope you will help OG better understand their consumers so that OG can further prioritize and incorporate environmentally sustainable tourism moving forward. 


\section{Appendix A3: Participant Recruitment Email - Category 3 (Prospects)}

Hi there!

You are receiving this email today to see if you are interested in participating in a research study relating to Operation Groundswell.

As an organization, Operation Groundswell (OG) is looking to understand its participants better. OG is hoping to better understand how its alumni and new applications feel about the range of trips within the environmental program, and the sustainability initiatives undertaken as a company. This study is being conducted by a graduate student at Ryerson University who does not have any prior experience with, nor a professional relationship with OG.

If you are receiving this email, you have expressed an interest in OG's product offerings by completing the online inquiry form.

Participation in this study would require you to participate in a maximum one-hour long interview with a graduate student at Ryerson University who is conducting research on sustainable tourism. Depending on your location and preference, interviews can be held over Skype or in-person on the Ryerson University campus.

If you choose to participate, you will be entered for a chance to win one of four CAD $\$ 100.00$ gift cards to the outdoor outfitter, Mountain Equipment Co-Op (MEC), valid at any Canadian MEC location. MEC offers a range of gear that you may need for a future OG trip!

If you would like to learn more, please respond to this email and the researcher will be in touch to address any questions you may have. The first 40 individuals who would like to participate in this study will be contacted to set up a date and time for their interview. Interviews will take place during a two-week period in December, 2018.

Thank you for taking the time to read this. We hope you will help OG better understand their alumni so that $\mathrm{OG}$ can further prioritize and incorporate environmentally sustainable tourism moving forward. 


\title{
Appendix B: Informed Consent Form
}

\author{
Ryerson \\ University \\ TITLE OF STUDY \\ A Consumer Analysis of Operation Groundswell's Environmental Program and Carbon Offset Initiative: \\ Informing Future Business Strategy Pertaining to Sustainable Tourism

\section{PRINCIPAL INVESTIGATOR} \\ The principal investigator of this research study is Halina (Hally) Charendoff, a Master's Student in the \\ Environmental Applied Science and Management program at Ryerson University. Hally can be reached at \\ any time at hcharendoff@ryerson.ca.

\section{PURPOSE OF STUDY} \\ As an organization, Operation Groundswell (OG) is looking to understand its participants better. OG is \\ hoping to better understand how its alumni and new applicants feel about the range of trips within the \\ environmental program, and the sustainability initiatives undertaken as a company. The purpose of this \\ research study, therefore, is to provide OG with an enhanced understanding of their past and prospective \\ participants so they can identify how to further incorporate and prioritize environmentally-sustainable \\ tourism in their product offerings, and in their operations as a company.
}

\section{STUDY PROCEDURES}

Data for this research study is being collected exclusively through semi-structured interviews with OG alumni and prospective participants. Interviews will be conducted via Zoom, or in-person on the Ryerson University campus, depending on the location and preference of research participants. Interviews will not exceed one hour, and there will be no further participation required for the study following interviews. All interviews will be audio recorded so the researcher can transcribe interviews and analyze the data collected. In the reporting of data, all research participants will be referred to by their preferred pseudonyms, which will be collected during interviews. All audio-recordings and interview transcriptions will be destroyed upon successful completion of the researcher's project, which is scheduled for summer 2019.

\section{RISKS}

The risks associated with this research study are very low. There is, however, the risk of a question triggering unpleasant memories or feelings. If any question asked makes you uncomfortable you are permitted to skip to another question or withdraw participation at any time. If you choose to withdraw participation, all data collected up until that point will not be used.

\section{BENEFITS}

By participating in this research study, you will contribute to OG's understanding of their consumers in relation to environmentally-sustainable tourism. By doing so, you will aid in OG's understanding of how to further incorporate environmentally-sustainable tourism into both their product offerings, and their sustainability initiatives as a company. Participation in this study will influence OG's strategy for environmentally-sustainable tourism. Consequently, future trips and sustainability initiatives of the company may take your insights into consideration. I cannot guarantee, however, that you will receive any benefits from partaking in this study.

\section{CONFIDENTIALITY}


While the researcher will have access to the personal information gathered from research participants during data collection, all information will be kept confidential. In the reporting of results, all research participants will be referred to by their preferred pseudonyms. Preferred pseudonyms will be collected during interviews. If a research participant does not have a preferred pseudonym, the researcher will assign one to that individual. All data will be aggregated and personal information such as names and emails will be destroyed upon successful completion of the researcher's project, which is scheduled for summer 2019.

\title{
COMPENSATION
}

All research participants who partake in an interview will be entered for a chance to win one of four CAD $\$ 100.00$ gift cards to the outdoor outfitter, Mountain Equipment Co-Op (MEC), valid at any Canadian MEC location. MEC offers a range of gear that participants may need for a future OG trip. The four winners of the MEC gift cards will be drawn after all interviews have been completed. Winners will be randomly selected using a computer-generated name drawing program and will be notified by email if selected as a winner. MEC gift cards will be sent by mail (post) to the four winners. If you choose to stop participating in the study at any time, you will no longer be eligible for the MEC gift card draw.

\section{CONTACT INFORMATION}

If you have questions about this study or experience adverse effects as a result of participating in this study, you may contact the researcher whose contact information can be found on the first page of this form.

\section{VOLUNTARY PARTICIPATION}

Your participation in this study is voluntary. If you decide to partake, you must complete this informed consent form, acknowledging your understanding of your participation in this research study. After you sign the consent form, you are still free to withdraw participation at any time without needing to provide a reason and without cost. If you decide to withdraw participation at any time, the data collected up until that point will not be used.

\section{CONSENT}

I have read and understand the information provided and have had the opportunity to ask questions before signing this document. I understand that my participation is voluntary and that I am free to withdraw at any time, without giving reason and without cost. If I choose to withdraw at any time, all data collected up until that point will not be used. I voluntarily agree to take part in this research study. I agree to have my interview audio-recorded so the researcher can transcribe and refer back to the information discussed in the interview. I agree to having the data collected from my interview included in the researcher's final research report for her Master's milestone.

Participant's Signature Date

Investigator's Signature Date

\author{
Participant's Initials
}




\title{
Appendix C1: Interview Guide Before Pilot - Category 1 (Alumni)
}

\author{
$\underline{\text { Interview Guide Category 1: Alumni }}$
}

Thank you for agreeing to partake in this research study.

To reiterate, I am a Master's student at Ryerson University with no personal or professional affiliation with Operation Groundswell, so hopefully you feel comfortable to be candid and honest with your responses. This study is being conducted to help Operation Groundswell (referred to from now on as OG) better understand how their consumers feel about their environmental program and their carbon offset initiative. I, the researcher, am conducting interviews with OG's past and prospective participants so that OG can identify if and how they can further incorporate and prioritize environmentally-sustainable tourism into their product offerings and operations as a company.

By partaking in this interview, you will be entered for a chance to win one of four CAD $\$ 100.00$ gift cards to Mountain Equipment Co-Op, valid at any Canadian MEC location. The four winners will be randomly selected once all interviews have been completed, and the four winners will be notified by email and mailing addresses will be collected. The MEC gift cards will be sent by mail (post) to the four winners within 2 months of the final interview which is taking place on December 22nd, 2018.

The researcher will be keeping all personal information (names and contact information) completely confidential in the reporting of result and will not be shared with OG or anyone. Contrary to what I indicated in the informed consent form, I won't be collecting preferred pseudonyms and instead will be assigning a number to each research participant, based on the order in which your interview took place.

At the end of the interview I will ask you to add anything that may not have come up with the questions that I asked. This is an informal discussion so I can understand your perspectives so please feel free to share anything you think is relevant to this study.

This interview will take less than 1 hour to complete.

Before we begin are there any questions or concerns you have about the informed consent form or the interview process?

Let's begin with you telling me a bit about your experience with OG.

\section{Discussion Questions}

1. How did you first hear about OG?

2. What made you want to travel with OG?

3. Which trip(s) did you participate in with OG?

a. What about this particular trip interested you?

4. When you were choosing which of OG's trips to participate in, what were some of the most important factors in your decision-making?

a. E.g. program dates, price, program focus, types of excursions, recommendations from family/friends/peers

5. Was there anything that almost prevented you from travelling with OG?

a. If yes, was it in relation to OG or was it an external factor?

6. OG has 9 primarily core values outlined in their backpactivist manifesto: being prepared to change, living life to the fullest, being conscientious, being respectful, embodying humility, 
engaging with others in solidarity, being group focused, having a thirst for learning, and becoming a leader and agent of change

a. What is your understanding of these core values?

b. What do these core values mean to you?

7. OG's trips are rooted in volunteer tourism, also called voluntourism. How would you define the notion of voluntourism?

8. Do you think voluntourism is a good thing? Why or why not?

9. What were your main motivations for participating in this type of travel (being involved in and contributing to volunteer projects)?

a. Some potential motivations could be wanting to have a different experience outside of your comfort zone, wanting to obtain a deeper understanding of the world around you, wanting to learn more about contemporary global issues, wanting to make a difference in others' lives, or wanting to be selfless and altruistic

10. How did your trip with OG impact you?

a. To what extent are you more aware of social, political, or environmental issues since travelling with OG?

i. How so?

b. To what extent are you inclined to partake in volunteer work at home since travelling with OG?

i. How so?

c. To what extent are you inclined to proactively seek out your own volunteer work when travelling independent from OG or another tour operator?

i. How so?

11. If you were to opt to partake in an environmentally-focused trip with OG (for example, animal conservation, sustainable agriculture or local food production), what environmental focus would you be interested in getting involved with?

a. What experiences/projects/activities would you like to partake in?

12. What elements of the natural environment do you consider the most important?

a. How could these elements be incorporated into an OG trip?

13. How would you define carbon offsetting?

14. Last time you booked, did you come across information about OG's carbon offset initiative on their website?

a. If yes, do you think their communication of this sustainability initiative was effective?

i. If yes, why?; If not, why not?

15. Does knowing about OG's established carbon offset initiative make you more inclined to choose them as a tour operator over another similar company without established sustainability initiatives?

a. If yes, why?; If not, why not?

16. If the carbon offset initiative were voluntary instead of being an included cost, would you opt to contribute to this initiative? Why or why not?

17. Why did you to choose OG over other tour operators?

18. On a scale of $1-5,1$ being the least satisfied and 5 being completely satisfied, how would you rate your experience on the trip(s) you participated in?

19. Were your impressions of the itinerary on the website before travel different from your experiences on the trip?

a. If so, how?

b. What, if anything do you think could be improved to manage prospective participants' expectations of trips with OG?

20. OG has a focus on integrating sustainable tourism into their trips. Do you think OG successfully integrates sustainable tourism into their trips, regardless of it's within the environmental, human rights, health, or education programs? 
a. Why or why not?

b. If not, how do you think they can more effectively integrate sustainable tourism into their trips?

21. Right now, OG has 7 environmental trips including animal conservation, sustainable agriculture, and local food production. Do you think OG has enough environmentally-focused programs compared to their human rights, health, and education program?

a. If yes, why?

b. If no, what topics would you recommend they develop trips around?

22. If you were to travel with OG within the next year (365 days), what program type (environment, human rights, health, education), would you be most likely to participate in and why?

a. What, if anything would make you inclined to participate in an environmentally-focused trip with OG?

23. Is there anything else you would like to discuss or make note of in relation to OG's environmental program or carbon offset initiative? 


\title{
Appendix C2: Interview Guide Before Pilot - Category 2 (Drop-Outs)
}

\author{
Interview Guide Category 2: Drop-Outs
}

Thank you for agreeing to partake in this research study.

To reiterate, I am a Master's student at Ryerson University with no personal or professional affiliation with Operation Groundswell, so hopefully you feel comfortable to be candid and honest with your responses. This study is being conducted to help Operation Groundswell (referred to from now on as OG) better understand how their consumers feel about their environmental program and their carbon offset initiative. I, the researcher, am conducting interviews with OG's past and prospective participants so that OG can identify if and how they can further incorporate and prioritize environmentally-sustainable tourism into their product offerings and operations as a company.

By partaking in this interview, you will be entered for a chance to win one of four CAD $\$ 100.00$ gift cards to Mountain Equipment Co-Op, valid at any Canadian MEC location. The four winners will be randomly selected once all interviews have been completed, and the four winners will be notified by email and mailing addresses will be collected. The MEC gift cards will be sent by mail (post) to the four winners within 2 months of the final interview which is taking place on December 22nd, 2018.

The researcher will be keeping all personal information (names and contact information) completely confidential in the reporting of result and will not be shared with OG or anyone. Contrary to what I indicated in the informed consent form, I won't be collecting preferred pseudonyms and instead will be assigning a number to each research participant, based on the order in which your interview took place.

At the end of the interview I will ask you to add anything that may not have come up with the questions that I asked. This is an informal discussion so I can understand your perspectives so please feel free to share anything you think is relevant to this study.

This interview will take less than 1 hour to complete.

Before we begin are there any questions or concerns you have about the informed consent form or the interview process?

Let's begin with you telling me a bit about your experience with OG.

\section{Discussion Questions}

1. How did you first hear about OG?

2. Was the reason you didn't travel a result of anything to do with OG, i.e. not personal circumstances?

a. If yes, how can OG address this?

3. OG has 9 primarily core values outlined in their backpactivist manifesto: being prepared to change, living life to the fullest, being conscientious, being respectful, embodying humility, engaging with others in solidarity, being group focused, having a thirst for learning, and becoming a leader and agent of change

a. What is your understanding of these core values?

b. What do these core values mean to you?

4. OG's trips are rooted in volunteer tourism, also called voluntourism. How would you define the notion of voluntourism?

5. Do you think voluntourism is a good thing? Why or why not? 
6. What were your main motivations for wanting to participate in this type of travel (being involved in and contributing to volunteer projects)?

a. Some potential motivations could be wanting to have a different experience outside of your comfort zone, wanting to obtain a deeper understanding of the world around you, wanting to learn more about contemporary global issues, wanting to meet like-minded people, wanting to make a difference in others' lives, or wanting to be selfless and altruistic

7. If you were to opt to partake in an environmentally-focused trip with OG (for example, trips focusing on animal conservation, sustainable agriculture or local food production), what environmental focus would you be interested in getting involved with?

a. What experiences/projects/activities would you like to partake in?

8. What elements of the natural environment do you consider the most important?

a. Would you like to see these elements incorporated into an OG trip?

9. How would you define carbon offsetting?

10. Did you come across information about OG's carbon offset initiative on their website?

a. If yes, do you think their communication of this sustainability initiative was effective?

i. If yes, why?; If not, why not?

11. Does knowing that OG has an established carbon offset initiative make you more inclined to choose them as a tour operator over another similar company without established sustainability initiatives?

a. If yes, why; if not, why not?

12. If the carbon offset initiative were voluntary instead of being an included cost, would you opt to contribute to this initiative?

a. Why or why not?

13. Right now, OG has 7 environmental trips including animal conservation, sustainable agriculture, and local food production. Do you think OG should expand their environmental program to include more environmentally-focused trips?

a. If yes, what topics would you recommend they develop trips around?

14. If you were to travel with OG within the next year (365 days), what program type (environment, human rights, health, education), would you be most likely to participate in and why?

a. What would make you inclined to participate in an environmentally-focused trip with OG?

15. Is there anything else you would like to discuss or make note of in relation to OG's environmental program or carbon offset initiative? 


\title{
Appendix C3: Interview Guide Before Pilot - Category 3 (Prospects)
}

\author{
Interview Guide Category 3: Prospects
}

Thank you for agreeing to partake in this research study.

To reiterate, I am a Master's student at Ryerson University with no personal or professional affiliation with Operation Groundswell, so hopefully you feel comfortable to be candid and honest with your responses. This study is being conducted to help Operation Groundswell (referred to from now on as OG) better understand how their consumers feel about their environmental program and their carbon offset initiative. I, the researcher, am conducting interviews with OG's past and prospective participants so that OG can identify if and how they can further incorporate and prioritize environmentally-sustainable tourism into their product offerings and operations as a company.

By partaking in this interview, you will be entered for a chance to win one of four CAD $\$ 100.00$ gift cards to Mountain Equipment Co-Op, valid at any Canadian MEC location. The four winners will be randomly selected once all interviews have been completed, and the four winners will be notified by email and mailing addresses will be collected. The MEC gift cards will be sent by mail (post) to the four winners within 2 months of the final interview which is taking place on December 22nd, 2018.

The researcher will be keeping all personal information (names and contact information) completely confidential in the reporting of result and will not be shared with OG or anyone. Contrary to what I indicated in the informed consent form, I won't be collecting preferred pseudonyms and instead will be assigning a number to each research participant, based on the order in which your interview took place.

At the end of the interview I will ask you to add anything that may not have come up with the questions that I asked. This is an informal discussion so I can understand your perspectives so please feel free to share anything you think is relevant to this study.

This interview is expected to take less than 1 hour to complete, depending on the length of your answers.

Before we begin are there any questions or concerns you have about the informed consent form or the interview process?

Let's begin with you telling me a bit about your experience with OG.

\section{Discussion Questions}

1. How did you first hear about OG?

2. What made you want to learn more about OG by filling out their online inquiry form?

3. When you filled out the online inquiry form, was it to find out more about a specific program (human rights, health, environment, education), or OG in general?

4. If you were inquiring about a specific program, which program was it and why were you interested in it?

5. OG has 9 primarily core values outlined in their backpactivist manifesto: being prepared to change, living life to the fullest, being conscientious, being respectful, embodying humility, engaging with others in solidarity, being group focused, having a thirst for learning, and becoming a leader and agent of change

a. What is your understanding of these core values?

b. What do these core values mean to you? 
6. OG's trips are rooted in volunteer tourism, also called voluntourism. How would you define the notion of voluntourism?

7. Do you think voluntourism is a good thing? Why or why not?

8. What were your main motivations for inquiring about this type of travel (being involved in and contributing to volunteer projects)?

a. Some potential motivations could be wanting to have a different experience outside of your comfort zone, wanting to obtain a deeper understanding of the world around you, wanting to learn more about contemporary global issues, wanting to make a difference in others' lives, or wanting to be selfless and altruistic

9. If you were to opt to partake in an environmentally-focused trip with OG (for example, trips focusing on animal conservation, sustainable agriculture or local food production), what environmental focus would you be interested in getting involved with?

a. What experiences/projects/activities would you like to partake in?

10. What elements of the natural environment do you consider the most important?

a. Would you like to see these elements incorporated into an OG trip?

11. How would you define carbon offsetting?

12. Did you come across information about OG's carbon offset initiative on their website?

a. If yes, do you think their communication of this sustainability initiative was effective?

i. If yes, why?; If not, why not?

13. Does knowing that OG has an established carbon offset initiative make you more inclined to choose them as a tour operator over another similar company without established sustainability initiatives?

a. If yes, why; if not, why not?

14. If the carbon offset initiative were voluntary instead of being an included cost, would you opt to contribute to this initiative?

a. Why or why not?

15. Did you come across any other organizations that are offering a similar product as OG?

a. If yes, which one(s)

b. If yes, is there anything that differentiates OG?

c. If yes, is there anything you would recommend OG improves upon?

16. Right now, OG has 7 environmental trips including animal conservation, sustainable agriculture, and local food production. Do you think OG should expand their environmental program to include more environmentally-focused trips?

a. If yes, what topics would you recommend they develop trips around?

17. If you were to travel with OG within the next year (365 days), what program type (environment, human rights, health, education), would you be most likely to participate in and why?

a. What would make you inclined to participate in an environmentally-focused trip with OG?

18. Is there anything else you would like to discuss or make note of in relation to OG's environmental program or carbon offset initiative? 


\title{
Appendix D1: Interview Guide After Pilot - Category 1 (Alumni)
}

\author{
$\underline{\text { Interview Guide Category 1: Alumni }}$
}

Thank you for agreeing to partake in this research study.

To reiterate, I am a Master's student at Ryerson University with no personal or professional affiliation with Operation Groundswell, so hopefully you feel comfortable to be candid and honest with your responses. This study is being conducted to help Operation Groundswell (referred to from now on as OG) better understand how their consumers feel about their environmental program and their carbon offset initiative. I, the researcher, am conducting interviews with OG's past and prospective participants so that OG can identify if and how they can further incorporate and prioritize environmentally-sustainable tourism into their product offerings and operations as a company.

By partaking in this interview, you will be entered for a chance to win one of four CAD $\$ 100.00$ gift cards to Mountain Equipment Co-Op, valid at any Canadian MEC location. The four winners will be randomly selected once all interviews have been completed, and the four winners will be notified by email and mailing addresses will be collected. The MEC gift cards will be sent by mail (post) to the four winners within 2 months of the final interview which is taking place on December 22nd, 2018.

The researcher will be keeping all personal information (names and contact information) completely confidential in the reporting of result and will not be shared with OG or anyone. Contrary to what I indicated in the informed consent form, I won't be collecting preferred pseudonyms and instead will be assigning a number to each research participant, based on the order in which your interview took place.

At the end of the interview I will ask you to add anything that may not have come up with the questions that I asked. This is an informal discussion so I can understand your perspectives so please feel free to share anything you think is relevant to this study.

This interview will take less than 1 hour to complete.

Before we begin are there any questions or concerns you have about the informed consent form or the interview process?

Let's begin with you telling me a bit about your experience with OG.

\section{$\underline{\text { Discussion Questions }}$}

1. How did you first hear about OG?

2. What made you want to travel with OG?

3. Which trip(s) did you participate in with OG?

a. What about this particular trip interested you?

4. When you were choosing which of OG's trips to participate in, what were some of the most important factors in your decision-making?

a. E.g. program dates, price, program focus, types of excursions, recommendations from family/friends/peers

5. Was there anything that almost prevented you from travelling with OG?

a. If yes, was it in relation to OG or was it an external factor?

6. OG's trips are rooted in volunteer tourism, also called voluntourism. How would you define the notion of voluntourism?

7. Do you think voluntourism is a good thing? Why or why not? 
8. What were your main motivations for participating in this type of travel (being involved in and contributing to volunteer projects)?

a. Some potential motivations could be wanting to have a different experience outside of your comfort zone, wanting to obtain a deeper understanding of the world around you, wanting to learn more about contemporary global issues, wanting to make a difference in others' lives, or wanting to be selfless and altruistic

9. How did your trip with OG impact you?

a. To what extent are you more aware of social, political, or environmental issues since travelling with OG?

i. How so?

b. To what extent are you inclined to partake in volunteer work at home since travelling with OG?

i. How so?

c. To what extent are you inclined to proactively seek out your own volunteer work when travelling independent from OG or another tour operator?

i. How so?

10. If you were to opt to partake in an environmentally-focused trip with OG (for example, animal conservation, sustainable agriculture or local food production), what environmental focus would you be interested in getting involved with?

a. What experiences/projects/activities would you like to partake in?

11. What elements of the natural environment do you consider the most important?

a. How could these elements be incorporated into an OG trip?

12. Have you heard of the term carbon offsetting?

a. If yes, are you comfortable telling me how you would define carbon offsetting?

13. Last time you booked or reviewed OG's website, did you come across information about OG's carbon offset initiative on their website?

a. If yes, do you think their communication of this sustainability initiative was effective?

i. If yes, why?; If not, why not?

14. Does knowing about OG's established carbon offset initiative make you more inclined to choose them as a tour operator over another similar company without established sustainability initiatives?

a. If yes, why?; If not, why not?

15. If the carbon offset initiative were voluntary instead of being an included cost, would you opt to contribute to this initiative? Why or why not?

16. Why did you to choose OG over other tour operators?

17. On a scale of $1-5,1$ being the least satisfied and 5 being completely satisfied, how would you rate your experience on the trip(s) you participated in?

18. Were your impressions of the itinerary on the website before travel different from your experiences on the trip?

a. If so, how?

b. What, if anything do you think could be improved to manage prospective participants' expectations of trips with OG?

19. OG has a focus on integrating sustainable tourism into their trips. Do you think OG successfully integrates sustainable tourism into their trips, regardless of it's within the environmental, human rights, health, or education programs?

a. Why or why not?

b. If not, how do you think they can more effectively integrate sustainable tourism into their trips?

20. Right now, OG has 7 environmental trips including animal conservation, sustainable agriculture, and local food production. Do you think OG has enough environmentally-focused programs compared to their human rights, health, and education program? 
a. If yes, why?

b. If no, what topics would you recommend they develop trips around?

21. If you were to travel with OG within the next year (365 days), what program type (environment, human rights, health, education), would you be most likely to participate in and why?

a. What would make you inclined to participate in an environmentally-focused trip with OG?

22. Is there anything else you would like to discuss or make note of in relation to OG's environmental program or carbon offset initiative? 


\title{
Appendix D2: Interview Guide After Pilot - Category 2 (Drop-Outs)
}

\author{
Interview Guide Category 2: Drop-Outs
}

Thank you for agreeing to partake in this research study.

To reiterate, I am a Master's student at Ryerson University with no personal or professional affiliation with Operation Groundswell, so hopefully you feel comfortable to be candid and honest with your responses. This study is being conducted to help Operation Groundswell (referred to from now on as OG) better understand how their consumers feel about their environmental program and their carbon offset initiative. I, the researcher, am conducting interviews with OG's past and prospective participants so that OG can identify if and how they can further incorporate and prioritize environmentally-sustainable tourism into their product offerings and operations as a company.

By partaking in this interview, you will be entered for a chance to win one of four CAD $\$ 100.00$ gift cards to Mountain Equipment Co-Op, valid at any Canadian MEC location. The four winners will be randomly selected once all interviews have been completed, and the four winners will be notified by email and mailing addresses will be collected. The MEC gift cards will be sent by mail (post) to the four winners within 2 months of the final interview which is taking place on December 22nd, 2018.

The researcher will be keeping all personal information (names and contact information) completely confidential in the reporting of result and will not be shared with OG or anyone. Contrary to what I indicated in the informed consent form, I won't be collecting preferred pseudonyms and instead will be assigning a number to each research participant, based on the order in which your interview took place.

At the end of the interview I will ask you to add anything that may not have come up with the questions that I asked. This is an informal discussion so I can understand your perspectives so please feel free to share anything you think is relevant to this study.

This interview will take less than 1 hour to complete.

Before we begin are there any questions or concerns you have about the informed consent form or the interview process?

Let's begin with you telling me a bit about your experience with OG.

\section{$\underline{\text { Discussion Questions }}$}

1. How did you first hear about OG?

2. Was the reason you didn't travel a result of anything to do with OG, i.e. not personal circumstances?

a. If yes, how can OG address this?

3. How would you describe OG's mission and values?

4. OG's trips are rooted in volunteer tourism, also called voluntourism. How would you define the notion of voluntourism?

5. Do you think voluntourism is a good thing? Why or why not?

6. What were your main motivations for wanting to participate in this type of travel (being involved in and contributing to volunteer projects)?

a. Some potential motivations could be wanting to have a different experience outside of your comfort zone, wanting to obtain a deeper understanding of the world around you, wanting to learn more about contemporary global issues, wanting to meet like-minded 
people, wanting to make a difference in others' lives, or wanting to be selfless and altruistic

7. If you were to opt to partake in an environmentally-focused trip with OG (for example, trips focusing on animal conservation, sustainable agriculture or local food production), what environmental focus would you be interested in getting involved with?

a. What experiences/projects/activities would you like to partake in?

8. What elements of the natural environment do you consider the most important?

a. How could these elements be incorporated into an OG trip?

9. Have you heard of the term carbon offsetting?

a. If yes, are you comfortable telling me how you would define carbon offsetting?

10. Did you come across information about OG's carbon offset initiative on their website?

a. If yes, do you think their communication of this sustainability initiative was effective?

i. If yes, why?; If not, why not?

11. Does knowing that OG has an established carbon offset initiative make you more inclined to choose them as a tour operator over another similar company without established sustainability initiatives?

a. If yes, why; if not, why not?

12. If the carbon offset initiative were voluntary instead of being an included cost, would you opt to contribute to this initiative?

a. Why or why not?

13. Right now, OG has 7 environmental trips including animal conservation, sustainable agriculture, and local food production. Do you think OG should expand their environmental program to include more environmentally-focused trips?

a. If yes, what topics would you recommend they develop trips around?

14. If you were to travel with OG within the next year (365 days), what program type (environment, human rights, health, education), would you be most likely to participate in and why?

a. What would make you inclined to participate in an environmentally-focused trip with OG?

15. Is there anything else you would like to discuss or make note of in relation to OG's environmental program or carbon offset initiative? 


\title{
Appendix D3: Interview Guide After Pilot - Category 3 (Prospects)
}

\author{
Interview Guide Category 3: Prospects
}

Thank you for agreeing to partake in this research study.

To reiterate, I am a Master's student at Ryerson University with no personal or professional affiliation with Operation Groundswell, so hopefully you feel comfortable to be candid and honest with your responses. This study is being conducted to help Operation Groundswell (referred to from now on as OG) better understand how their consumers feel about their environmental program and their carbon offset initiative. I, the researcher, am conducting interviews with OG's past and prospective participants so that OG can identify if and how they can further incorporate and prioritize environmentally-sustainable tourism into their product offerings and operations as a company.

By partaking in this interview, you will be entered for a chance to win one of four CAD $\$ 100.00$ gift cards to Mountain Equipment Co-Op, valid at any Canadian MEC location. The four winners will be randomly selected once all interviews have been completed, and the four winners will be notified by email and mailing addresses will be collected. The MEC gift cards will be sent by mail (post) to the four winners within 2 months of the final interview which is taking place on December 22nd, 2018.

The researcher will be keeping all personal information (names and contact information) completely confidential in the reporting of result and will not be shared with OG or anyone. Contrary to what I indicated in the informed consent form, I won't be collecting preferred pseudonyms and instead will be assigning a number to each research participant, based on the order in which your interview took place.

At the end of the interview I will ask you to add anything that may not have come up with the questions that I asked. This is an informal discussion so I can understand your perspectives so please feel free to share anything you think is relevant to this study.

This interview is expected to take less than 1 hour to complete, depending on the length of your answers.

Before we begin are there any questions or concerns you have about the informed consent form or the interview process?

Let's begin with you telling me a bit about your experience with OG.

\section{Discussion Questions}

1. How did you first hear about OG?

2. What made you want to learn more about OG by filling out their online inquiry form?

3. When you filled out the online inquiry form, was it to find out more about a specific program (human rights, health, environment, education), or OG in general?

4. If you were inquiring about a specific program, which program was it and why were you interested in it?

5. How would you describe OG's mission and values?

6. OG's trips are rooted in volunteer tourism, also called voluntourism. How would you define the notion of voluntourism?

7. Do you think voluntourism is a good thing? Why or why not?

8. What were your main motivations for inquiring about this type of travel (being involved in and contributing to volunteer projects)? 
a. Some potential motivations could be wanting to have a different experience outside of your comfort zone, wanting to obtain a deeper understanding of the world around you, wanting to learn more about contemporary global issues, wanting to make a difference in others' lives, or wanting to be selfless and altruistic

9. If you were to opt to partake in an environmentally-focused trip with OG (for example, trips focusing on animal conservation, sustainable agriculture or local food production), what environmental focus would you be interested in getting involved with?

a. What experiences/projects/activities would you like to partake in?

10. What elements of the natural environment do you consider the most important?

a. How could these elements be incorporated into an OG trip?

11. How would you define carbon offsetting?

12. Did you come across information about OG's carbon offset initiative on their website?

a. If yes, do you think their communication of this sustainability initiative was effective?

i. If yes, why?; If not, why not?

13. Does knowing that OG has an established carbon offset initiative make you more inclined to choose them as a tour operator over another similar company without established sustainability initiatives?

a. If yes, why; if not, why not?

14. If the carbon offset initiative were voluntary instead of being an included cost, would you opt to contribute to this initiative?

a. Why or why not?

15. Did you come across any other organizations that are offering a similar product as OG?

a. If yes, which one(s)

b. If yes, is there anything that differentiates OG?

c. If yes, is there anything you would recommend OG improves upon?

16. Right now, OG has 7 environmental trips including animal conservation, sustainable agriculture, and local food production. Do you think OG should expand their environmental program to include more environmentally-focused trips?

a. If yes, what topics would you recommend they develop trips around?

17. If you were to travel with OG within the next year (365 days), what program type (environment, human rights, health, education), would you be most likely to participate in and why?

a. What would make you inclined to participate in an environmentally-focused trip with OG?

18. Is there anything else you would like to discuss or make note of in relation to OG's

environmental program or carbon offset initiative? 


\section{Appendix E: Example of NVivo Nodes and Theme Organization}

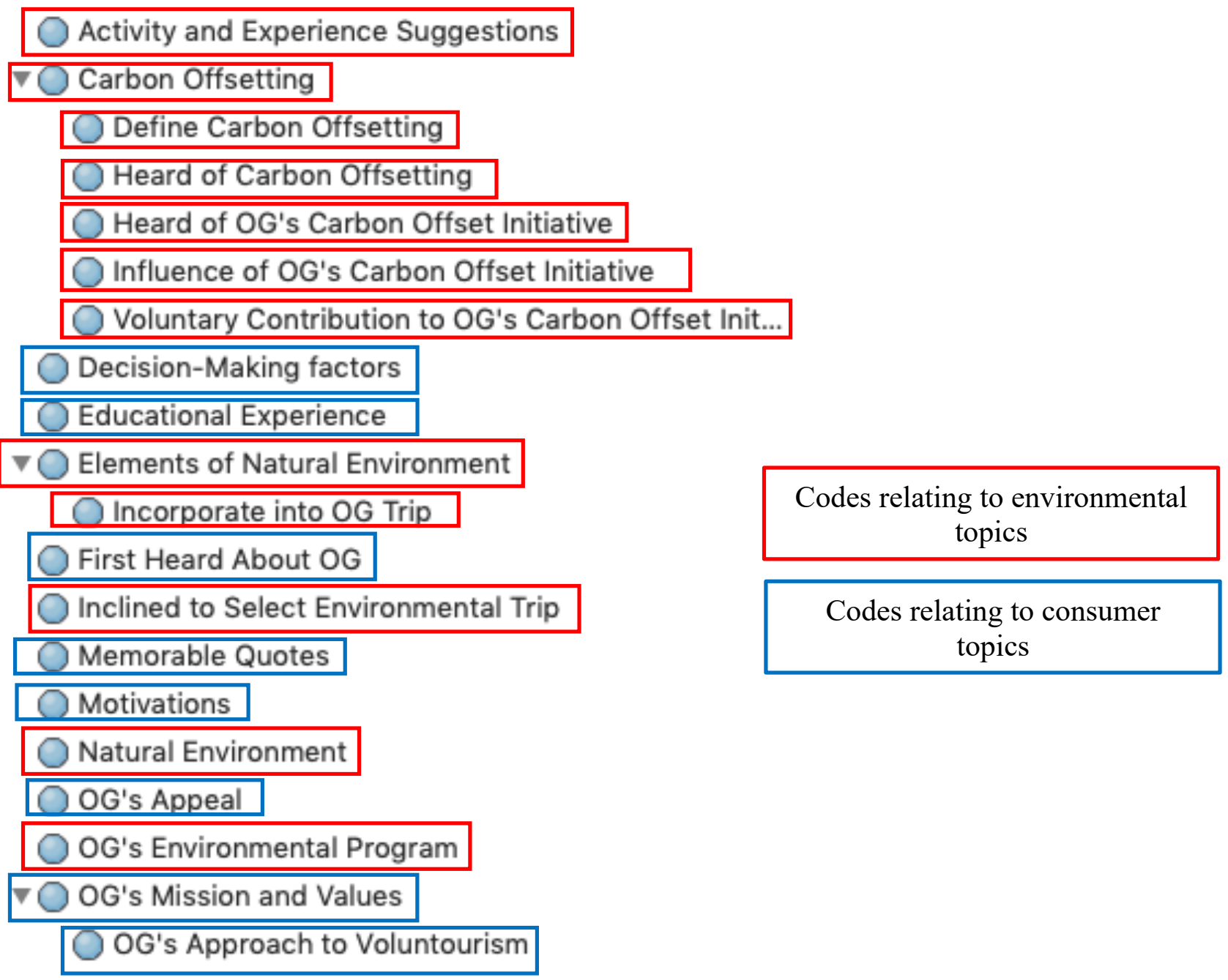




\section{References}

Aall, C. (2014). Sustainable Tourism in Practice: Promoting or Perverting the Quest for Sustainable Development? Sustainability, 6, 2562-2583.

Alberini, A., \& Segerson, K. (2002). Assessing Voluntary Programs to Improve Environmental Quality. Environmental and Resource Economics, 22, 157-184.

Ambec, S. \& Lanoie, P. (2008). Does It Pay to Be Green? A Systematic Overview. Academy of Management Perspectives, 22(4), 45-62.

Andereck, K., Valentine, K.M., Knopf, R.C., \& Vogt, C.A. (2005). Residents' Perceptions of Community Tourism Impacts. Annals of Tourism Research, 32(4), 1056-1076.

Andereck, K. \& Nyaupane, G.P. (2011). Exploring the Nature of Tourism and QOL Perceptions Among Residents. Journal of Travel Research, 50(3), 248-260.

Andereck, K., McGehee, N.G., Lee, S., \& Clemmons, D. (2012). Experience Expectations of Prospective Volunteer Tourists. Journal of Travel Research, 51(2), 130-141.

Aragon-Correa, J. A., Martin-Tapia, I., \& De La Torre-Ruiz, J. (2015). Sustainability Issues and Hospitality and Tourism Firms' Strategies. International Journal of Contemporary Hospitality Management. 27(3), 498-522.

Arana, J., Leon, C., Moreno-Gil, S., \& Zubiaurre, A. (2013). A Comparison of Tourists' Valuation of Climate Change Policy Using Different Pricing Frame. Journal of Travel Research, 52(1), 82-92.

Atkins, S.G. (2012). Smartening-Up Voluntourism: SmartAid's Expansion of the PersonalityFocused Performance Requirements Form (PPRF). International Journal of Tourism Research, 14, 369-390.

Ayuso, S. (2006). Adoption of Voluntary Environmental Tools for Sustainable Tourism: Analyzing the Experience of Spanish Hotels. Corporate Social Responsibility and Environmental Management, 13, 207-220.

Ayuso, S. (2007). Comparing Voluntary Policy Instruments for Sustainable Tourism: The Experience of the Spanish Hotel Sector. Journal of Sustainable Tourism, 15(2), 144-159.

Babakhani, N., Ritchie, B.W. \& Dolnicar, S. (2017). Improving Carbon Offsetting Appeals in Online Airplane Ticket Purchasing: Testing New Messages and Using New Test Methods. Journal of Sustainable Tourism, 25(7), 955-969.

Babbie, E. \& Benaquisto, L. (2010). Fundamentals of Social Research (Second Canadian Edition). Toronto, ON: Nelson. 
Bailey, A.W. \& Russell, K.C. (2012). Volunteer Tourism: Powerful Programs or Predisposed Participants? Journal of Hospitality and Tourism Management, 19, 123-132.

Ballantyne, R., Packer, J. \& Hughes, K. (2009). Tourists' Support for Conservation Messages and Sustainable Management Practices in Wildlife Tourism Experiences. Tourism Management, 30(5), 658-664.

Banki, S. \& Schonell, R. (2018). Voluntourism and the Contract Corrective. Third World Quarterly, 39(8), 1475-1490.

Becken, S. (2004). How Tourists and Tourism Experts Perceive Climate Change and CarbonOffsetting Schemes. Journal of Sustainable Tourism, 12(4), 332-345.

Becken, S. \& Mackey, B. (2017). What Role for Offsetting Aviation Greenhouse Gas Emissions in a Deep-Cut Carbon World? Journal of Air Transport Management, 63, 71-83.

Blackman, D.A. \& Benson, A.M. (2010). The Role of the Psychological Contract in Managing Research Volunteer Tourism. Journal of Travel and Tourism Marketing, 27, 221-235.

Boluk, K., Kline, C. \& Stroobach, A. (2016). Exploring the Expectations and Satisfaction Derived from Volunteer Tourism Experiences. Tourism and Hospitality Research, 17(3), 272-285.

Boote, D. N., \& Beile, P. (2005). Scholars before Researchers: On the Centrality of the Dissertation Literature Review in Research Preparation. American Educational Research Association, 34(6), 3-15.

Borden, D.S., Coles, T., \& Shaw, G. (2017). Social Marketing, Sustainable Tourism, and Small/Medium Size Tourism Enterprises: Challenges and Opportunities for Changing Guest Behaviour. Journal of Sustainable Tourism, 25(7), 903-920.

Bows, A., Anderson, K., \& Peeters, P. (2009). Air Transport, Climate Change and Tourism. Tourism \& Hospitality: Planning \& Development, 6(1), 7-20.

Broad, S. (2003). Living the Thai Life - A Case Study of Volunteer Tourism at the Gibbon Rehabilitation Project, Thailand. Tourism Recreation Research, 28(3), 63-72.

Broad S, \& Jenkins J. (2008). Gibbons in Their Midst? Conservation Volunteers' Motivations at the Gibbon Rehabilitation Project, Phuket, Thailand. In Journeys of Discovery in Volunteer Tourism, Lyon, K. \& Wearing S. CABI Publishing: Cambridge, MA; 72-85. Brown P. 2003. Mi

Brondo, K.V., Kent, S. \& Hill, A. (2016). Teaching Collaborative Environmental Anthropology: A Case Study Embedding Engaged Scholarship in Critical Approaches to Voluntourism. Annals of Anthropological Practice, 40(2), 193-206. 
Brown, S. (2005). Travelling with a Purpose: Understanding the Motives and Benefits of Vacationers. Current Issues in Tourism, 8(6), 479-496.

Buckley, R. (2012). Sustainable Tourism: Research and Reality. Annals of Tourism Research, 39(2), 528-546.

Budeanu, A. (2005). Impacts and Responsibilities for Sustainable Tourism: A Tour Operator's Perspective. Journal of Cleaner Production, 13(2), 89-97.

Bumpus, A.G. \& Liverman, D.M. (2008). Accumulation by Decarbonization and the Governance of Carbon Offsets. Economic Geography, 84(2), 127-155.

Caric, H. \& Mackelworth, P. (2014). Cruise Tourism Environmental Impacts - The Perspective from the Adriatic Sea. Ocean and Coastal Management, 102, 350-363.

Cheer, J. M., Milano, C. \& Novelli, M. (2019). Tourism and Community Resilience in the Anthropocene: Accentuating Temporal Overtourism. Journal of Sustainable Tourism, 27(4), 554-572.

Choi, C., Chort, V., Jayawardena, C., Kibicho, W. \& Pollard, A. (2013). Trends and Sustainability in the Canadian Tourism and Hospitality Industry. Worldwide Hospitality and Tourism Themes, 5(2), 132-150.

Coghlan, A. (2008). Exploring the Role of Expedition Staff in Volunteer Tourism. International Journal of Tourism Research, 10, 183-191.

Cohen, R. \& Kennedy, P. (2000). Global Sociology. Houndsmills, Basingstoke, UK: Macmillan Press.

Conn, V.S. (2017). Don't Rock the Analytical Boat: Correlation Is Not Causation. Western Journal of Nursing Research, 39(6), 731-732.

Coren, N. \& Gray, T. (2012). Commodification of Volunteer Tourism: A Comparative Study of Volunteer Tourists in Vietnam and Thailand. International Journal of Tourism Research, $14,222-234$.

Creswell, J.W. (2007). Qualitative Inquiry and Research Design: Choosing Among Five Approaches (2 ${ }^{\text {nd }}$ Edition). Thousand Oaks, CA: Sage.

Curtin, S. \& Busby, G. (1999). Sustainable Destination Development: The Tour Operator Perspective. International Journal of Tourism Research, 1, 135-147.

Dodds, R. \& Graci, S. (2009). Canada's Tourism Industry - Mitigating the Effects of Climate Change: A Lot of Concern but Little Action. Tourism and Hospitality Planning \& Development, 6(1), 39-51. 
Dodds, R. \& Kuehnel, J. (2010). CSR Among Canadian Mass Tour Operators: Good Awareness but Little Action. International Journal of Contemporary Hospitality Management, 22(2), 221-224.

Dodds, R., Kelman, I., Thiesen, N., Bessada, T., Garcia, J. \& McDougall, A. (2012). Industry Perspectives on Carbon Offsetting Programs in Canada and the United States. Sustainability: Science, Practice, \& Policy, 8(2): 31-4.

Dodds, R. (2013). Will Tourists Pay for A Healthy Environment? Assessing Visitors' Perceptions and Willingness to Pay for Conservation and Preservation in the Island of Koh Phi Phi, Thailand. International Journal of Tourism Anthropology, 3(1), 28-42.

Dodds, R. \& Holmes, M. (2016). Is There a Benefit from Being Green? Assessing Benefits from Marketing Sustainability by North American Hotels. Journal of Hotel and Business Management, 5(2), 1-9.

Easterling, D. (2004). The Residents' Perspective in Tourism Research: A Review and Synthesis. Journal of Travel \& Tourism Marketing, 17(4), 45-62.

Foller-Carroll, A. \& Charlebois, S. (2016). The Attitudes of Students and Young Professionals Toward Voluntourism: A Study Abroad Perspective. International Journal of Culture, Tourism and Hospitality Research, 10(2), 138-160.

Fusch, P.I. \& Ness, L.R. (2015). Are We There Yet? Data Saturation in Qualitative Research. The Qualitative Report 2015, 20(9), 1408-1416.

Garay, L. Gomis, J.M. \& Gonzalez, F. (2018). The Value of Sustainability as a Factor of Differentiation in the Tourism Intermediation Process: An Analysis of Catalan SMEs. Cuadernos de Turismo, 41, 669-673.

Germann Molz, J. (2017). Giving Back, Doing Good, Feeling Global: The Affective Flows of Family Voluntourism. Journal of Contemporary Ethnography, 46(3), 334-360.

Gjerald, O. (2005). Sociocultural Impacts of Tourism: A Case Study from Norway. Journal of Tourism and Cultural Change, 3(1), 36-58.

Goffi, G., Masiero, L., \& Pencarelli, T. (2018). Rethinking Sustainability in the Tour-Operating Industry: Worldwide Survey of Current Attitudes and Behaviours. Journal of Cleaner Production, 183, 172-182.

Gossling, S. (2002). Global Environmental Consequences of Tourism. Global Environmental Change, 12(4), 283-302.

Gossling, S., Broderick, J., Ceron, J.P., Dubois, G., Peeters, P. \& Strasdas, W. (2007). Voluntary Carbon Offsetting Schemes for Aviation: Efficiency, Credibility and Sustainable Tourism. Journal of Sustainable Tourism, 15(3), 223-248. 
Gossling, S. \& Peeters, P. (2015). Assessing Tourism's Global Environmental Impact 19002050. Journal of Sustainable Tourism, 23(5), 639-659.

Goulding, C. (1999). Consumer Research, Interpretive Paradigms and Methodological Ambiguities. European Journal of Marketing, 33(9/10), 859-873.

Greathouse-Amador, L.M. (2005). Tourism and Policy in Preserving Minority Languages and Culture: The Cuetzalan Experience. Review of Policy Research, 22(1), 49-58.

Green, J.F. (2017). Blurred Lines: Public-Private Interactions in Carbon Regulations. International Interactions, 43(1), 103-128.

Grimm, K. E. and Needham, M.D. (2012) Moving beyond the "I" in Motivation: Attributes and Perceptions of Volunteer Tourists. Journal of Travel Research 51(4), 488-501.

Gursoy, D. \& Rutherford, D.G. (2004). Host Attitudes Toward Tourism: An Improved Structural Model. Annals of Tourism Research, 31(3), 495-516.

Gurung, D.B. \& Seeland, K. (2011). Ecotourism Benefits and Livelihood Improvement for Sustainable Development in the Nature Conservation Areas of Bhutan. Sustainable Development, 19(5), 348-358.

Guttentag, D.A. (2009). The Possible Negative Impacts of Volunteer Tourism. International Journal of Tourism Research, 11, 537-551.

Hammersley, L.A. (2014). Volunteer Tourism: Building Effective Relationships of Understanding. Journal of Sustainable Tourism, 22(6), 855-873.

Han, H., \& Yoon, H.J. (2015). Hotel Customers' Environmentally Responsible Behavioral Intention: Impact of Key Constructs on Decision in Green Consumerism. International Journal of Hospitality Management, 45, 22-33.

Hasanova, N. (2017). Voluntourism: Who Are We Truly Helping? Journal of Prenatal \& Neonatal Nursing, 30(2), 93-94.

Hashemkhani Zolfani, S., Sedaghat, M., Maknoon, R., \& Kazimieras Zavadskas, E. (2015). Sustainable Tourism: A Comprehensive Literature Review on Frameworks and Applications. Economic Research, 28(1), 1-30.

Hockerts, K. (2015). A Cognitive Perspective on the Business Case for Corporate Sustainability. Business Strategy and the Environment, 24, 102-122.

Huang, Y., Wu, J., \& Shi, W. (2018). The Impact of Font Choice on Web Pages: Relationship with Willingness to Pay and Tourism Motivation. Tourism Management, 66, 191-199. 
Hughes, G. (2002). Environmental Indicators. Annals of Tourism Research, 29(2), 457-477.

Hwang, K. \& Lee, J. (2018). Antecedents and Consequences of Ecotourism Behaviour: Independent and Interdependent self-Construals, Ecological Belief, Willingness to Pay for Ecotourism Services and Satisfaction with Life. Sustainability, 10(3), 1-18.

Hyams, K. \& Fawcett, T. (2013). The Ethics of Carbon Offsetting. Wiley Interdisciplinary Reviews: Climate Change, 4(2), 91-98.

Kasim, A. (2006). The Need for Business Environmental and Social Responsibility in the Tourism Industry. International Journal of Hospitality \& Tourism Administration, 7(1), $1-22$.

Kreiss, C., Nasr, N. \& Kashmanian, R. (2016). Making the Business Case for Sustainability: How to Account for Intangible Benefits - A Case Study Approach. Environmental Quality Management, 26(1), 5-24.

Larson, R.B. (2018). Controlling Social Desirability Bias. International Journal of Market Research, 00(0)

Leech, N.L. \& Onwuegbuzie, A.J. (2011). Beyond Constant Comparison Qualitative Data Analysis: Using NVivo. School Psychology Quarterly, 26(1), 70-84.

Lenzen, M., Sun, Y.Y., Faturay, F., Ting, Y.P., Geschke, A. \& Malik, A. (2018). The Carbon Footprint of Global Tourism. Nature Climate Change, 8, 522-528.

Lepp, A. (2008). Discovering Self and Discovering Others Through the Taita Discovery Centre Volunteer Tourism Programme, Kenya. In Journeys of Discovery in Volunteer Tourism, Lyon, K. \& Wearing, S. CABI Publishing: Cambridge, MA; 86-100.

Liston-Heyes, C. \& Daley, C. (2017). Voluntourism, Sensemaking, and The Leisure-Volunteer Duality. Tourist Studies, 17(3), 283-305.

Lo, A.S. \& Lee, C.Y.S. (2011). Motivations and Perceived Value of Volunteer Tourists from Hong Kong. Tourism Management (32), 326-334.

Lovell, H., Bulkeley, H. \& Liverman, D. (2009). Carbon Offsetting: Sustaining Consumption? Environment and Planning A, 41(10), 2357- 2379.

Luh Sin, H., Oakes, T. \& Mostafanezhad, M. (2015). Travelling for a Cause: Critical Examinations of Volunteer Tourism and Social Justice. Tourist Studies, 15(2), 119-131.

Machado, P.M., Siciu, M.C., Costa, L.L., Tavares, D.C. \& Zalmon, I.R. (2017). Tourism Impacts on Benthic Communities of Sandy Beaches. Marine Ecology, 38(4), 1-11. 
Mair, J. (2011). Exploring Air Travellers' Voluntary Carbon-Offsetting Behaviour. Journal of Sustainable Tourism, 19(2), 215-230.

Maslow, A.H. (1954) Motivation and Personality. New York: Harper and Brothers.

Maslow, A.H. (1970) Motivation and Personality (3rd Edition). New York: Harper and Row.

Mbaiwa, J.E. (2003). The Socio-Economic and Environmental Impacts of Tourism Development on the Okavango Delta, North-Western Botswana. Journal of Arid Environments, 54(2). $447-467$.

Mbaiwa, J.E. (2004). The Socio-Cultural Impacts of Tourism Development in the Okavango Delta, Botswana. Journal of Tourism and Cultural Change, (2)3, 163-184.

McGehee, N.G. \& Santos, C.A. (2005). Social Change, Discourse and Volunteer Tourism. Annals of Tourism Research, 32(3), 760-779.

McGloin, C. \& Georgeou, N. (2016). "Looks Good on Your CV": The Sociology of Voluntourism Recruitment in Higher Education. Journal of Sociology, 52(2), 403-417.

McIntosh, A.J. \& Zahra, A. (2007). A Cultural Encounter Through Volunteer Tourism: Towards the Ideals of Sustainable Tourism? Journal of Sustainable Tourism, 15(5), 541-556.

Melissen, F., Cavagnaro, E., Damen, M., \& Duewke, A. (2016). Is the Hotel Industry Prepared to Face the Challenge of Sustainable Development? Journal of Vacation Marketing, 22(3), 227-238.

Merriam, S.B. (2009). Qualitative Research: A Guide to Design and Implementation. San Francisco, CA: Jossey-Bass.

Mohd Suki, N., \& Mohd Suki, N. (2015). Consumers' Environmental Behaviour Towards Staying at a Green Hotel: Moderation of Green Hotel Knowledge. Management of Environmental Quality, 26(1), 103-117.

Murtagh, B., Boland, P. \& Shirlow, P. (2017). Contested Heritages and Cultural Tourism. International Journal of Heritage Studies, 23(6), 506-520.

Naidoo, R. \& Adamowicz, W.L. (2005). Biodiversity and Nature-Based Tourism at Forest Reserves in Uganda. Environment and Development Economics, 10(2), 159-178.

Neto, F. (2003). A New Approach to Sustainable Tourism Development: Moving Beyond Environmental Protection. Natural Resources Forum, 27, 212-222.

Noonan, D.S. \& Rizzo, I. (2017). Economics of Cultural Tourism: Issues and Perspectives. Journal of Cultural Economics, 41, 95-107. 
Occhipinti, L. (2016). Not Just Tourists: Short-Term Missionaries and Voluntourism. Human Organization, 75(3), 258-268.

Onel, N. (2017). Pro-Environmental Purchasing Behaviour of Consumers: The Role of Norms. Social Marketing Quarterly, 23(2), 103-121.

Ooi, N. \& Laing, J.H. (2010). Backpacker Tourism: Sustainable and Purposeful? Investigating the Overlap Between Backpacker Tourism and Volunteer Tourism Motivations. Journal of Sustainable Tourism, 18(2), 191-206.

Operation Groundswell (2019). What We Do. Retrieved from https://operationgroundswell.com/what-we-do/who-we-are/.

Pforr, C. (2001). Concepts of Sustainable Development, Sustainable Tourism, and Ecotourism: Definitions, Principles, and Linkages. Scandinavian Journal of Hospitality and Tourism, $1(1), 69-71$.

Poon Tip, B. (2009). Sustainable Tourism. International Trade Forum, 1, 21-23.

Polat, N. (2015). Technological Innovations in Cruise Tourism and Results of Sustainability. Procedia Social and Behavioural Sciences, 195, 438-445.

Popsa, R.E. (2017). The Business Case for Sustainability in Tourism - An Overview in the Current Economic Context. Quaestus (10), 104-110.

Prud'homme, B., \& Raymond, L. (2016). Implementation of Sustainable Development Practices in the Hospitality Industry. International Journal of Contemporary Hospitality Management, 28(3), 609-639.

Qiao, G. \& Gao, J. (2017). Chinese Tourists' Perceptions of Climate Change and Mitigation Behaviour: An Application of Norm Activation Theory. Sustainability, 9(8), 2-13.

Rahman, I., Park, J. \& Chi, C.G.Q. (2015). Consequences of "Greenwashing": Consumers' Reactions to Hotels' Green Initiatives. International Journal of Contemporary Hospitality Management, 27(6), 1054-1081.

Raymond, E.M. \& Hall, C.M. (2008). The Development of Cross-Cultural (Mis)Understanding Through Volunteer Tourism. Journal of Sustainable Tourism, 16(5), 530-543.

Sanchez-Medina, P.S., Diaz-Pichardo, R., \& Cruz-Bautista, M. (2016). Stakeholder Influence on the Implementation of Environmental Management Practices in the Hotel Industry. International Journal of Tourism Research, 18, 387-398.

Schneller, A.J. \& Coburn, S. (2018). For-Profit Environmental Voluntourism in Costa-Rica: Teen Volunteer, Host Community, and Environmental Outcomes. Journal of Sustainable Tourism, 26(5), 832-851. 
Scott, D., Gossling, S. Hall, C.M. \& Peeters, P. (2016). Can Tourism Be Part of the Decarbonized Global Economy? The Costs and Risks of Alternative Carbon Reduction Policy Pathways. Journal of Sustainable Tourism, 24(1), 52-72.

Sekhar, N.U. (2003). Local People's Attitudes Towards Conservation and Wildlife Tourism Around Sariska Tiger Reserve, India. Journal of Environmental Management, 69(4), 339347.

Silva, J.A. \& Khatiwada, L.K. (2014). Transforming Conservation into Cash? Nature Tourism in Southern Africa. Africa Today, 61(1), 16-45.

Simpson, K. (2004). "Doing development": The Gap Year, Volunteer-Tourists and a Popular Practice of Development. Journal of International Development, 16(5), 681-692.

Sin, H.L. (2009). Volunteer Tourism - "Involve Me and I Will Learn?". Annals of Tourism Research, 36(3), 480-501.

Smith, V.L. \& Font, X. (2014). Volunteer Tourism, Greenwashing and Understanding Responsible Marketing Using Market Signalling Theory. Journal of Sustainable Tourism, 22(6), 942-963.

Sirilersuang, P. \& Pongkijvorasin, S. (2018). Dynamic Optimal Joint Policies for Tourism Promotion and Environmental Restoration. Environmental Economics and Policy Studies, 20(2), 261-286.

Steward, B. (2004). Writing a Literature Review. British Journal of Occupational Therapy, 67(11), 495-500.

Sujarittanonta, L. (2014). Voluntourism Product Development and Wildlife Conservation for Thailand. Worldwide Hospitality and Tourism Themes, 6(1), 40-50.

Tang, C., Zhong, L., Fan, W. \& Cheng, S. (2015). Energy Consumption and Carbon Emission for Tourism Transport in World Heritage Sites: A Case of the Wulingyuan Area in China. Natural Resources Forum, 39(2), 134-150.

Taiyab, N. (2006). Exploring the Market for Voluntary Carbon Offsets. London: IIED

Tepelus, C.M. (2005). Aiming for Sustainability in the Tour Operating Business. Journal of Cleaner Production, 13, 99-107.

Thomas, D.R. (2006). A General Inductive Approach for Analyzing Qualitative Evaluation Data. American Journal of Evaluation, 27(2), 237-246.

Tracy, S.J. (2013). Qualitative Research Methods: Collecting Evidence, Crafting Analysis, Communicating Impact. Hoboken, NJ: Wiley-Blackwell. 
United Nations Environment Programme and United Nations World Tourism Organization. (2005). Making Tourism More Sustainable: A Guide for Policy Makers, UNEP/UNWTO, Paris/Madrid.

United Nations General Assembly. (2015). Transforming Our World: The 2030 Agenda for Sustainable Development. Retrieved from http://www.un.org/en/development/desa/population/migration/generalassembly/docs/glob alcompact/A RES 70 1_E.pdf

United Nations World Tourism Organization. (2015). Tourism and the Sustainable Development Goals. Retrieved from http://cf.cdn.unwto.org/sites/all/files/pdf/sustainable_development_goals brochure.pdf

United Nations World Tourism Organization. (2018a). UNWTO Tourism Highlights 2018 Edition. Retrieved from https://www.e-unwto.org/doi/pdf/10.18111/9789284419876.

United Nations World Tourism Organization. (2018b). UNWTO World Tourism Barometer and Statistical Annex, 16(3). Retrieved from https://www.eunwto.org/doi/pdf/10.18111/wtobarometereng.2018.16.1.3

Walsh, P.R. \& Dodds, R. (2017). Measuring the Choice of Environmental Sustainability Strategies in Creating a Competitive Advantage. Business Strategy and the Environment, 26(5), 672-687.

Wang, S., Hu, Y., He, H. \& Wang, G. (2017). Progress and Prospects for Tourism Footprint Research. Sustainability, 9(10), 1-17.

Webster, J. \& Watson, R.T. (2002). Analyzing the Past to Prepare for the Future: Writing a Literature Review. Management Information Systems Quarterly, 26(2), xiii-xxiii.

Wilson, L. (2015). Finding the Win-Win: Providing Supportive and Enriching Volunteer Tourism Experiences While Promoting Sustainable Social Change. Worldwide Hospitality and Tourism Themes, 7(2), 201-207.

Wilson, T.D. (2008). Economic and Social Impacts of Tourism in Mexico. Latin American Perspectives, 160(35), 37-52.

World Commission on Environment and Development (WCED). 1987. Our Common Future. Oxford University Press: Oxford.

Wearing, S. \& Neil, J. (2000). Refiguring Self and Identity Through Volunteer Tourism. Society and Leisure, 23(2), 389-419.

Wearing, S. \& McGehee, N.G. (2013). Volunteer Tourism: A Review. Progress in Tourism Management, 38, 120-130. 
Wearing, S., Young, T. \& Everingham, P. (2017). Evaluating Volunteer Tourism: Has It Made a Difference? Tourism Recreation Research, 42(4), 512-521.

Yin, R. K. (2003). Application of Case Study Research (3rd Edition). Thousand Oaks, CA: Sage Publications, Inc.

Zhong, L., Deng, J. \& Xiang, B. (2008). Tourism Development and the Tourism Area Life-Cycle Model: A Case Study of Zhangjiajie National Forest Park, China. Tourism Management, 29(5), 841-956.

Zhong, L., Deng, J., Song, Z. \& Ding, P. (2011). Research on Environmental Impacts of Tourism in China: Progress and Prospect. Journal of Environmental Management, 92(11), 29722983. 